\title{
Diagnostic evaluation and management of chronic thromboembolic pulmonary hypertension: A clinical practice guideline
}

\author{
Sanjay Mehta MDCM FRCPC FCCP ${ }^{1}$, Doug Helmersen MD FRCPC ${ }^{2}$, Steeve Provencher MD MSc FRCPC ${ }^{3}$, \\ Naushad Hirani MD FRCPC ${ }^{2}$, Fraser D Rubens MD MSc FRCSC ${ }^{4}$, Marc De Perrot MD MSc ${ }^{5}$, Mark Blostein MD FRCPC ${ }^{6}$, \\ Kim Boutet MD FRCPC ${ }^{7}$, George Chandy MD MSc FRCPC ${ }^{8}$, Carole Dennie MD FRCPC ${ }^{9}$, John Granton MD FRCPC ${ }^{10}$, \\ Paul Hernandez MDCM FRCPC ${ }^{11}$, Andrew M Hirsch MD FRCPC ${ }^{12}$, Karen Laframboise MD FRCPC ${ }^{13}$, Robert D Levy MD FRCPC ${ }^{14}$, \\ Dale Lien MD FRCPC ${ }^{15}$, Simon Martel MD FRCPC ${ }^{3}$, Gerard Shoemaker MD FRCPC ${ }^{1}$, John Swiston MD MPH FRCPC ${ }^{14}$, \\ Justin Weinkauf MD FRCPC ${ }^{15}$; for the Canadian Thoracic Society Pulmonary Vascular Disease - CTEPH CPG \\ Development Committee, and the Canadian Thoracic Society Canadian Respiratory Guidelines Committee
}

S Mehta, D Helmersen, S Provencher, et al; for the Canadian Thoracic Society Pulmonary Vascular Disease - CTEPH CPG Development Committee, and the Canadian Thoracic Society Canadian Respiratory Guidelines Committee. Diagnostic evaluation and management of chronic thromboembolic pulmonary hypertension: A clinical practice guideline. Can Respir J 2010;17(6):301-334.

BACKGROUND: Pulmonary embolism is a common condition. Some patients subsequently develop chronic thromboembolic pulmonary hypertension (CTEPH). Many care gaps exist in the diagnosis and management of CTEPH patients including lack of awareness, incomplete diagnostic assessment, and inconsistent use of surgical and medical therapies.

METHODS: A representative interdisciplinary panel of medical experts undertook a formal clinical practice guideline development process. A total of 20 key clinical issues were defined according to the patient population, intervention, comparator, outcome (PICO) approach. The panel performed an evidence-based, systematic, literature review, assessed and graded the relevant evidence, and made 26 recommendations.

RESULTS: Asymptomatic patients postpulmonary embolism should not be screened for CTEPH. In patients with pulmonary hypertension, the possibility of CTEPH should be routinely evaluated with initial ventilation/ perfusion lung scanning, not computed tomography angiography. Pulmonary endarterectomy surgery is the treatment of choice in patients with surgically accessible CTEPH, and may also be effective in CTEPH patients with disease in more 'distal' pulmonary arteries. The anatomical extent of CTEPH for surgical pulmonary endarterectomy is best assessed by contrast pulmonary angiography, although positive computed tomography angiography may be acceptable. Novel medications indicated for the treatment of pulmonary hypertension may be effective for selected CTEPH patients.
CONCLUSIONS: The present guideline requires formal dissemination to relevant target user groups, the development of tools for implementation into routine clinical practice and formal evaluation of the impact of the guideline on the quality of care of CTEPH patients. Moreover, the guideline will be updated periodically to reflect new evidence or clinical approaches.

Key Words: Chronic thromboembolic pulmonary hypertension; Clinical practice guideline; Pulmonary endarterectomy; Pulmonary hypertension; Thromboembolism

L'évaluation diagnostique et la prise en charge de l'hypertension pulmonaire thromboembolique : Des lignes directrices pour la pratique clinique

\begin{abstract}
HISTORIQUE : L'embolie pulmonaire est un trouble courant. Certains patients se mettent ensuite à faire de l'hypertension pulmonaire thromboembolique chronique (HPTEC). Il existe de nombreuses lacunes dans le diagnostic et la prise en charge des patients atteints d'HPTEC, y compris l'absence de sensibilisation, le diagnostic incomplet et le recours erratique aux thérapies chirurgicales et médicales.

MÉTHODOLOGIE : Un groupe interdisciplinaire représentatif d'experts médicaux a entrepris un processus officiel d'élaboration de lignes directrices pour la pratique clinique. Au total, ce groupe a défini 20 enjeux cliniques clés selon la population de patients, l'intervention, le comparateur et les issues (approche PICO). Le groupe a procédé à une analyse bibliographique probante et systématique, évalué et coté les données probantes pertinentes et fait 26 recommandations.
\end{abstract}

${ }^{1}$ Southwest Ontario Pulmonary Hypertension Clinic, London Health Sciences Centre, Schulich School of Medicine Eु Dentistry, University of Western Ontario, London, Ontario; ${ }^{2}$ University of Calgary Pulmonary Hypertension Clinic, Division of Respiratory Medicine, Peter Lougheed Hospital, Calgary, Alberta; ${ }^{3}$ Pulmonary Hypertension Program, Institut Universitaire de Cardiologie et de Pneumologie de Québec,

Université Laval, Québec, Québec; ${ }^{4}$ University of Ottawa Heart Institute, Division of Cardiac Surgery, University of Ottawa, Ottawa;

${ }^{5}$ Toronto Pulmonary Endarterectomy Program, University of Toronto, Division of Thoracic Surgery, Toronto General Hospital, Toronto, Ontario; ${ }^{6}$ Division of Hematology, Department of Medicine, Sir Mortimer B Davis Jewish General Hospital, McGill University, Montréal; ${ }^{7}$ Centre for Pulmonary Vascular Disease, Sir Mortimer B Davis Jewish General Hospital, McGill University, and Sacré-Coeur Hospital Respiratory Division, Centre Hospitalier Universitaire de Montreal, Montréal, Québec; ${ }^{8}$ University of Ottawa Heart Institute Pulmonary Hypertension Clinic, Respirology Division, The Ottawa Hospital, University of Ottawa, Ottawa; ${ }^{9}$ Thoracic and Cardiac Imaging Sections, The Ottawa Hospital, Cardiac Radiology, University of Ottawa Heart Institute, University of Ottawa, Ottawa; ${ }^{10}$ University Health Network Pulmonary Hypertension Program, Faculty of Medicine, University of Toronto, Division of Respirology, Toronto, Ontario; ${ }^{11}$ Pulmonary Hypertension Clinic, Respirology Division, Department of Medicine, QEII Health Sciences Centre, Dalhousie University, Halifax, Nova Scotia; ${ }^{12}$ Center for Pulmonary Vascular Disease, Sir Mortimer B Davis Jewish General Hospital, McGill University, Montréal, Québec; ${ }^{13}$ Division of Respirology, Critical Care and Sleep Medicine, University of Saskatchewan, Saskatoon, Saskatchewan; ${ }^{14}$ Pulmonary Hypertension Program, Respirology Division, Vancouver General Hospital, Department of Medicine, University of British Columbia, Vancouver, British Columbia;

${ }^{15}$ University of Alberta Pulmonary Hypertension Clinic, University of Alberta, Edmonton, Alberta

Correspondence: Dr Sanjay Mehta, Southwest Ontario Pulmonary Hypertension Clinic, Division of Respirology, London Health Sciences Centre Victoria Hospital, Professional Building E1.325, 800 Commissioner's Road East, London, Ontario N6A 5W9. Telephone 519-667-6723, fax 519-685-8406, e-mail sanjay.mehta@lhsc.on.ca

Reprint requests: Ms Candice Brown, Canadian Thoracic Society, The Lung Association - National Office, 300 - 1750 Courtwood Crescent,

Ottawa, Ontario K2C 2B5. Telephone 613-569-6411 ext 228, fax 613-569-8860, e-mail cbrown@lung.ca 
RÉSULTATS : Les patients asymptomatiques après une embolie pulmonaire ne devraient pas subir un dépistage d'HPTEC. Chez les patients atteints d'hypertension pulmonaire, il faudrait évaluer systématiquement la possibilité d'HPTEC par scintigraphie pulmonaire initiale de ventilation et de perfusion plutôt que par angiographie par tomodensitométrie. L'endartériectomie pulmonaire est le traitement de choix chez les patients dont l'HPTEC est chirurgicalement accessible et peut également être efficace chez les patients atteints d'HPTEC qui touche les artères pulmonaires plus « distales ». En prévision de l'endartériectomie pulmonaire, l'étendue anatomique de l'HPTEC est mieux évaluée par angiographie pulmonaire de contraste, mais l'angiographie par tomodensitométrie positive peut être acceptable. De nouveaux médicaments indiqués pour traiter l'hypertension pulmonaire peuvent être efficaces pour des patients sélectionnés atteints d'HPTEC.

CONCLUSIONS : Les présentes lignes directrices doivent être diffusées officiellement aux groupes d'utilisateurs ciblés pertinents, doivent s'associer à la mise au point d'outils qui seront adoptés en pratique clinique et doivent faire l'objet d'une évaluation officielle de leurs répercussions sur la qualité des soins aux patients atteints d'HPTEC. De plus, ces lignes directrices seront mises à jour périodiquement pour refléter les nouvelles données probantes ou approches cliniques.

\section{TABLE OF CONTENTS}

\section{SECTION I: INTRODUCTION}

A. Chronic thromboembolic pulmonary hypertension

B. Objective/scope

C. Target patient population

D. Target users

E. Methodology

\section{SECTION II: EPIDEMIOLOGY OF CTEPH}
A. Introduction
B. Epidemiology of CTEPH
C. Clinical risk factors for CTEPH

\section{SECTION III: DIAGNOSIS OF CTEPH}

A. Introduction

B. Early detection of CTEPH in patients with acute pulmonary thromboembolism

1. Screening for CTEPH in asymptomatic patients with acute pulmonary thromboembolism

C. Assessment of the presence of CTEPH in patients with PH

1. Nuclear V/Q lung scanning versus CT pulmonary angiography to rule out CTEPH

2. Nuclear $\mathrm{V} / \mathrm{Q}$ lung scanning to assess surgical accessibility of CTEPH

3. CT or MR pulmonary angiography versus conventional pulmonary angiography to assess surgical accessibility of CTEPH

\section{SECTION IV: MEDICAL AND SURGICAL MANAGEMENT OF CTEPH}

A. General medical management of CTEPH patients

1. Chronic anticoagulation

2. CCB therapy
3. Digoxin therapy

4. Supplemental nocturnal/exertional oxygen

5. Cardiopulmonary exercise rehabilitation

6. Use of IVC filters

B. Management of CTEPH patients pre-PEA

1. Introduction

2. Parenteral prostanoid therapy in CTEPH patients pre-PEA

3. Oral PH-specific medical therapy in CTEPH patients pre-PEA

C. PEA in CTEPH patients

1. Introduction

2. PEA in patients with surgically accessible CTEPH

3. PEA in patients with distal CTEPH

4. Post-PEA long-term follow-up in a PH centre

5. PH-specific medical therapy in CTEPH patients with residual $\mathrm{PH}$ post-PEA

D. Management of CTEPH patients not eligible for PEA

1. Introduction

2. $\mathrm{PH}$-specific medical therapy in patients with inoperable CTEPH

3. Combination PH-specific medical therapy in CTEPH patients

4. Balloon angioplasty in CTEPH patients

E. Consideration of transplantation in CTEPH patients

1. Referral of CTEPH patients for lung transplantation

SECTION V: DIAGNOSIS AND MANAGEMENT OF CTEPH: SUMMARY OF RECOMMENDATIONS 


\section{SECTION I: INTRODUCTION}

A. Chronic thromboembolic pulmonary hypertension

Pulmonary hypertension $(\mathrm{PH})$ is a serious condition of the pulmonary blood vessels characterized by increased pulmonary arterial pressure (PAP), and is often associated with progressive right ventricular (RV) failure and a high risk of death. PH is increasingly recognized as an important cause of dyspnea and exercise limitation in many patients. As per the current WHO PH classification system - revised at Dana Point, California (USA) in 2008 (Table 1) - PH can be associated with underlying disorders of the heart (eg, systolic left ventricular [LV] failure) and lungs (eg, chronic obstructive pulmonary disease [COPD]), or be due to intrinsic disease of the small pulmonary arteries, known as pulmonary arterial hypertension (PAH).

A very important and common cause of $\mathrm{PH}$ is chronic thromboembolic PH (CTEPH). CTEPH is a result of pulmonary vascular obstruction characterized by recurrent, unresolved pulmonary emboli (PE) and/or progressive pulmonary vascular thrombosis and scarring. In the present document, CTEPH is defined as follows:

1. A mean PAP (mPAP) of $25 \mathrm{mmHg}$ or greater and pulmonary vascular resistance (PVR) of 3 Wood units (240 dyne.s $/ \mathrm{cm}^{5}$ ) or greater.

2. Persistent angiographic pulmonary arterial thrombotic obstruction despite at least three months of effective, uninterrupted anticoagulation.

Clinical recognition and management of CTEPH are important for several reasons. First, CTEPH is believed to be one of the most common causes of PH. Second, CTEPH is a serious, progressive and often fatal disease. Patients with untreated CTEPH experience significantly increased mortality - observational studies $(1,2)$ have estimated the median survival rate in severe CTEPH patients to be as low as $10 \%$ to $20 \%$ at two to three years. Third, CTEPH is potentially curable with pulmonary endarterectomy (PEA) surgery. Finally, CTEPH patients may also benefit from treatment with novel $\mathrm{PH}$-specific medications that are currently available for patients with other types of $\mathrm{PH}$ such as $\mathrm{PAH}$.

Key clinical care gap: What is the best evidence-based approach to the diagnostic evaluation and management of patients with CTEPH?

\section{B. Objective/scope}

The overall objective of the present clinical practice guideline $(\mathrm{CPG})$ is to inform and provide evidence-based recommendations for the diagnostic evaluation, and surgical and medical management of patients with CTEPH.

The document was developed specifically for physicians and health care teams involved in the clinical care of patients with CTEPH. A CTEPH CPG is needed to ensure consistency of best practice, to identify systematic gaps in care, and to provide direction for future research in diagnosis and management.

As such, the scope of the present CPG encompasses the following: the diagnostic approach to CTEPH in patients with a history of PE or who present with $\mathrm{PH}$; surgical management such as balloon angioplasty, PEA surgery and lung transplantation; and the medical management of CTEPH patients including the consideration of supplemental oxygen, digoxin, anticoagulation
TABLE 1

WHO clinical classification of pulmonary hypertension (Dana Point, USA [revision, 2008])

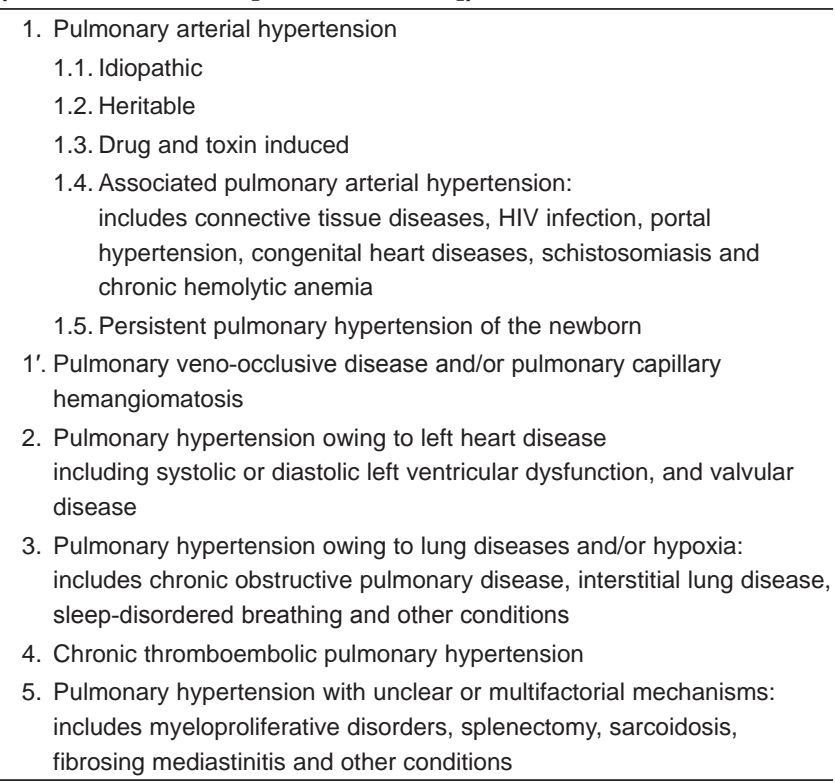

Data from reference 175

and the use of novel PH-specific medications. The current document does not address the health economics of the management of CTEPH, nor does it cover the clinical management of patients with acute PE or PH due to causes other than CTEPH. The CPG also does not serve as a technical guide to PEA or the perioperative care of CTEPH patients.

Since 2001, several American, Canadian and European medical societies have developed guidelines for the diagnosis and management of $\mathrm{PH}(3-8)$. The present $\mathrm{CPG}$ is intended to complement other published $\mathrm{PH}$ guidelines, with specific emphasis on patients with CTEPH and clinical practice in Canada.

\section{Target patient population}

The current CPG applies to adult individuals with CTEPH a common and clinically important cause of $\mathrm{PH}$ that is characterized by recurrent, unresolved $\mathrm{PE}$ and/or progressive pulmonary thrombosis and scarring.

\section{Target users}

The present CPG is intended for use by health care teams that care for individuals with venous thromboembolic disease, $\mathrm{PH}$ and CTEPH. Specifically, family practitioners and specialist physicians (respirologists, cardiologists, hematologists, internists, cardiac and thoracic surgeons, and radiologists), and other health care professionals who currently care for patients with deep vein thrombosis (DVT)/PE, $\mathrm{PH}$ and/or CTEPH can use these guidelines to help improve their clinical practice.

The CPG is also intended to support advocacy on behalf of access to optimal health care for patients with $\mathrm{PH}$, and to help health care institutions in planning and delivering optimal care for patients with CTEPH.

\section{E. Methodology}

Guideline development process: The Canadian Thoracic Society Pulmonary Vascular Disease - CTEPH CPG Development 
Committee comprised individuals with content expertise in each of the topic areas from all of the following proposed relevant disciplines: respirology, cardiology, cardiac and thoracic surgery, radiology and hematology. Regular consultation was provided by a research coordinator, a consulting methodologist and a librarian. Through a series of Internet conference and face-to-face meetings beginning in January 2009, CTEPH was agreed on as the topic of this, the first Canadian PH-specific CPG. This was based on a perceived systematic care gap regarding clinical recognition of CTEPH, the rational use of diagnostic testing and the appropriate consideration of potentially curative management through PEA surgery. Based on extensive discussions, a series of clinically important and actionable questions were developed in accordance with a 'PICO' process, taking into consideration the Patient population(s), Intervention(s), Comparator(s) and Outcome(s). This template was further used to frame the search strategy given the inclusion and exclusion criteria desired.

The individual clinical questions selected for systematic review and formulation of recommendations were believed to represent clinically important issues currently facing clinicians caring for CTEPH patients. Questions and the search strategy were formulated to assess the potential impact of diagnostic and treatment approaches on a range of important outcomes. These included cardiopulmonary hemodynamic parameters (PAP, PVR, cardiac output/index [CO/CI], right atrial pressure and RV size/function), as assessed either through pulmonary artery catheterization, echocardiography, radionuclide or magnetic resonance (MR) cardiac imaging, plasma levels of brain natriuretic peptide (BNP) and the $\mathrm{N}$-terminal pro-BNP (NTpro-BNP), and clinical outcomes (symptoms, WHO functional class, health-related quality of life [HRQoL] scores, ability to return to work, functional/ exercise capacity [6 min walk test distance (6MWD) and cardiopulmonary exercise testing], rates of hospitalization, recurrent or progressive pulmonary thromboembolism, and survival). Questions possibly leading to important avenues of future research were also considered.

Literature search: In January 2009, the key published literature databases (PUBMED, EMBASE, Cochrane Library, Canadian Medical Association InfoBase and the National Guideline Clearinghouse) were searched for relevant original articles published from 1960 through October 2008, that addressed any of the proposed clinical questions in any of the following areas: the epidemiology of CTEPH and risk factors for development of CTEPH; the diagnostic approach to define the presence, extent and severity of CTEPH; or the medical or surgical management of CTEPH (See Appendix 1 for search strategy).

Study selection criteria: Following completion of the literature search, titles and abstracts were reviewed for relevance to CTEPH, and appropriate full-text articles were retrieved and reviewed in detail (Figure 1). Animal studies, pathology or other preclinical studies, clinical images, isolated hemodynamic reports, letters, editorials, duplicate publications without original data, reviews, studies published in a language other than English or French, and studies of uniquely pediatric populations were excluded. Articles were selected for inclusion in the systematic evidence review if they reported original data that addressed CTEPH epidemiology, diagnosis or treatment.
Critical appraisal of identified studies: Data from all articles relevant to each PICO question were abstracted into tables by a panel member. During discussion of each question, the data were reviewed by the panel, and evidence addressing each clinical question was assessed according to components of the Grading of Recommendations Assessment, Development and Evaluation (GRADE) criteria (9) (Table 2). In descending order of preference, the following minimum levels of evidence needed to inform the clinical questions were the following: evidence-based CPGs, systematic reviews, randomized controlled trials (RCTs), meta-analyses, nonrandomized comparative studies, prospective or retrospective single-cohort case series, and case reports.

Initial review of the available body of evidence on the epidemiology, diagnosis or management of CTEPH indicated an overall low quality of data, given the few RCTs or large case-control studies, and a preponderance of small, openlabel, uncontrolled studies. Therefore, no formal pooling of the data was performed, and overall ORs for risk or benefit were not calculated.

Synthesis of evidence-based clinical judgment of risk versus clinical benefit: For each clinical question, the panel first considered the strength and directness of the published evidence supporting an intervention or treatment approach. Individual members were then invited to share their personal experiences with an intervention or treatment in CTEPH patients. Finally, the panel extensively discussed the potential health benefit of an intervention or treatment to an individual CTEPH patient, the overall impact on the population burden of morbidity and mortality of CTEPH, and issues of risk, burden on a patient to adhere, and cost effectiveness of an intervention or treatment. These discussions and the resulting synthesis of clinical judgment are presented, in brief, for each recommendation below.

Formulation of recommendations: Following the open and extensive discussions for each question, a draft recommendation was proposed, discussed and revised. The strength of the recommendation was based on consideration both of the GRADE quality of the evidence, and the expert panel's synthesis of clinical judgment (Table 2). The recommendation consensus process was open and used a six-point voting scale (Table 3), whereby it was defined a priori that a recommendation would only be accepted if each panel member voted for option 1, 2 or 3. In the event of a failure to reach unanimity of votes for these first three options, another period of discussion ensued, whereby dissenting opinions were heard and considered. The recommendation was revised and followed by a second round of voting using a three-point scale, for which acceptance of a recommendation required unanimity for option 1 or 2 . Through this process, all recommendations achieved acceptance, with a second round of voting required for only one recommendation.

Canadian Thoracic Society CTEPH CPG document: The draft CTEPH guideline was circulated to CPG methodologists, and $\mathrm{PH}$ and CTEPH content experts in Canada and internationally, to obtain feedback on the collection, interpretation and grading of the evidence, and on the development and content of the recommendations.

Relevant medical health care associations including the Canadian Association of Thoracic Surgeons, and 


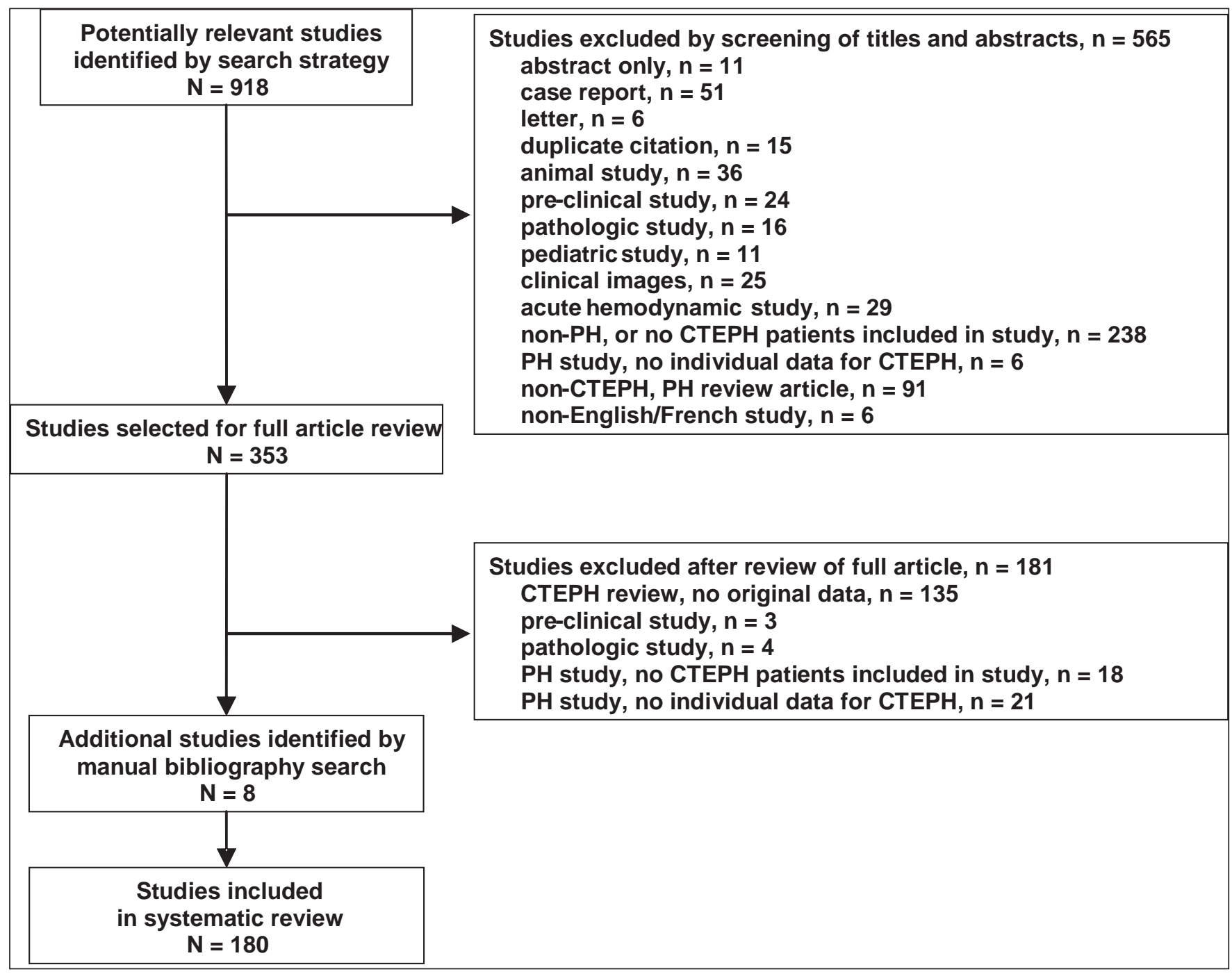

Figure 1) Study selection process flow diagram. CTEPH Chronic thromboembolic pulmonary hypertension; PH Pulmonary hypertension

TABLE 2

Grading of Recommendations Assessment, Development and Evaluation (GRADE): Strength of evidence and grading of recommendations

\footnotetext{
Quality of evidence

Grade A

Grade B

Grade C

Strength of recommendations

Grade 1

Grade 2

When there is insufficient evidence or no consensus

Adapted from reference 9

the Canadian Association of Radiologists and Thrombosis Interest Group of Canada were invited to review and endorse the document. Moreover, the document was reviewed by Pulmonary Hypertension Association Canada - a Canadian, national $\mathrm{PH}$ patient support group - and revised after consideration of patients' views and preferences.
}

Well-designed, randomized controlled trials with consistent and directly applicable results

Randomized trials with limitations including inconsistent results or major methodological weaknesses

Observational studies, and from generalization from randomized trials in one group of patients to a different group of patients

Strong recommendation, with desirable effects clearly outweighing undesirable effects (or vice versa) Wording of recommendation: We recommend that.....

Weak recommendation, with desirable effects closely balanced with undesirable effects Wording of recommendation: We suggest that.....

Wording of recommendation: There was no consensus on a recommendation for or against ...
The living guideline/future updates: The literature will be reviewed periodically, and the Canadian Thoroacic Society (CTS) CTEPH CPG will be continuously updated electronically and in print on a regular basis as new or compelling evidence is identified. The first proposed update is scheduled for 2011. 
TABLE 3

Voting scales for assessing consensus on draft recommendations

\begin{tabular}{ll}
\hline First round of voting & Wholeheartedly agree \\
& Agree \\
& Can support \\
& Reservations - would like more discussion \\
& Serious concerns - needs more discussion \\
& Cannot participate - block it \\
Second round of voting & Agree \\
& Can support \\
& Cannot support - block it \\
\hline
\end{tabular}

For a recommendation to be approved during the first round of voting, unanimity was required on options 1, 2 or 3. If this was not achieved, additional discussion and revision of the recommendation ensued, after which the second round of voting proceeded, during which unanimity on either option 1 or 2 was required for a recommendation to be approved

\section{SECTION II: EPIDEMIOLOGY OF CTEPH}

\section{A. Introduction}

An appreciation of the epidemiology of CTEPH and the clinical risk factors for the development of CTEPH is important for the clinical assessment of a patient with suspected CTEPH. Moreover, there are important knowledge gaps in our understanding of CTEPH epidemiology. Therefore, similar to the subsequent sections on diagnosis and treatment of CTEPH, this section was included in the systematic literature review and synthesis of the evidence. However, this information does not necessarily apply in the clinical approach to the diagnosis and treatment of CTEPH in an individual patient, and does not translate into simple, actionable recommendations to improve clinical care of CTEPH patients.

As such, no formal recommendations were developed in this section. However, the results of the systematic literature review are presented as important background material on the epidemiology and clinical risk factors for the development of CTEPH.

\section{B. Epidemiology of CTEPH}

There is compelling evidence supporting the concept of PE overt or occult - triggering a cascade of events that may eventually result in CTEPH. PE is a common condition, with an annual incidence estimated to be 20 per 100,000 to 70 per 100,000 population, and a per-person lifetime incidence of approximately 5\% (10-12). PE is largely considered by physicians to be an acute and reversible disease. Patients are deemed to be 'cured' after appropriate anticoagulation. However, a recent systematic review (13) documented significant residual perfusion defects on ventilation/ perfusion (V/Q) scintigraphy or computed tomography (CT) angiography in $57 \%$ and $52 \%$ of patients at six and 11 months after acute PE, respectively. Prospective echocardiographic studies (14-19) have also documented that $2 \%$ to $44 \%$ of patients experience persistent $\mathrm{PH}$ and/or RV hypokinesis following acute $\mathrm{PE}$, with functional impairment also being common (14). These data suggest that a substantial proportion of patients with symptomatic acute $\mathrm{PE}$ will experience persistent pulmonary vascular sequelae. CTEPH represents a severe long-term consequence among survivors of acute PE.
Original estimates suggested that $0.1 \%$ to $0.5 \%$ of patients who survive an episode of acute PE develop CTEPH $(20,21)$. More recently, prospective observational studies suggest that the cumulative incidence of CTEPH may range from $1 \%$ to $4 \%$ (Table 4). Although these studies differ significantly in terms of study population and design, five larger prospective studies (22-27) provided the most robust data regarding the incidence of CTEPH after PE. In a single-centre study of 223 consecutive patients after a first episode of symptomatic PE (22), patients with unexplained persistent dyspnea and abnormal echocardiography underwent V/Q scintigraphy, pulmonary angiography and right heart catheterization. The cumulative incidence of symptomatic CTEPH was $1.0 \%$ at six months, $3.1 \%$ at one year and $3.8 \%$ at two years. In another prospective study (24), a similar diagnostic workup for CTEPH was performed in cases of persistent perfusion abnormalities on routine V/Q scintigraphy repeated one and 12 months following symptomatic PE in 320 patients. The cumulative incidence of CTEPH was $0.9 \%$ to $1.3 \%$ at six to 12 months. The cumulative incidence of CTEPH was $2.7 \%$ at one year in a prospective study of 110 consecutive patients (25) after screening for persistent dyspnea. Given the low incidence, the authors suggested that an active search for CTEPH was not indicated after acute PE.

Multicentre prospective studies of post-PE cohorts have generally yielded lower incidence rates. In a 12-centre study of 259 consecutive patients diagnosed with a first episode of acute PE in the absence of persistent thrombophilia (23), symptomatic CTEPH was only diagnosed in two patients $(0.8 \%)$ at 14 and 22 months after the acute PE. Finally, in a large two-centre study of 866 consecutive patients in which V/Q scintigraphy, pulmonary angiography and right heart catheterization were performed in cases of persistent $\mathrm{PH}$ on routine echocardiography, $0.5 \%$ were found to have CTEPH $(26,27)$.

Based on the known incidence of PE (10-12), these estimates would suggest a theoretical annual incidence of CTEPH of two to 28 cases per million population. This is higher than the one to 1.75 cases per million population annual incidence documented in a recent United Kingdom registry (28). Similarly, only 73 patients were diagnosed with CTEPH over a five-year period in Switzerland (29), representing $29 \%$ of patients diagnosed with $\mathrm{PH}$ in participating centres.

There is ongoing debate as to whether the findings from prospective observational studies represent the true incidence of CTEPH. Indeed, the incidence of CTEPH may have been underestimated because of the exclusion of patients with previous venous thromboembolism (VTE) events, thrombophilia or other potential causes of $\mathrm{PH}$. Moreover, the significant proportion (up to 60\%) of CTEPH patients without a previous episode of clinically apparent acute PE may have been missed in these postsymptomatic PE studies (30-32). Conversely, in addition to potential lead-time bias, it is possible that some of the patients had previously unidentified CTEPH when they presented with the clinical picture of acute PE. Furthermore, prospective observational studies with routine screening may lead to detection of early and, occasionally, asymptomatic cases. The clinical consequences of these 'milder' cases of CTEPH, such as progression to 
TABLE 4

Incidence of chronic thromboembolic pulmonary hypertension (CTEPH) following acute pulmonary embolism (PE)

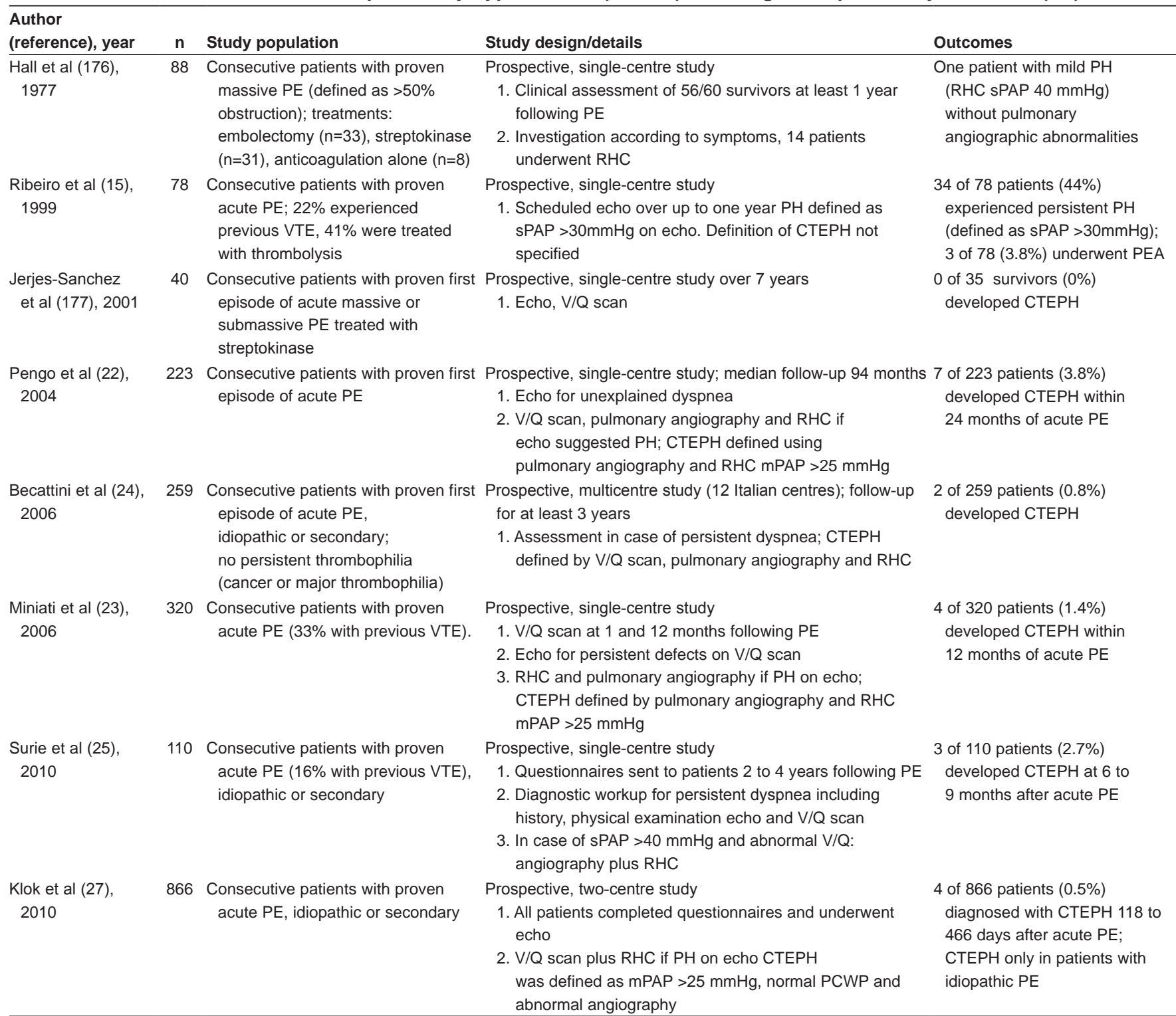

Echo Echocardiography; mPAP Mean pulmonary artery pressure; PCWP Pulmonary capillary wedge pressure; PEA Pulmonary endarterectomy; PH Pulmonary hypertension; RHC Right heart catheterization; SPAP Systolic pulmonary artery pressure; V/Q Ventilation-perfusion; VTE Venous thromboembolism

symptomatic disease and need for evaluation or treatment, are uncertain. The incidence of clinically relevant $\mathrm{CTEPH}$ may, thus, be lower than the above studies reported. Nevertheless, the discrepancy between theoretical estimates and the number of patients diagnosed with CTEPH underscores the fact that CTEPH is likely to be underdiagnosed.

The time course of development of CTEPH following an acute PE event is also a matter of debate. While most cases of CTEPH are diagnosed during the first two years following acute symptomatic PE (22-26), some patients may present many years later (33-35). This 'late' clinical worsening after a prolonged 'asymptomatic' period following an acute PE event has been attributed to progressive vasculopathy of distal small pulmonary arteries $(36,37)$.

\section{Clinical risk factors for CTEPH}

Although VTE is a common condition, only a small minority of patients who experience an acute PE develop CTEPH (22-27). Moreover, in patients diagnosed with CTEPH, only approximately one-half have experienced a previously documented acute VTE event $(21,30)$. Therefore, to better identify patients with PE who are more likely to develop CTEPH, many studies have assessed potential risk factors for CTEPH including demographic factors, specific details of the PE, the presence of underlying medical conditions and thrombophilic abnormalities (Table 5).

Risk factors for CTEPH at the time of acute PE: Many studies have assessed patients at the time of acute PE to identify risk factors predictive of persistent echocardiographic $\mathrm{PH}$ 


\section{TABLE 5}

Risk factors for the development of chronic thromboembolic pulmonary hypertension (CTEPH)

\begin{tabular}{|c|c|}
\hline Individual risk factors & Author (reference), year \\
\hline \multicolumn{2}{|l|}{ Risk factors present at the time of acute pulmonary embolism diagnosis } \\
\hline Younger age & Pengo et al (22), 2004; Becattini et al (24), 2006 \\
\hline Previous pulmonary embolism & Pengo et al (22), 2004 \\
\hline $\begin{array}{l}\text { Idiopathic pulmonary embolism (absence of either transient or } \\
\text { permanent risk factors* }{ }^{*} \text { ) }\end{array}$ & Pengo et al (22), 2004 \\
\hline Large perfusion defects & Pengo et al (22), 2004; Becattini et al (24), 2006 \\
\hline Recurrent pulmonary embolism & Pengo et al (22), 2004 \\
\hline \multicolumn{2}{|l|}{ Risks factors observed at the time of CTEPH diagnosis } \\
\hline \multicolumn{2}{|l|}{ Demographic } \\
\hline Female sex in Japanese population & Tanabe et al (48), 2005; Nakamura et al (47), 2002 \\
\hline Non-O blood group & Bonderman et al (32), 2009 \\
\hline \multicolumn{2}{|l|}{ Thrombophilias } \\
\hline Antiphospholipid antibodies & $\begin{array}{l}\text { Bonderman et al (32), 2009; Wolf et al (46), 2000; Tanabe et al (48), 2005; } \\
\text { Nakamura et al (47), 2002; Colorio et al (52), 2001; Bonderman et al (67), 2007; } \\
\text { Jais et al (55), 2005, Martinuzzo et al (56), } 1998\end{array}$ \\
\hline Factor V Leiden mutation ${ }^{\dagger}$ & Lang et al (50), 1996, Wolf et al (46), 2000 \\
\hline Hemoglobin abnormalities & Bonderman et al (32), 2009; Bonderman et al (72), 2005 \\
\hline Increased factor VIII level & Wong et al (51), 2010; Bonderman et al (54), 2003 \\
\hline Increased plasma lipoprotein (a) level & Ignatescu et al (59), 1998 \\
\hline \multicolumn{2}{|l|}{ Disease associations } \\
\hline Splenectomy & $\begin{array}{l}\text { Condliffe et al (31), 2009; Bonderman et al (32), 2009; Suntharalingam et al (45), 2007; } \\
\text { Bonderman et al (67), 2007; Jais et al (55), 2005; Jais et al (68), 2003; } \\
\text { Chou et al (69), 2001; Cappellini et al (70), 2000; Stewart et al (71), 1996; } \\
\text { Bonderman et al (72), } 2005\end{array}$ \\
\hline Ventriculoatrial shunt & Bonderman et al (32), 2009; Bonderman et al (72), 2005 \\
\hline Thyroid replacement therapy & Bonderman et al (32), 2009 \\
\hline Inflammatory disorder (eg, osteomyelitis, inflammatory bowel disease) & Bonderman et al (72), 2005 \\
\hline
\end{tabular}

*Permanent risk factor defined as constitutive thrombophilia (deficiency of antithrombin, protein C or protein S; mutation in factor $V$ Leiden or prothrombin gene; and the presence of lupus anticoagulants), active cancer, immobilization from chronic medical illness, or two or more first-degree relatives with venous thromboembolism. ${ }^{\dagger}$ This is controversial: the prevalence of factor $V$ Leiden mutations was higher than in patients with idiopathic pulmonary arterial hypertension or healthy subjects (46). However, in another study (50), the prevalence of factor $V$ Leiden in CTEPH was found to be comparable with the general population

at some point in the future. Age older than 70 years and echocardiographic-estimated systolic PAP of greater than 50 $\mathrm{mmHg}$ at the time of acute PE were independently associated with a higher risk of persistent $\mathrm{PH}$ after one year (15). A higher obstruction index on initial V/Q lung scan $(24,36)$ or CT pulmonary angiogram (19) also appeared to be associated with a higher risk of persistent PH. This, however, was not observed in all studies (18).

While thrombolytic therapy is associated with early resolution of clots and improved RV function compared with heparin alone (38), the effect of thrombolysis on the subsequent risk of persistent $\mathrm{PH}$ remains uncertain. Observational studies $(15,39)$ have suggested that the treatment received during the acute phase of PE had no significant effects on the long-term pulmonary hemodynamics. In contrast, one small study (40) reported that patients assessed seven years after randomization to thrombolysis $(\mathrm{n}=12)$ versus control heparin $(\mathrm{n}=11)$ in the Urokinase PE (41) and Urokinase/streptokinase PE (42) trials, had improved pulmonary hemodynamic parameters at rest and during exercise, and experienced less functional impairment.

Importantly, persistent $\mathrm{PH}$ on echocardiography following PE may not necessarily be due to CTEPH. For example, age and concomitant congestive heart failure - both associated with increases in PAP $(43,44)$ - were related to persistent PH in the study by Ribeiro et al (15). Moreover, persistent PH was mild to moderate in most of these patients. Among the
34 of 78 (44\%) patients with persistent $\mathrm{PH}$ (defined as an estimated systolic PAP of greater than $30 \mathrm{mmHg}$ ) in this study (15), only four patients had a systolic PAP of greater than $40 \mathrm{mmHg}$ at one year. Thus, the clinical relevance of persistent $\mathrm{PH}$ in the absence of clearly defined CTEPH remains uncertain.

Fewer studies have assessed variables at the time of acute $\mathrm{PE}$ that are specifically associated with an increased risk of CTEPH (Table 5). Pengo et al (22) identified a history of previous PE events, younger age and larger perfusion defect at the time of acute PE as risk factors for the development of CTEPH. PE that occurred in the absence of either a transient or a permanent thrombotic risk factor was also predictive of subsequent CTEPH diagnosis. Interestingly, a previous VTE and the presence of thrombophilia at the time of PE were not associated with subsequent risk of CTEPH in that study. Although this was not specifically tested, Miniati et al (23) also suggested younger age and a higher initial obstruction index at the time of acute PE were risk factors for CTEPH.

Risk factors identified at the time of CTEPH diagnosis: The low incidence of CTEPH following acute PE has made identification of predisposing risk factors difficult in prospective studies of patients with PE. As such, multiple case series and case-control studies have assessed and identified a variety of risk factors present at the time of CTEPH diagnosis (Table 5).

It is well accepted that inherited thrombophilias predispose to VTE disease. Moreover, previous VTE is clearly more 
common in CTEPH patients versus patients with other types of $\mathrm{PH}(32,45,46)$. However, many case series $(33,46-48)$ have confirmed that most patients with CTEPH do not suffer from the common inherited thrombophilias. For example, in a study of 147 consecutive patients with CTEPH (46), the prevalence of most common hereditary thrombotic risk factors was similar to that in idiopathic PAH patients and healthy subjects, although the prevalence of factor V Leiden was higher. Another case series of 20 patients with CTEPH (50) found a similar low prevalence $(5 \%)$ of factor V Leiden mutations (49), which is comparable with the prevalence in the general population. Moreover, the prevalence of factor $\mathrm{V}$ Leiden does not appear to be higher in CTEPH patients than in patients with previous VTE (51).

Antiphospholipid antibodies (APLA) have been documented in a significant proportion of CTEPH patients $(47,48,52-55)$ and in several studies $(32,46,56)$ more frequently than in patients with other forms of $\mathrm{PH}$ or healthy subjects (46). Moreover, CTEPH patients were more likely to have higher titres of APLA (46). In contrast, one large observational study (51) found that the prevalence of APLA in CTEPH patients was similar to patients with other types of $\mathrm{PH}$. Levels of factor VIII and von Willebrand factor were also reported to be higher in CTEPH than in PAH patients or healthy subjects $(51,54)$. Non-O-type blood groups, which are associated with higher levels of plasma factor VIII and von Willebrand Factor than blood group $\mathrm{O}(57,58)$, are more common in CTEPH patients $(32,54)$. Plasma lipoprotein (a) levels have also been shown to be higher in CTEPH patients than in PAH patients and healthy subjects (59).

There is evidence that fibrinolysis may also be impaired in CTEPH patients. Studies in healthy subjects (60) documented an enhanced fibrinolytic potential in the pulmonary artery compared with the aorta under normal physiological conditions. In CTEPH, increased expression of factor VIII and plasminogen activation inhibitor (PAI)-1 (an inhibitor of fibrinolysis) on the surface of neovessels within nonresolving pulmonary thromboemboli have been observed, which may favour in situ thrombosis (61). Despite the fact that the balance between levels of plasma tissue plasminogen activator and PAI- 1 in patients with CTEPH appears to be normal in some studies (61-63), some recent studies (64-66) suggest that the fibrin clot of CTEPH patients is relatively resistant to plasmin-mediated lysis, possibly due to alterations in fibrinogen structure. The conflicting nature of contemporary data preclude drawing conclusions about the relative roles of traditional inherited thrombophilias or defective fibrinolysis in the development of CTEPH.

Several case series $(31,67-71)$ and large case-control studies $(32,45,55,72)$ have documented a link between CTEPH and previous splenectomy, and whether they are related to hemolytic anemia, myeloproliferative disease or trauma $(31,68,72)$. Importantly, the majority of patients who underwent previous splenectomy had inoperable CTEPH $(31,45,67)$. Other reported risk factors include chronic inflammatory disorders such as osteomyelitis and inflammatory bowel disease (72), an infected pacemaker (32) and ventriculoatrial shunts $(32,72)$. One case-control study (32) also documented that chronic venous ulcers, malignancy, myeloproliferative syndromes, thyroid hormone replacement therapy and hemoglobin abnormalities were more frequent in CTEPH patients than in patients with other types of $\mathrm{PH}$. Other rare combined coagulation defects, sickle cell disease, hereditary stomatocytosis and Klippel-Trénaunay syndrome have also been described in association with CTEPH in small case series (30).

There is also evidence that an underlying genetic predisposition may be involved in the pathogenesis of CTEPH. For example, there are ethnic differences in the demographics of CTEPH patients (a 2:1 female to male ratio has been reported in Japan $[47,48]$ compared with the $1: 1$ ratio reported in Europe $[32,45,46,72])$. Moreover, specific human leukocyte antigen subtypes are associated with CTEPH in Japan $(48,73)$. Of note, CTEPH has not been found to be associated with mutations in BMPR2, the gene locus implicated in hereditary $\mathrm{PAH}$, and in some sporadic cases of idiopathic $\mathrm{PAH}$ (45).

Underlying demographic, clinical and thrombosis-specific factors that influence the risk of developing CTEPH still need to be clarified. Although recent studies have improved our understanding of CTEPH in terms of its natural history and risk factors, further research will be required to define the complete epidemiology of CTEPH.

\section{SECTION III: DIAGNOSIS OF CTEPH}

\section{A. Introduction}

Importance and rationale of diagnosis of CTEPH: As mentioned, CTEPH is a common cause of PH that may affect up to $4 \%$ of patients following acute, symptomatic $\mathrm{PE}$, and is associated with a significant mortality rate, with a median two- to three-year survival rate of as low as $10 \%$ to $20 \%$ in untreated patients with severe CTEPH $(1,2)$. Thus, an important focus of the management of CTEPH is the early and accurate diagnosis of CTEPH in patients who are at risk either following an acute PE or who present with clinical features of $\mathrm{PH}$.

In patients who experience acute symptomatic $\mathrm{PE}$, ongoing symptoms of dyspnea or chest pain are common, and may identify patients at risk for CTEPH. Moreover, persistent pulmonary vascular perfusion defects are also common, being present in 73 (29\%) of 254 patients after acute PE at a median follow-up period of 12 months, and are associated with a greater prevalence of persistent symptoms, worse exercise capacity and higher systolic PAP (74). Therefore, there may be benefit to routine clinical and imaging follow-up of patients following PE to diagnose CTEPH earlier, or to identify patients at increased risk of developing CTEPH. It is important to recognize that a historical diagnosis of an acute VTE event lacks adequate sensitivity, and is not required to consider the diagnosis of CTEPH because many patients with CTEPH have not experienced a documented DVT or PE $(72,75)$.

Similar to patients with $\mathrm{PH}$ due to other causes, many patients with CTEPH present with clinical features of $\mathrm{PH}$ and $\mathrm{RV}$ failure. Therefore, in the evaluation of a patient with $\mathrm{PH}$, it is critical to consider the possible contribution of CTEPH because it is a treatable and potentially curable cause of $\mathrm{PH}$ with PEA surgery.

Approach to diagnosis of CTEPH: The goals of the diagnostic approach are to first establish the diagnosis of CTEPH, then to 
define the extent of disease and distribution of the pulmonary arterial occlusion(s) and, together with an evaluation of the severity of the $\mathrm{PH}$ and other comorbid illnesses, subsequently determine eligibility for PEA surgery or medical therapy.

Based on its high sensitivity and negative predictive value for excluding the possibility of CTEPH, V/Q nuclear lung scanning has been advocated as a first screening test to rule out CTEPH. It is mandatory that once the suspicion of CTEPH has been confirmed by a positive perfusion scintigram in the presence of $\mathrm{PH}$ by echocardiography, the patients should be transferred to a CTEPH expert centre for further work up. Classic pulmonary angiography has been the goldstandard test for confirming the diagnosis of CTEPH, and guiding the consideration of eligibility for PEA surgery and its approach. However, because of the invasive nature and the risks, other methods of pulmonary vascular imaging have been commonly used in the initial workup for CTEPH. Alternative approaches include pulmonary spiral CT angiography or MR angiography; however, these have not generally replaced conventional pulmonary angiography. It must be emphasized that the diagnosis of pulmonary vascular disease, with all of the available imaging modalities, depends critically on the presence of adequate local expertise, which is based, in large part, on experience with such cases.

CT pulmonary angiography is used to confirm the presence of CTEPH and to evaluate the feasibility of PEA surgery in patients with CTEPH (76-79). Additionally, CT pulmonary vascular abnormalities may correlate with PEA surgical outcomes, and CT may also be useful in identifying other parenchymal lung diseases and their severity (80). Aside from the characteristic CTEPH imaging features of proximal pulmonary arterial occlusions and web formations, other CT findings that are associated with CTEPH include mosaic perfusion abnormalities, pleural-based densities and bronchial arterial collaterals (79-83). CT scans may also be helpful in excluding other causes of pulmonary artery obstruction such as fibrosing mediastinitis, mediastinal tumours or pulmonary sarcomas (84).

MR angiographic imaging offers the potential for 'one-stop shopping' for the evaluation of patients with $\mathrm{PH}$. In addition to evaluating for the presence and severity of $\mathrm{PH}$ and RV failure (85), contrast-enhanced MR angiography can identify both acute PE and CTEPH $(86,87)$.

\section{B. Early detection of CTEPH in patients with acute pulmonary thromboembolism}

1. Screening for CTEPH in asymptomatic patients with acute pulmonary thromboembolism

Clinical question: Following an acute VTE event, should asymptomatic patients be screened (echocardiography, V/Q, CT or MR) to increase the rate of diagnosis of CTEPH or improve clinical outcomes of CTEPH patients?

Introduction: The majority of patients diagnosed with $\mathrm{PE}$ experience resolution of their clinical symptoms and normalization of pulmonary hemodynamics with appropriate systemic anticoagulant therapy. A small proportion of these patients are believed to develop CTEPH, which may result in symptoms of dyspnea and exercise limitation. Given the poor prognosis of untreated CTEPH and the availability of effective treatment approaches, screening for CTEPH in asymptomatic patients after an episode of acute pulmonary thromboembolism may be of clinical value.

Key evidence: No studies that addressed these clinical questions were identified. Thus, the recommendation informing this question is based on the consensus of the expert panel.

Expert panel synthesis of clinical judgment: The panel appreciated the lack of any direct evidence to address whether screening increases the rate of diagnosis of CTEPH, or results in improved CTEPH outcomes. Other relevant factors in screening for CTEPH were considered including the high likelihood of significant direct benefit to the patient such as low overall impact on morbidity and mortality of the population, the likely low burden of adherence and minimal adverse effects. In addition, the lack of any data addressing cost effectiveness was also discussed.

As a result, there was consensus for a weak recommendation at this time.

\section{Clinical question}

Following an acute VTE event, should asymptomatic patients be screened (echocardiography, V/Q, CT or MR) to increase the rate of diagnosis of CTEPH or improve clinical outcomes of CTEPH patients?

\section{Recommendations 1 and 2}

- We do not suggest routine echocardiographic screening for CTEPH in asymptomatic patients following an acute VTE (grade of recommendation: 2C).

- We do not suggest routine follow-up imaging (V/Q, CT or MR) as a screening tool for CTEPH in asymptomatic patients following an acute VTE event (grade of recommendation: $2 \mathrm{C}$ ).

Although no cost-effectiveness data are available, it was strongly believed that routine echocardiographic screening for CTEPH was unlikely to be cost effective. The panel did not address the use of imaging modalities (V/Q, CT or MR) for clinical indications other than CTEPH screening (eg, to establish a baseline before surveillance for recurrent PE).

The panel emphasized that these negative recommendations do not apply to the following two specific populations:

1. Patients with persistent symptoms of dyspnea, fatigue, exercise limitation, dizziness or chest pain following an acute VTE event. These patients would merit appropriate clinical and diagnostic investigation for many possible conditions including CTEPH; and

2. Patients in whom $\mathrm{PH}$ is documented at the time of the acute VTE event. These patients would merit appropriate clinical and diagnostic follow-up to confirm either resolution of the acute $\mathrm{PH}$, or to establish the presence of persistent $\mathrm{PH}$, which may suggest the presence of CTEPH or another cause of significant pulmonary vascular disease.

Areas for future research: Given the clinical importance of CTEPH and the significant benefits of available treatment approaches, research to more effectively identify asymptomatic patients with an elevated risk of developing CTEPH would be of potential benefit. Moreover, further research will be essential to supporting both clinical benefit and cost effectiveness of screening approaches for CTEPH in asymptomatic patients. 


\section{Assessment of the presence of CTEPH in patients with $\mathrm{PH}$}

\section{Nuclear V/Q lung scanning versus CT pulmonary angiography to rule out CTEPH}

Clinical question: Should nuclear V/Q lung scanning or CT pulmonary angiography be used as a screening test to rule out CTEPH in patients diagnosed with $\mathrm{PH}$ ?

Introduction: CTEPH is a common and important cause of $\mathrm{PH}$. In all patients with $\mathrm{PH}$, the possibility of CTEPH should specifically be considered, and appropriate imaging performed to confirm or refute the diagnosis of CTEPH. Although both nuclear V/Q lung scanning and spiral CT pulmonary angiography have been suggested as possible imaging modalities to screen for the presence of CTEPH, it is unclear which imaging approach is most effective at ruling out the possibility of CTEPH.

Key evidence: One large, single-centre, retrospective survey (88) compared the sensitivity of $\mathrm{V} / \mathrm{Q}$ versus CT pulmonary angiography in excluding a diagnosis of CTEPH in 227 subjects using conventional pulmonary angiography as the gold-standard technique. The presence of significant largevessel CTEPH that could be accessible to PEA surgery was suspected in 78 subjects. Sixty-one patients had large-vessel CTEPH confirmed on pulmonary angiography, while the remaining 17 had the diagnosis made in the setting of a high clinical probability and another imaging modality. This large-vessel CTEPH was detected by V/Q with a sensitivity of $97.4 \%$, while CT pulmonary angiography was only $51 \%$ sensitive. However, because the diagnosis of CTEPH was only confirmed by angiography in 61 of 78 subjects, the sensitivity of CT angiography may have been underestimated. In the 149 subjects without CTEPH, V/Q had a specificity of $90 \%$ and CT pulmonary angiography had a specificity of $99 \%$ (89).

The recommendation informing this question is based on this evidence and the consensus of the expert panel.

Expert panel synthesis of clinical judgment: The panel graded the evidence base as weak, but the lower sensitivity of CT pulmonary angiography for CTEPH was consistent with the clinical experience of panel members. Moreover, the panel considered the significant potential for direct health benefit to the individual patient in the accurate diagnosis of CTEPH including reduced morbidity and mortality, and improved HRQoL as well as minimal burden on the patient to adhere, with few adverse effects of the recommended approach.

As a result, there was consensus for a strong recommendation despite the low-grade evidence.

\section{Clinical question}

Should nuclear V/Q lung scanning or CT pulmonary angiography be used as a screening test to rule out CTEPH in patients diagnosed with $\mathrm{PH}$ ?

\section{Recommendation 3}

- We recommend nuclear V/Q lung scanning instead of CT pulmonary angiography as a screening test to rule out the possibility of CTEPH in patients diagnosed with $\mathrm{PH}$ (grade of recommendation: $1 \mathrm{C}$ ). A normal V/Q scan effectively rules out the possibility of CTEPH.

A high-probability V/Q scan is consistent with, but not diagnostic of, CTEPH. Indeterminate or nondiagnostic V/Q lung scan results are common in patients with $\mathrm{PH}$ due to other causes such as PAH or pulmonary veno-occlusive disease, and in patients with underlying pulmonary disease. These V/Q scan results would usually require further clinical and diagnostic assessment.

Areas for future research: The clinical importance of mild abnormalities on V/Q lung scans resulting in low or very low probability interpretations, remains uncertain, specifically with regard to ruling out CTEPH. Further studies will need to define the negative predictive value of such $\mathrm{V} / \mathrm{Q}$ scan results. The panel recognized the potential clinical utility of novel CT imaging approaches for the assessment of possible CTEPH including newer generation multislice scanners that may have improved sensitivity for detecting CTEPH, highresolution CT for the identification of parenchymal abnormalities, minimum intensity projection imaging to improve resolution and quantification of increased total bronchial artery cross-sectional area as a dichotomous parameter for the presence of CTEPH.

The panel suggested further research because the sensitivity of these newer imaging modalities in ruling out CTEPH has yet to be validated in studies or in clinical experience.

\section{Nuclear V/Q lung scanning to assess surgical accessibility of CTEPH}

Clinical question: Should nuclear V/Q lung scanning be used to assess the anatomical extent of potentially surgically accessible CTEPH in patients with suspected CTEPH?

Introduction: Following a diagnosis of CTEPH, the anatomical extent of CTEPH must be defined to assess the potential surgical resectability of the disease and to consider PEA surgery. The usual clinical practice is to assess the anatomical extent of CTEPH with conventional contrast pulmonary angiography. It is unclear whether nuclear V/Q lung scanning can effectively assess the surgical accessibility of CTEPH.

Key evidence: No studies have specifically compared V/Q lung scan results with any gold standard imaging approach to determine the extent of surgically accessible CTEPH.

Thus, the recommendation informing this question is based on the consensus of the expert panel.

Expert panel synthesis of clinical judgment: The lack of available evidence suporting the use of V/Q lung scanning to assess the extent of CTEPH and potential surgical accessibility was emphasized. This was also consistent with the clinical experience of the panel members who suggested that the extent of $\mathrm{V} / \mathrm{Q}$ scan perfusion defects largely underestimates the extent of significant pulmonary arterial obstruction. The potential advantages of using V/Q lung scanning to both diagnose CTEPH and to define the extent of CTEPH were appreciated. These advantages included some minimal direct health benefit to the patient in reducing the burden of adherence, reducing the morbidity and adverse effects related to performing other imaging studies, and reducing the cost of investigating these patients. However, these benefits were believed to be minor compared with the significant potential harm of not adequately characterizing the anatomical extent and surgical accessibility of CTEPH.

As a result, there was consensus for a strong negative recommendation. 


\section{Clinical question}

Should nuclear V/Q lung scanning be used to assess the anatomical extent of potentially surgically accessible CTEPH in patients with suspected CTEPH?

\section{Recommendation 4}

- We recommend that the results of a V/Q lung scan should not be used to assess the anatomical extent of potentially surgically accessible CTEPH (grade of recommendation: $1 \mathrm{C}$ ).

\section{CT or MR pulmonary angiography versus conventional} pulmonary angiography to assess surgical accessibility of CTEPH

Clinical question: Should CT pulmonary angiography or MR pulmonary angiography be used to assess the anatomical extent of potentially surgically accessible CTEPH in patients with suspected CTEPH?

Introduction: Following a diagnosis of CTEPH, the anatomical extent of CTEPH must be defined to assess the potential surgical resectability of the disease and to consider PEA surgery. It is unclear whether CT or MR pulmonary angiography can effectively assess the surgical accessibility of CTEPH compared with the traditional gold-standard test - conventional contrast pulmonary angiography.

Key evidence: Only a few studies have addressed this clinical question, with conflicting results. An uncontrolled case series (90) compared CT angiography with pulmonary angiography in 55 CTEPH patients, 40 of whom underwent PEA surgery. CT angiography and conventional pulmonary angiography were equally accurate in the detection of potentially resectable central disease (79\% versus $74 \%$, respectively). CT was judged more accurate for the detection of segmental vessel disease; however, statistical significance was not evaluated.

In this study (90), MR angiography was also performed in 26 of these CTEPH subjects and found to be less accurate in detecting central disease $39 \%$ and $46 \%$ accuracy for two reviewers) than both $\mathrm{CT}$ and conventional pulmonary angiography. Another case series (85) compared pulmonary MR and digital subtraction angiography (DSA) in $34 \mathrm{CTEPH}$ patients undergoing PEA surgery. MR angiography was equivalent to DSA for the detection of chronic pulmonary vascular thromboembolic disease in main, lobar and segmental pulmonary vessels, but inferior to DSA at the subsegmental level $(\mathrm{P}<0.001)$. The authors also suggested that MR may be superior to DSA for determining the exact central beginning of thromboembolic material.

Thus, the recommendation informing this question is based on this weak evidence and the consensus of the expert panel.

Expert panel synthesis of clinical judgment: The panel emphasized the limited evidence supporting CT and MR angiography for defining the anatomical extent of surgically accessible CTEPH.

In considering CT angiography, the significant supportive clinical experience of panel members was appreciated. The panel also considered other factors including the significant direct health benefit to the patient such as reduced morbidity and improved HRQoL, minimal burden on the patient to adhere, few adverse effects of CT angiography and potential cost effectiveness.
In considering MR angiography, other factors considered included the minimal burden of adherence and adverse effects, but also the lack of evidence to suggest any direct health benefit to the patient or any impact on morbidity or mortality. The panel emphasized the high likelihood of lack of cost effectiveness and the limited current access to MR technology.

As a result, there was consensus for weak recommendations.

\section{Clinical question}

Should CT pulmonary angiography or MR pulmonary angiography be used to assess the anatomical extent of potentially surgically accessible CTEPH in patients with suspected CTEPH?

\section{Recommendations 5 and 6}

- We suggest the routine clinical use of a positive CT pulmonary angiogram to assess the anatomical extent of surgically accessible CTEPH (grade of recommendation: 2C). A negative CT pulmonary angiogram does not effectively rule out the presence of surgically accessible CTEPH, which is better assessed by contrast pulmonary angiography.

- We do not suggest the routine use of MR pulmonary angiography in the preoperative assessment of patients with CTEPH (grade of recommendation: 2C).

Evidence of proximal CTEPH on a CT pulmonary angiogram may be adequate for consideration of PEA surgery in some centres, although conventional pulmonary angiography remains the gold standard to assess the anatomical surgical extent of CTEPH. Management of such patients requires further consideration of conventional pulmonary angiography in centres with expertise in the assessment of CTEPH patients for PEA surgery.

Areas for future research: Future studies using newer multislice CT scanners may help establish a role for CT pulmonary angiography in ruling out CTEPH, or in more effectively defining the anatomical extent and burden of CTEPH for surgical PEA. In addition, ongoing research using existing MR imaging modalities and novel approaches, such as the use of hyperpolarized gases, holds promise for the assessment of pulmonary vascular disease including V/Q relationships (91).

\section{SECTION IV: MEDICAL AND SURGICAL MANAGEMENT OF CTEPH}

\section{A. General medical management of CTEPH patients}

Many treatments have been used for CTEPH patients since the initial recognition of this condition almost five decades previously (92-94). It has become established over recent years that PEA surgery is the treatment of choice for CTEPH because of significant improvement in the majority of patients and the potential of cure in many. In addition, the potential benefits of novel, $\mathrm{PH}$-specific medications have been investigated for patients who are either not candidates for PEA or experience residual PH following PEA surgery.

General medical 'supportive' management of patients with CTEPH involves systemic anticoagulation, optimization of fluid status with carefully adjusted doses of diuretics and treatment of resting hypoxemia with supplemental oxygen. In 
selected CTEPH patients, other cardiac medications (eg, digoxin and calcium-channel blockers [CCBs]) are occasionally considered, with risks versus benefits carefully weighed. CTEPH is often diagnosed in mid to late adulthood, and other management interventions not directly related to the CTEPH would also maintain general health and may optimize clinical outcomes in this population. These include routine vaccination, preventive cancer screening and other general health interventions. Despite the importance of these general health measures, they were not within the scope of the present CPG.

The panel did not specifically address which management interventions might be best managed by particular members of the health care team (eg, family physician versus $\mathrm{PH}$ specialist versus anticoagulation clinic), but did identify this topic as a potential issue for future research. The panel also recognized the need for individual physicians, hospitals and $\mathrm{PH}$ centres in different Canadian jurisdictions to customize their approach to these interventions based on locally available resources. The committee emphasized the importance of a collaborative interprofessional team approach among $\mathrm{PH}$ specialists, family physicians and allied health care providers (where available) in the management of CTEPH patients.

\section{Chronic anticoagulation in CTEPH patients}

Clinical question: Should patients with CTEPH be chronically anticoagulated to reduce the risk of recurrent or progressive pulmonary artery thrombosis and/or worsening $\mathrm{PH}$, or to improve clinical outcomes?

Introduction: Epidemiological and pathological evidence strongly support the central role of initial VTE in the pathophysiology of CTEPH. Therefore, chronic anticoagulation is usually instituted in all CTEPH patients including those who do not undergo PEA, and in CTEPH patients before and following PEA surgery. However, the benefits and risks of chronic anticoagulation in the long-term management of these three subpopulations of CTEPH patients are unclear.

Key evidence: No studies that addressed the benefits or risks of chronic anticoagulation versus cessation of anticoagulation in CTEPH patients were identified. Thus, the recommendation informing this question is based on the consensus of the expert panel.

Expert panel synthesis of clinical judgment: The absence of any long-term data supporting chronic anticoagulation in patients with CTEPH was appreciated. However, the panel was very concerned about recurrent or progressive pulmonary artery thrombosis following discontinuation of anticoagulation, and the risk of worsening $\mathrm{PH}$ and $\mathrm{RV}$ failure in the absence of any specific evidence supporting the safety of cessation of anticoagulation. Thus, the potential significant direct health benefits of chronic anticoagulation in the individual CTEPH patient and the potential high impact on overall CTEPH morbidity and mortality were emphasized. The panel considered other factors including moderate adverse effects, an inconclusive cost effectiveness and an intermediate burden on the patient to adhere to chronic anticoagulation.

As a result, there was consensus for a weak recommendation in favour of chronic anticoagulation.

\section{Clinical question}

Should patients with CTEPH be chronically anticoagulated to reduce the risk of recurrent or progressive pulmonary artery thrombosis and/or worsening $\mathrm{PH}$, or to improve clinical outcomes?

\section{Recommendation 7}

- We suggest that all CTEPH patients, including patients who do not undergo PEA and patients post-PEA surgery, be chronically anticoagulated (grade of recommendation: 2C).

In the absence of comparative evidence, either chronic oral warfarin, or subcutaneous, therapeutic-dose, low-molecularweight heparin are acceptable. For oral warfarin, the usual clinical therapeutic range of international normalized ratio of 2 to 3 may need to be modified based on individual patient characteristics such as active bleeding or hypercoagulable state.

The panel emphasized that this recommendation in favour of chronic anticoagulation is independent of the presence of an inferior vena cava (IVC) filter.

Areas for future research: Although the risks and burden of chronic anticoagulation are recognized, there is also a significant risk of recurrent VTE disease if anticoagulation is stopped. Therefore, future studies would be helpful in defining the clinical value of chronic anticoagulation in selected CTEPH populations, especially after PEA surgery. Moreover, the relative benefits of different anticoagulant agents and high-versus low-intensity chronic anticoagulation need to be studied in CTEPH patients pre- and post-PEA surgery, and in patients not undergoing PEA surgery.

\section{CCB therapy}

Clinical question: Should patients with symptomatic CTEPH be treated with high-dose CCBs to improve operability or clinical outcomes?

Introduction: In selected patients with idiopathic PAH and marked acute vasodilator responsiveness, the use of high-dose CCB therapy has been shown to be associated with long-term hemodynamic, clinical and survival benefit. Some CTEPH patients may also demonstrate significant acute pulmonary vasodilation during invasive hemodynamic monitoring (95). Therefore, CCBs may be of clinical benefit in patients with CTEPH.

Key evidence: No studies that addressed this clinical question were identified. Thus, the recommendation informing this question is based on the consensus of the expert panel and clinical experience with the use of CCBs in $\mathrm{PAH}$ patients.

Expert panel synthesis of clinical judgment: The significant clinical benefit of high-dose CCBs in a highly selected group of acute vasodilator-responsive idiopathic PAH patients was recognized. However, the panel emphasized the limited clinical utility and benefit of CCBs in the vast majority of idiopathic PAH patients (who do not manifest acute vasodilator responsiveness) and in most patients with other types of $\mathrm{PH}$. For specific CTEPH patients, other factors considered included a minimal direct health benefit, an overall low potential impact on morbidity and mortality, inconclusive cost effectiveness and an intermediate burden on the patient to adhere to high-dose 
CCBs. Moreover, the significant potential for adverse effects of high-dose CCBs, such as systemic hypotension and worsening RV failure, raised much concern.

As a result, there was consensus for a strong negative recommendation.

\section{Clinical question}

Should patients with symptomatic CTEPH be treated with high-dose CCBs to improve operability or clinical outcomes?

\section{Recommendation 8}

- We strongly recommend against the use of high-dose CCBs in patients with CTEPH (grade of recommendation: $1 \mathrm{C}$ ).

CCB therapy in CTEPH patients: Areas for future research: In some CTEPH patients with marked acute vasodilator responsiveness, the potential benefit of high-dose CCBs has not been tested. The panel recommends further study of the epidemiology, pathophysiology and clinical significance of acute vasoreactivity in CTEPH patients, and the clinical value and risks of high-dose CCBs in such patients.

\section{Digoxin therapy}

Clinical question: Should patients with CTEPH be treated with digoxin to reduce the incidence of atrial arrhythmias or improve clinical outcomes?

Introduction: Based on the evidence of some clinical benefit in LV heart failure, the use of digoxin has been considered for patients with $\mathrm{PH}$ and RV failure. It is unclear whether digoxin is of clinical benefit in patients with CTEPH.

Key evidence: No studies that addressed this clinical question were identified. Thus, the recommendation informing this question is based on the consensus of the expert panel.

Expert panel synthesis of clinical judgment: The absence of any published evidence that addressed the use of digoxin in CTEPH patients was appreciated. The panel emphasized the likelihood of limited clinical benefit, the limited impact of digoxin on overall CTEPH morbidity and mortality, and inconclusive cost effectiveness. The panel recognized a low burden of adherence and the low risk of digoxin therapy in the presence of adequate clinical monitoring.

As a result, there was expert consensus for a weak negative recommendation on the routine use of digoxin in $\mathrm{CTEPH}$ patients.

\section{Clinical question}

Should patients with CTEPH be routinely treated with digoxin to reduce the incidence of atrial arrhythmias or improve clinical outcomes?

\section{Recommendation 9}

- We do not suggest routine digoxin therapy in patients with CTEPH (grade of recommendation: 2C). The expert panel recognized that digoxin may be of some limited benefit in selected CTEPH patients with RV failure or atrial arrhythmias.

Areas for future research: Further research on the potential benefits of digoxin therapy on both short-term and long-term clinical outcomes in CTEPH patients with RV failure or atrial arrhythmias may be clinically useful.

\section{Supplemental nocturnal/exertional oxygen therapy}

Clinical question: Should CTEPH patients who manifest isolated nocturnal and/or exertional oxygen desaturation receive long-term oxygen therapy to improve clinical outcomes?

Introduction: In CTEPH patients with hypoxemia at rest, supplemental oxygen therapy is indicated similar to hypoxemic patients with other cardiopulmonary disorders. Despite adequate oxygenation at rest, patients with CTEPH can manifest isolated oxygen desaturation on exertion and/or nocturnally. There are significant potential adverse effects of such repetitive desaturations such as worsening $\mathrm{PH}$ and a risk of RV failure. It is unclear whether CTEPH patients with exertional and/or nocturnal desaturation benefit from supplemental oxygen therapy.

Key evidence: No studies that addressed this clinical question were identified. Thus, the recommendation informing this question is based on the consensus of the expert panel.

Expert panel synthesis of clinical judgment: The absence of published evidence that addressed the use of supplemental oxygen to prevent exertional or nocturnal desaturation in CTEPH patients was appreciated. The panel recognized a potential clinical benefit of oxygen therapy in this situation as well as the low risk, but also noted the cost implications of long-term oxygen therapy. The lack of evidence supporting clinical benefit of supplemental oxygen for isolated exertional and/or nocturnal oxygen desaturation in other chronic pulmonary diseases (eg, COPD) was also considered.

As a result, there was no expert consensus on a recommendation for the use of supplemental oxygen for isolated exertional and/or nocturnal oxygen desaturation in CTEPH patients. Despite this lack of consensus, the panel appreciated that oxygen therapy for isolated nocturnal and/or exertional desaturation may be of benefit in individual patients.

\section{Clinical question \\ Should CTEPH patients who manifest isolated nocturnal and/or exertional oxygen desaturation receive long-term oxygen therapy to improve clinical outcomes?}

\section{Recommendation 10}

- There was no expert consensus on a recommendation for or against the use of supplemental oxygen in patients with CTEPH who manifest isolated nocturnal and/or exertional oxygen desaturation. Treatment with supplemental oxygen is clearly indicated for CTEPH patients who manifest hypoxemia at rest.

Areas for future research: The panel suggests further study of supplemental oxygen, specifically during exercise or nocturnally in CTEPH patients, with regard to possible beneficial effects on end points such as pulmonary hemodynamics, symptoms, WHO functional class or HRQoL.

\section{Cardiopulmonary exercise rehabilitation in $\mathrm{CTEPH}$ patients}


Clinical question: Should a cardiopulmonary exercise program be implemented to improve clinical outcomes in CTEPH patients being considered for PEA surgery, or in patients with inoperable CTEPH or residual $\mathrm{PH}$ following PEA surgery?

Introduction: Lack of fitness due to inadequate levels of physical activity is recognized to be an important contributor to clinical symptoms, poor functional status and worse clinical outcomes in many chronic cardiopulmonary conditions. The significant clinical benefits of a structured cardiopulmonary rehabilitation program for conditions such as COPD and congestive heart failure are well recognized.

Similarly, cardiopulmonary exercise rehabilitation may be of benefit in CTEPH patients. For example, preoperative cardiopulmonary exercise rehabilitation could improve outcomes in CTEPH patients undergoing PEA surgery. Other CTEPH patients who are inoperable or who experience residual PH following PEA surgery may also benefit from cardiopulmonary exercise rehabilitation.

Key evidence: A single RCT (96) addressed the potential benefit of structured cardiopulmonary exercise rehabilitation in patients with $\mathrm{PH}$. Thirty patients were assigned to a structured rehabilitation program that consisted of an initial three-week, in-hospital phase, and a home-based program for an additional 12 weeks, with the training group consisting of 15 subjects. Both groups received common elements including healthy nutrition, massage therapy, counselling and muscular relaxation. The supervised in-hospital exercise program consisted of daily interval bicycle ergometer training for $10 \mathrm{~min} /$ day to $25 \mathrm{~min} /$ day (initially at a low intensity [10 W to $60 \mathrm{~W}]$ ), which was increased as tolerated to $60 \mathrm{~min}$ of walking five days/week, single muscle group strength training five days/week and respiratory muscle training $30 \mathrm{~min} /$ day for five days/week. Each component was continued during the home-based period, with telephone follow-up every two weeks in both groups.

The exercise group experienced significant placebo-corrected improvements in both primary end points at 15 weeks: 6MWD improved by $111 \mathrm{~m}$ and improved HRQoL scores. Overall, exercise training was well tolerated, with no dropouts. The exercise group also showed improvements in WHO functional class, peak oxygen consumption and workload achieved during training.

This study included six subjects with CTEPH, two of whom were randomly assigned to the active rehabilitation group. However, no specific data on these patients were provided.

Thus, the recommendation informing this question is based on limited evidence and the consensus of the expert panel, some of whom have experience with cardiopulmonary exercise rehabilitation in CTEPH patients.

Expert panel synthesis of clinical judgment: The absence of specific data on cardiopulmonary exercise rehabilitation in CTEPH patients was recognized. The panel considered other factors in grading the strength of recommendation such as the likelihood of some direct benefit to the CTEPH patient, and the potential for a significant overall impact on CTEPH morbidity and HRQoL, extrapolated from the benefits of rehabilitation in $\mathrm{PH}$ patients and in patients with other chronic cardiopulmonary conditions. However, inconclusive cost effectiveness, a moderately high burden of adherence and some potential adverse effects of exercise rehabilitation such as severe dyspnea, chest pain, systemic hypotension, lightheadedness, syncope and, potentially, death were also recognized. In CTEPH patients specifically, the panel was concerned that the potential benefits of an exercise rehabilitation program before PEA could be outweighed by the resulting delay in PEA and worsening of the degree of PH or RV failure.

As a result, there was consensus for a weak recommendation.

\section{Clinical question}

Should a cardiopulmonary exercise program be implemented to improve clinical outcomes in CTEPH patients being considered for PEA surgery, or in patients with inoperable CTEPH or residual $\mathrm{PH}$ post-PEA?

\section{Recommendation 11}

- We suggest cardiopulmonary exercise rehabilitation in CTEPH patients (grade of recommendation: 2C).

Given the potential risks of exercise rehabilitation, the panel strongly urged that cardiopulmonary exercise rehabilitation be pursued only in a monitored setting under the supervision of a rehabilitation expert knowledgeable about PH. Moreover, exercise rehabilitation should be pursued with great caution in patients with severe WHO functional class III/IV CTEPH and/or RV failure. The panel emphasized that a decision to enroll CTEPH patients in a cardiopulmonary exercise rehabilitation program before PEA should be weighed carefully against the potential harm of delaying PEA surgery. Areas for future research: The panel recommends further research into the potential beneficial effects of a structured cardiopulmonary exercise rehabilitation program on clinically important outcomes in CTEPH patients - specifically, CTEPH patients who are inoperable or have residual $\mathrm{PH}$ post-PEA. In addition, specific study of the benefits versus risks of cardiopulmonary exercise rehabilitation pre-PEA, such as the risks of delaying PEA surgery, would be clinically helpful.

\section{Use of IVC filters}

Clinical question: Should IVC filters routinely be inserted to reduce the occurrence of future PE and/or re-do PEA surgery, or improve long-term survival in patients with CTEPH?

Introduction: It is generally believed that CTEPH is a result of an initial pulmonary embolic event, which usually arises from the deep venous system of the lower extremities and pelvis. In patients with recurrent pulmonary emboli despite systemic anticoagulation, or in patients in whom anticoagulation is contraindicated due to bleeding risk, insertion of an umbrella-type filter device into the IVC has been recommended to prevent future pulmonary emboli. In CTEPH patients, there may be a benefit of IVC filter insertion. However, IVC filter insertion may also have significant risks including retroperitoneal hemorrhage, future venous thrombosis, postphlebitic limb or filter migration/embolization. As a result of the uncertainty of the benefit-risk balance of IVC filters, there is a marked variability in the routine clinical use of IVC filters in CTEPH patients among centres with expertise in CTEPH and PEA surgery.

Key evidence: No studies that addressed this clinical question were identified. Thus, the recommendation informing this question is based on the consensus of the expert panel. 
Expert panel synthesis of clinical judgment: The lack of evidence to support any benefit of IVC filter insertion was emphasized. Some potential for limited direct health benefit to the patient, such as limited impact on morbidity and mortality, was recognized. In additon, potential moderate adverse effects, a low burden of adherence and inconclusive economic effects were also discussed. Furthermore, there is no evidence to indicate that the risks of IVC filter insertion in CTEPH patients are different versus other patients.

As a result, the consensus of the panel was not to make a recommendation at this time.

\section{Clinical question}

Should IVC filters routinely be inserted to reduce the occurrence of future $\mathrm{PE}$ and/or re-do PEA surgery, or improve long-term survival in patients with CTEPH?

\section{Recommendation 12}

- There was no expert consensus on a recommendation for or against the routine use of IVC filters in patients with CTEPH.

Areas for future research: The panel supports further study of IVC filters in CTEPH patients. Specific data on the risk of development/progression of CTEPH due to recurrent PE post-PEA and the effect of IVC filters on this risk would be clinically helpful. Studies defining the risk of IVC filters (eg, retroperitoneal hemorrhage, filter migration and complications of intravenous contrast) specifically in the CTEPH population would also be helpful.

\section{B. Management of CTEPH patients pre-PEA \\ 1. Introduction}

Following appropriate diagnostic workup as above, PEA is the treatment of choice for symptomatic patients with proximal CTEPH. Preoperative evaluation of prospective PEA patients involves assessment for the presence of left-sided heart disease and is routinely evaluated clinically with echocardiography. Left heart catheterization with coronary angiography is usually performed in patients with risk factors for coronary artery disease. The presence of any significant underlying lung disease is also assessed clinically, radiographically and with pulmonary function tests. A patient's baseline functional capacity is established through objective exercise testing such as the 6MWD. Patients are also assessed for significant underlying disease, such as malignancy, using age-appropriate and targeted screening based on a careful review of the presenting symptoms.

Patients are usually maintained on systemic anticoagulation until just before PEA, although the actual protocol depends on local experience and preference of the PEA surgical centre. Supplemental oxygen and diuretics are often administered to optimize a patient's oxygenation and volume status.

\section{Parenteral prostanoid therapy in CTEPH patients pre- PEA surgery}

Clinical question: Should patients with symptomatic, surgically accessible CTEPH be treated with parenteral prostanoids (intravenous epoprostenol, subcutaneous or intravenous treprostinil) before PEA surgery to improve operability or clinical outcomes?
Introduction: In symptomatic patients with surgically accessible CTEPH, PEA surgery is the treatment of choice. In some of these patients, especially those with severe $\mathrm{PH}$ and RV failure, aggressive medical therapy pre-PEA with parenteral prostanoids (eg, intravenous epoprostenol, or subcutaneous or intravenous treprostinil) may be beneficial as a 'bridge' to PEA surgery to improve the results of PEA surgery and longterm hemodynamic or clinical outcomes.

Key evidence: This issue has been addressed in two small retrospective studies. In a retrospective case-series of 33 CTEPH patients (97), intravenous epoprostenol treatment before PEA surgery in 12 patients with a PVR of greater than 1200 dyne.s $/ \mathrm{cm}^{5}$ improved pulmonary hemodynamics and reduced plasma BNP levels. The outcomes of the subsequent PEA were similar in these 12 epoprostenol-treated, severe CTEPH patients when compared with the outcomes in the other 21 patients with milder CTEPH who were not treated medically before PEA. In another retrospective series of nine patients with severe CTEPH (severity not defined) (98), intravenous epoprostenol was associated with improved hemodynamics and clinical status in six, but worsening in three. All patients subsequently underwent successful PEA. There are no data regarding the use of subcutaneous or intravenous treprostinil in CTEPH patients before PEA surgery.

Thus, the recommendation informing this question is based on weak evidence and the consensus of the expert panel.

Expert panel synthesis of clinical judgment: The clinical experience of several panel members, who reported successful use of intravenous epoprostenol in severely ill CTEPH patients before PEA surgery, was considered. Other factors that were considered in grading the strength of recommendation included a moderate likelihood of direct benefit to the patient; however, overall, there was only a limited potential impact on morbidity and mortality given the low-grade evidence. In addition, a high burden of adherence and moderate adverse effects of intravenous epoprostenol treatment, such as potentially greater perioperative bleeding due to antiplatelet effects, were recognized in addition to the lack of any costeffectiveness data.

As a result, there was consensus for a weak recommendation.

\section{Clinical question}

Should patients with symptomatic, surgically accessible CTEPH be treated with parenteral prostanoids (intravenous epoprostenol, subcutaneous or intravenous treprostinil) before PEA surgery to improve operability or clinical outcomes?

\section{Recommendation 13}

- We suggest pre-PEA treatment with intravenous epoprostenol in selected patients with severe surgically accessible CTEPH (WHO functional class III or IV with a PVR of greater than 1200 dyne $\bullet / \mathrm{cm}^{5}$ and/or RV failure) because this may improve hemodynamics and operability (grade of recommendation: $2 \mathrm{C}$ ). The decision to institute pre-PEA parenteral epoprostenol therapy should be at the discretion of a centre with experience treating CTEPH patients and in consultation with a PEA surgeon. 
In the absence of any current evidence or experience, the use of subcutaneous or intravenous treprostinil in these patients cannot currently be recommended.

Although the above definition of 'severe' CTEPH was selected by the panel, there is no such definition with universal consensus. Therefore, the definition of severe CTEPH depends on the experience of each PEA centre. The panel strongly cautioned that the institution of medical therapy should not delay referral to a $\mathrm{PH}$ expert centre for consideration of PEA in patients who have surgically accessible CTEPH because such a delay may adversely impact the clinical outcome.

\section{Oral PH-specific medical therapy in $\mathrm{CTEPH}$ patients pre-PEA}

Clinical question: Should patients with symptomatic, surgically accessible CTEPH be treated with oral $\mathrm{PH}$-specific medications (endothelin-receptor antagonists [ERAs] or phosphodiesterase type 5 inhibitors [PDE-5is) before PEA surgery to improve operability or clinical outcomes?

Introduction: In symptomatic patients with surgically accessible CTEPH, PEA surgery is the treatment of choice. However, the potential benefit of novel, oral $\mathrm{PH}$-specific medical therapy before PEA to improve clinical outcomes of subsequent PEA surgery is unclear.

Key evidence: No studies that addressed this clinical question were identified. Thus, the recommendation informing this question is based on the consensus of the expert panel.

Expert panel synthesis of clinical judgment: The absence of any specific data supporting pre-PEA, $\mathrm{PH}$-specific medical therapy was appreciated. Other factors considered in grading the strength of recommendation included some possibility of direct benefit to the CTEPH patient, but limited impact on overall CTEPH morbidity and mortality. For oral therapy specifically, a low burden of adherence, minimal adverse effects and inconclusive cost effectiveness were discussed.

The panel emphasized that the limited potential benefits of $\mathrm{PH}$-specific medical therapy before PEA surgery could easily be outweighed by a resulting delay in PEA surgery and worsening of the degree of $\mathrm{PH}$ or RV failure.

As a result, the consensus of the panel was not to make a recommendation at this time.

\section{Clinical question}

Should patients with symptomatic, surgically accessible CTEPH be treated with oral $\mathrm{PH}$-specific medications (ERAs, or PDE-5is) before PEA surgery to improve operability or clinical outcomes?

\section{Recommendation 14}

- Currently, we do not recommend for or against the use of oral $\mathrm{PH}$-specific medical therapy in CTEPH patients who are being considered for PEA. The panel emphasized that a decision to treat CTEPH patients with oral $\mathrm{PH}$ medications should not delay referral to an expert centre for consideration of PEA in patients with surgically accessible CTEPH because such a delay may adversely impact the clinical outcome.
Areas for future research: Future research defining the benefits versus risks of medical $\mathrm{PH}$-specific therapy pre-PEA, especially in delaying PEA surgery, would be clinically helpful. Moreover, the usefulness of novel approaches (eg, cardiac MR and serum markers such as BNP) to assess RV function and distal pulmonary arteriopathy before PEA surgery to better predict the risks of surgery would also elucidate the potential role of $\mathrm{PH}$-specific medical therapy in the treatment of $\mathrm{PH}$ and RV failure pre-PEA surgery and, possibly, improve outcomes.

\section{PEA in CTEPH patients \\ 1. Introduction}

The pathophysiology of $\mathrm{PH}$ and RV overload in many CTEPH patients is related to the presence chronic, organized thrombotic vascular disease at the level of the larger proximal pulmonary arteries including the main, lobar and segmental pulmonary arteries. By definition, such disease is not treatable with simple anticoagulation because the occlusive material is believed to have evolved from a thrombus to more organized or fibrotic tissue. No medications have been shown to be effective in treating this occlusive pulmonary arterial disease.

The current surgical procedure for PEA as a standard approach to the treatment of CTEPH was first developed in the late 1980s at the University of California at San Diego (California, USA) by the team led by Dr Ken Moser (35). Since the initial reports, there have been several modifications to the surgical approach to PEA. Approximately 4000 procedures have been completed in specialized centres in many countries worldwide $(99,100)$.

The accepted approach to the pulmonary arteries is through a median sternotomy using central cannulation with cardiopulmonary bypass. Due to bronchial artery hyperplasia in CTEPH $(75,82)$, PEA is usually performed under deep hypothermic circulatory arrest or low-flow bypass to minimize bleeding, and to optimize visualization and the quality of the pulmonary artery dissection. After aortic cross-clamping and the administration of myocardial protection with cardioplegia, the right and left main pulmonary arteries are sequentially approached through arteriotomies extending out close to the pericardial reflection. The right pulmonary artery is approached from the space between the superior vena cava and the aorta. Once the blood vessel is opened, an appropriate endarterectomy plane is developed in the posterior wall of the vessel using blunt dissection. The specimen is prepared circumferentially, with subsequent careful dissection distally into the lobar and segmental vessels of each lung. The periods of circulatory arrest are generally limited to a maximum of $20 \mathrm{~min}$, with corporeal reperfusion for $10 \mathrm{~min}$ between periods of arrest (101). Two 20 min periods are usually required for complete excision of bilateral specimens. After the specimen has been completely removed, the pulmonary artery is closed, and the patient is subsequently rewarmed and weaned from cardiopulmonary bypass. Postoperative care is usually in an intensive care unit setting with routine clinical and hemodynamic monitoring.

\section{PEA in patients with surgically accessible CTEPH}

Clinical question: Should patients with surgically accessible CTEPH undergo PEA to improve clinical outcomes?

Introduction: PEA has become the standard of care given the dramatic hemodynamic and clinical improvements that 
have been observed in many CTEPH patients. This is in contrast to the poor prognosis for survival that has historically been associated with CTEPH $(1,2,102)$. For example, survival at two years was less than 20\% when mPAP exceeded $50 \mathrm{mmHg}$ in nonsurgically treated CTEPH patients in one study from an era before the availability of $\mathrm{PH}$-specific medications (1). A significant mortality of $32 \%$ was also found in CTEPH patients with less severe hemodynamics (2).

Key evidence: Although approximately 4000 PEA surgeries have been performed worldwide in the past 30 years, not all of these patients' outcomes are reported in the published literature. A large number of observational reports have described the effects of PEA surgery on pulmonary hemodynamics, cardiac size and function, clinical parameters and other important outcomes such as survival (28,45,100,103-130) (Table 6). However, there are no RCTs that directly compared PEA surgery for patients with surgically accessible CTEPH with either conservative management alone (eg, diuretics, oxygen and anticoagulation) or with conservative management plus novel $\mathrm{PH}$-specific medications without PEA.

In the vast majority of reports, there is an immediate improvement in hemodynamics after PEA including an increase in CI and significant decreases in PVR and PAP both on arrival to the intensive care unit and over the ensuing few days (100) (Table 6). RV remodelling also occurs quite rapidly after PEA. There is an immediate decrease in right-sided chamber sizes, a marked reduction in tricuspid insufficiency, with normalization of valve geometry, decreased leftward shift of the interventricular septum, increased LV end-diastolic area and reduced LV eccentricity $(106,131,132)$. Clinical improvement after PEA is likely related to improvement in pulmonary hemodynamics, blood flow and RV function following removal of pulmonary arterial obstructive material $(34,106)$, but may also be due to reversal of pulmonary vascular remodelling (133-135).

In experienced hands, perioperative (30-day) mortality ranges from $4 \%$ to $10 \%$, with the most common cause of early death related to persistent PH $(28,45,100,103,104,106$ 109,112-115,118-124,130). In the largest series (118), PEA perioperative mortality between 1998 and 2002 was $4.4 \%$ (22 of 500 ). Increasing surgical experience, technical refinements and better patient selection likely explain the improvements in perioperative mortality during the past 15 years. However, the purported benefits of PEA suffer from potential publication bias, and outcomes may vary significantly from centre to centre depending on experience and surgical expertise.

Among survivors of PEA, there is evidence that patients can expect significant improvement in long-term outcome. A comprehensive follow-up conducted in San Diego (California, USA) between 1970 and 1994 reported a survival rate of $75 \%$ six years after surgery in 514 PEA patients (103). The most common cause of late death was residual PH post-PEA, with death in this subgroup occurring at a mean of 2.73 years after surgery. More recent series have found two-year survival to be in the $85 \%$ to $90 \%$ range $(28,119,123,124,136-138)-$ in striking contrast to the natural history studies of nonsurgically treated CTEPH patients $(1,2,102)$.
Studies have also reported significant post-PEA improvements in long-term HRQoL $(124,139)$, exercise tolerance as measured by 6MWD $(28,45,114,115,120,122)$, peak oxygen consumption (137) and functional capacity $(28,107,108,112,122,123)$. The improvements in these clinical parameters have often been correlated with pulmonary hemodynamic improvement post-PEA.

The recommendation informing this question is based on this evidence and the consensus of the expert panel.

Expert panel synthesis of clinical judgment: The panel graded the published evidence supporting improved clinical outcomes post-PEA surgery in patients with surgically accessible CTEPH as being of moderate quality. The potential for significant direct health benefits of successful PEA surgery in an individual CTEPH patient was appreciated, as was the high overall impact of PEA surgery on morbidity and mortality in such patients with surgically-accessible CTEPH. Moderate adverse effects including risk of death or neurological complications, a high burden of adherence and inconclusive cost effectiveness of PEA surgery in such patients were also considered.

As a result, there was consensus for a strong recommendation.

\section{Clinical question}

Should patients with surgically-accessible CTEPH undergo PEA to improve clinical outcomes?

\section{Recommendation 15}

- We recommend PEA as the treatment of choice in patients with surgically-accessible CTEPH (grade of recommendation: 1C).

Surgical resectability of CTEPH is a critical issue in the optimal care of CTEPH patients and should be assessed at a centre with experience. In patients with surgically accessible CTEPH and an acceptable perioperative risk, PEA is the treatment of choice and should not be delayed because of consideration of a 'trial' of $\mathrm{PH}$-specific medical therapy. CTEPH patients with surgically accessible disease who also have significant underlying comorbidities should be carefully assessed at a centre experienced with CTEPH and in consultation with a PEA surgeon to accurately define the benefits versus the perioperative risks of PEA.

\section{PEA in patients with distal CTEPH}

Clinical question: Should patients with distal CTEPH be considered for PEA to improve clinical outcomes?

Introduction: PEA surgery is a very effective treatment approach for CTEPH patients with surgically accessible, 'proximal' pulmonary artery obstruction. However, the potential benefits of PEA surgery are uncertain in CTEPH patients without proximal pulmonary arterial obstruction, but only have 'distal' or 'peripheral' disease.

Key evidence: Two studies have specifically addressed this clinical question by comparing the hemodynamic and clinical outcomes of PEA surgery in CTEPH patients with 'central' versus more 'distal' pulmonary arterial thromboembolic disease. 
TABLE 6

Effects of pulmonary endarterectomy (PEA) surgery in patients with surgically accessible chronic thromboembolic pulmonary hypertension*

\begin{tabular}{|c|c|c|c|c|c|c|c|}
\hline $\begin{array}{l}\text { Author } \\
\text { (reference), year }\end{array}$ & Centre & $\mathbf{n}$ & Follow-up & Time period & $\begin{array}{l}\text { Perioperative } \\
\text { mortality, \% }\end{array}$ & Survival, \% & Other significant outcomes \\
\hline $\begin{array}{l}\text { Mayer et al (106), } \\
1996\end{array}$ & $\begin{array}{l}\text { Mainz, } \\
\text { (Germany) }\end{array}$ & 65 & 27 months & 1989-1995 & 24 & & Improved echocardiographic parameters and hemodynamics \\
\hline $\begin{array}{l}\text { Hartz et al (107), } \\
1996\end{array}$ & $\begin{array}{l}\text { Chicago } \\
\text { (USA) }\end{array}$ & 34 & 4-6 weeks & 1983-1995 & 23 & & Improved mPAP, CO, PVR and WHO FC \\
\hline $\begin{array}{l}\text { Archibald et al } \\
\text { (103), } 1999\end{array}$ & $\begin{array}{l}\text { San Diego } \\
\text { (USA) }\end{array}$ & 514 & 3.3 years & 1970-1994 & 10 & $\begin{array}{l}75 \\
\text { at }>6 \text { years }\end{array}$ & $\begin{array}{l}\text { Improved mPAP, CO, PVR, WHO FC and SF-36 scores; } 62 \% \text { of } \\
\text { unemployed patients returned to work, } 83 \% \text { no hospitalizations }\end{array}$ \\
\hline $\begin{array}{l}\text { Dartevelle et al } \\
\text { (108), } 1999\end{array}$ & $\begin{array}{l}\text { Clamart } \\
\text { (France) }\end{array}$ & 68 & 3 months & $1996-1998$ & 13 & & $\begin{array}{l}\text { Increased } \mathrm{Cl}(2.1 \rightarrow 2.8) \text {; decreased } \mathrm{mPAP}(53 \rightarrow 30) \text { and TPR } \\
\quad(1174 \rightarrow 519) ; \text { improved WHO FC in } 82 \%(3.2 \rightarrow 1.3)\end{array}$ \\
\hline $\begin{array}{l}\text { D'Armini et al } \\
\text { (113), } 2000\end{array}$ & $\begin{array}{l}\text { Pavia } \\
\text { (Italy) }\end{array}$ & 33 & 2 years & 1996-1999 & 9 & $\begin{array}{l}91 ; 85 \\
\text { at } 1,2 \text { years }\end{array}$ & $\begin{array}{l}\text { Decreased mPAP }(50 \rightarrow 19) \text { and PVR }(1056 \rightarrow 182) \text { at } 3 \text { months; } \\
\text { increased CO }(3.3 \rightarrow 5.6) \text { at } 3 \text { months; improved WHO FC } \\
(90 \% \text { FC I or II) }\end{array}$ \\
\hline $\begin{array}{l}\text { Menzel et al } \\
(132), 2002\end{array}$ & $\begin{array}{l}\text { Mainz } \\
\text { (Germany) }\end{array}$ & 39 & 13 days & Not specified & & & $\begin{array}{l}\text { Improved TR and RV echo parameters; increased } \mathrm{Cl}(2.3 \rightarrow 3.4) \text {; } \\
\text { decreased PVR }(895 \rightarrow 292)\end{array}$ \\
\hline $\begin{array}{l}\text { Thistlethwaite } \\
\text { et al (104), } 2002\end{array}$ & $\begin{array}{l}\text { San Diego } \\
\text { (USA) }\end{array}$ & 157 & 3 months & 1998-2000 & 5 & 98 & $\begin{array}{l}\text { Increased } \mathrm{Cl}(+0.85) \text { at } 2-11 \text { days; decreased SPAP }(-36) \text { and PVR } \\
(-612) \text { at } 2-11 \text { days; improved WHO FC (I/II in } 88 \%) \text { at } 3 \text { months }\end{array}$ \\
\hline $\begin{array}{l}\text { Zoia et al (109), } \\
2002\end{array}$ & $\begin{array}{l}\text { Pavia } \\
\text { (Italy) }\end{array}$ & 38 & 2 years & 1994-1999 & 8 & $\begin{array}{l}96 \\
\text { at } 2 \text { years }\end{array}$ & $\begin{array}{l}\text { Increased CO }(3.4 \rightarrow 4.7) \text { and RVEF; decreased mPAP }(50 \rightarrow 21) \\
\text { and PVR }(1067 \rightarrow 303) ; 54 \% \text { had normal PVR. Progressive } \\
\text { improvement in treadmill exercise distance to } 2 \text { years; improved } \\
\text { gas exchange }\end{array}$ \\
\hline $\begin{array}{l}\text { Jamieson et al } \\
\text { (118), } 2003\end{array}$ & $\begin{array}{l}\text { San Diego } \\
\text { (USA) }\end{array}$ & 500 & & 1998-2002 & 4 & & $\begin{array}{l}\text { Increased CO }(3.8 \rightarrow 5.5) \text {; decreased mPAP }(46 \rightarrow 28) \text { and PVR } \\
\quad(893 \rightarrow 285)\end{array}$ \\
\hline $\begin{array}{l}\text { Oikonomou et al } \\
\text { (110), } 2004\end{array}$ & $\begin{array}{l}\text { Ottawa } \\
\text { (Canada) }\end{array}$ & 37 & & 1995-2001 & & & Decreased mPAP $(50 \rightarrow 30)$ and PVR $(934 \rightarrow 212)$ \\
\hline $\begin{array}{l}\text { Puis et al (119), } \\
2005\end{array}$ & $\begin{array}{l}\text { Leuven } \\
\text { (Belgium) }\end{array}$ & 40 & 1.8 years & 1999-2003 & 5 & 85 & $\begin{array}{l}\text { Increased } \mathrm{Cl}(1.5 \rightarrow 2.6) ; \text { decreased } \mathrm{mPAP}(50 \rightarrow 38) \text { and PVR } \\
\quad(1246 \rightarrow 515)\end{array}$ \\
\hline $\begin{array}{l}\text { Casaclang- } \\
\text { Verdoza et al } \\
\text { (111), } 2006\end{array}$ & $\begin{array}{l}\text { Rochester } \\
\text { (USA) }\end{array}$ & 32 & 1 year & 1997-2003 & & & $\begin{array}{l}\text { Improved echocardiographic RVSP }(93 \rightarrow 55) \text {, RV size (end-diastolic } \\
\text { and end-systolic areas) }\end{array}$ \\
\hline $\begin{array}{l}\text { Matsuda et al } \\
\text { (120), } 2006\end{array}$ & $\begin{array}{l}\text { Osaka } \\
\text { (Japan) }\end{array}$ & 102 & 5 years & 1995-2005 & 8 & $\begin{array}{l}91,84 \\
\text { at } 3,5 \text { years }\end{array}$ & $\begin{array}{l}\text { Increased } \mathrm{Cl}(2.0 \rightarrow 2.5) \text { at } 1 \text { year; decreased mPAP }(46 \rightarrow 21) \text { and } \\
\text { PVR }(1072 \rightarrow 346) \text { at } 1 \text { year; increased } 6 \text { MWD }(358 \rightarrow 489) \text { and peak } \\
\mathrm{VO}_{2}(13.8 \rightarrow 20) \text { at } 2 \text { years }\end{array}$ \\
\hline $\begin{array}{l}\text { Mellemkjaer et al } \\
\text { (112), } 2006\end{array}$ & Denmark & 50 & 5 years & 1994-2004 & 9 after 2000 & $\begin{array}{l}74 \\
\text { at } 5 \text { years }\end{array}$ & Improved WHO FC and RVSP in $90 \%$ of patients at 3 months \\
\hline $\begin{array}{l}\text { Ogino et al (121), } \\
2006\end{array}$ & $\begin{array}{l}\text { Osaka } \\
\text { (Japan) }\end{array}$ & 88 & 5 years & 1995-2004 & 8 & $\begin{array}{l}91,86 \\
\text { at } 3,5 \text { years }\end{array}$ & Improved PVR, 68\% weaned from long-term oxygen \\
\hline $\begin{array}{l}\text { Hardziyenka et al } \\
\text { (122), } 2007\end{array}$ & $\begin{array}{l}\text { Amsterdam } \\
\text { (Neth) }\end{array}$ & 61 & 3 months & 2002-2005 & 10 & & - \\
\hline $\begin{array}{l}\text { Rubens et al } \\
(100), 2007\end{array}$ & $\begin{array}{l}\text { Ottawa } \\
\text { (Canada) }\end{array}$ & 106 & 1 month & 1995-2006 & 9 & & $\begin{array}{l}\text { Increased } \mathrm{Cl}(2.0 \rightarrow 3.2) \text {; decreased } \mathrm{mPAP}(47 \rightarrow 28) \text { and PVR } \\
\quad(810 \rightarrow 215)\end{array}$ \\
\hline $\begin{array}{l}\text { Reesink et al } \\
(114), 2007\end{array}$ & $\begin{array}{l}\text { Amsterdam } \\
\text { (Neth) }\end{array}$ & 42 & 12 months & $2003-2005$ & 10 & & $\begin{array}{l}\text { Decreased mPAP }(44 \rightarrow 25) \text { and TPR }(878 \rightarrow 444) \text {; increased } 6 \text { MWD } \\
(69 \% \text { to } 87 \% \text { predicted })\end{array}$ \\
\hline $\begin{array}{l}\text { Suntharalingam } \\
\text { et al (45), } 2007\end{array}$ & $\begin{array}{l}\text { Cambridge } \\
\text { (UK) }\end{array}$ & 102 & 12 months & 2004-2006 & 14 & & Decreased mPAP $(48 \rightarrow 29)$ and TPR $(960 \rightarrow 480)$ \\
\hline $\begin{array}{l}\text { Mikus et al (115), } \\
2008\end{array}$ & $\begin{array}{l}\text { Bologna } \\
\text { (Italy) }\end{array}$ & 40 & 7 months & 2004-2007 & 7 & & $\begin{array}{l}\text { Decreased mPAP }(49 \rightarrow 26) \text { and PVR }(794 \rightarrow 286) \text {; increased 6MWD } \\
\quad(371 \rightarrow 483)\end{array}$ \\
\hline $\begin{array}{l}\text { Condliffe et al } \\
\text { (28), } 2008\end{array}$ & $\begin{array}{l}\text { Cambridge } \\
\text { (UK) }\end{array}$ & 236 & 3 years & 2001-2006 & $\begin{array}{l}16 ; 11 \text { after } \\
2003\end{array}$ & $\begin{array}{l}88,76 \\
\text { at } 1,3 \text { years }\end{array}$ & $\begin{array}{l}\text { Increased } \mathrm{Cl}(2.1 \rightarrow 2.6) \text {; decreased mPAP }(48 \rightarrow 27) \text { and TPR } \\
\quad(1028 \rightarrow 464) \text {; improved WHO FC I/II }(12 \% \rightarrow 88 \%) \text { at } 3 \text { months; } \\
\text { increased } 6 \text { MWD }(275 \rightarrow 380)\end{array}$ \\
\hline $\begin{array}{l}\text { Corsico et al } \\
\text { (123), } 2008\end{array}$ & $\begin{array}{l}\text { Pavia } \\
\text { (Italy) }\end{array}$ & 157 & $4-5$ years & 1994-2006 & 12 & $\begin{array}{l}84 \\
\text { at } 5 \text { years }\end{array}$ & $\begin{array}{l}\text { Increased CO }(3.3 \rightarrow 4.5) \text { at } 4 \text { years; decreased mPAP }(48 \rightarrow 23) \text { and } \\
\text { PVR }(1140 \rightarrow 339) \text { at } 4 \text { years; improved WHO FC }(\mathrm{I}: 0 \% \rightarrow 74 \%) \text {; } \\
\text { progressive improvement in treadmill exercise distance to } 4 \text { years }\end{array}$ \\
\hline $\begin{array}{r}\text { Yoshimi et al } \\
(124), 2008\end{array}$ & $\begin{array}{l}\text { Chiba } \\
\text { (Japan) }\end{array}$ & 31 & 3.9 years & 1999-2006 & 8 & 92 & $\begin{array}{l}\text { Decreased mPAP }(47 \rightarrow 21) \text { and PVR }(904 \rightarrow 259) \text {; improved SF-36 } \\
\text { scores and BDI versus medically treated group }\end{array}$ \\
\hline
\end{tabular}

*Study included if $n>30.6 M W D 6$ min walk test distance (m); BDI Borg dyspnea index; Cl Cardiac index (L/min/m2); CO Cardiac output (L/min); FC functional class; mPAP Mean pulmonary arterial pressure ( $\mathrm{mmHg}$ ); Neth The Netherlands; PVR Pulmonary vascular resistance (dyne•s/cm $)^{5}$; RV Right venticular; RVEF RV ejection fraction; RVSP RV systolic pressure ( $\mathrm{mmHg}$ ); SF-36 Short Form Health Survey; SPAP Systolic pulmonary arterial pressure (mmHg); TPR Total pulmonary resistance (dyne.s/ $\left.\mathrm{cm}^{5}\right)$; TR Tricuspid regurgitation; UK United Kingdom; $\mathrm{VO}_{2}$ Oxygen consumption ( $\mathrm{mL} / \mathrm{kg} / \mathrm{min}$ ) 
In a retrospective case series of 39 CTEPH subjects undergoing PEA surgery (140), PVR decreased in all subjects; however, 17 of 39 (44\%) experienced residual $\mathrm{PH}$ post-PEA. Logistic regression analysis identified the three following variables that best predicted residual $\mathrm{PH}$ : higher preoperative PVR, lower CT angiographic quantification of central disease and a greater extent of distal involvement. The single preoperative imaging feature that correlated $(r=0.39$ to $0.64: \mathrm{P}<0.02)$ with residual $\mathrm{PH}$ post-PEA (higher PVR) was the presence of small-vessel disease characterized on CT using inhomogeneous lung attenuation in the absence of large-vessel/segmental CTEPH. In another retrospective case series of 83 CTEPH patients assessed for PEA surgery (124), 40 patients underwent PEA, of which 14 had distal small-vessel CTEPH based on CT angiographic perfusion scoring. In these 14 subjects, PEA was associated with improved physical aspects of HRQoL and baseline dyspnea index. However, PEA in 'distal' versus 'central' CTEPH was associated with greater perioperative mortality $(21.4 \%$ versus $7.7 \% ; \mathrm{P}<0.05)$ and more severe residual $\mathrm{PH}$ post-PEA.

The recommendation informing this question is based on this evidence and the consensus of the expert panel.

Expert panel synthesis of clinical judgment: The panel graded the published evidence supporting improved clinical outcomes post-PEA surgery in patients with distal CTEPH disease as weak. The potential for significant direct health benefits of successful PEA surgery in an individual CTEPH patient was appreciated. However, the panel was concerned about the potential for limited overall impact of PEA surgery on morbidity and mortality in such CTEPH patients with distal disease. Moreover, serious adverse effects including significant risk of death or neurological complications, a high burden of adherence and inconclusive cost effectiveness of PEA surgery in such patients were considered.

As a result, there was consensus for a weak recommendation.

\section{Clinical question}

Should patients with distal CTEPH be considered for PEA to improve clinical outcomes?

\section{Recommendation 16}

- We suggest that patients with distal CTEPH be considered for PEA on an individual basis at a centre experienced with PEA (grade of recommendation: 2C).

The expert panel recognized that the definitions of surgically accessible versus 'distal' disease are currently controversial and, as a result, the published results pertaining to PEA surgery in patients with 'distal' disease may not be generalizable. It was strongly emphasized that the potential eligibility for PEA of such patients with 'distal' CTEPH be assessed by a team or centre experienced with PEA in consultation with a PEA surgeon.

Areas for future research: There is marked heterogeneity in the literature for characterization of 'proximal' versus 'distal' CTEPH. Future studies should help define objective criteria for a more consistent radiological classification of the anatomical extent of CTEPH including the total burden of pulmonary arterial thromboembolic disease and the contribution of distal versus proximal disease. Moreover, additional long-term data regarding the natural history of 'distal' pulmonary arterial thromboembolic disease would be clinically useful.

\section{Post-PEA long-term follow-up in a PH centre}

Clinical question: Should CTEPH patients post-PEA be followed up long-term in a PH expert centre to improve clinical outcomes?

Introduction: $\mathrm{PH}$ is a complex condition that requires rigorous diagnostic investigation and regular clinical monitoring and is, thus, usually managed in a small number of PH expert centres. Moreover, an estimated $10 \%$ of patients undergoing PEA do not improve (21), and many other CTEPH patients experience residual PH post-PEA surgery. However, it remains unclear whether CTEPH patients postPEA surgery benefit from long-term follow-up in such PH expert centres.

Key evidence: No studies that addressed this clinical question were identified. Thus, the recommendation informing this question is based on the consensus of the expert panel.

Expert panel synthesis of clinical judgment: The panel recognized the lack of any published evidence supporting the benefit of long-term follow-up of CTEPH patients in a PH centre post-PEA surgery. Other factors including a direct health benefit in the individual CTEPH patient, and potentially significant overall impact on morbidity and mortality in post-PEA CTEPH patients were considered. Some burden of adherence in attending specific PH centres was recognized (particularly for patients residing in geographically remote areas of Canada), but a lack of adverse effects of follow-up in PH centres and unclear cost effectiveness were noted.

As a result, there was consensus for a weak recommendation.

\section{Clinical question \\ Should CTEPH patients post-PEA be followed-up long- term in a $\mathrm{PH}$ expert centre to improve clinical outcomes? \\ Recommendation 17 \\ - We suggest that post-PEA CTEPH patients may benefit from long-term follow-up in a $\mathrm{PH}$ expert centre (grade of recommendation: $2 \mathrm{C}$ ).}

Areas for future research: The panel identified the potential advantage of post PEA follow-up in PH centres in facilitating future Canadian CTEPH epidemiological research. The possibility of telehealth as a means to provide PH centre expertise to remote Canadian communities was raised as another area for future research.

\section{PH-specific medical therapy in CTEPH patients with residual $\mathrm{PH}$ post-PEA}

Clinical question: Should patients with symptomatic residual PH following PEA surgery be treated with PH-specific medications (ERAs, PDE-5is or prostanoids) to improve clinical outcomes? 
Introduction: In many CTEPH patients who undergo PEA surgery, significant clinical and hemodynamic benefit is observed. However, some patients will experience clinically important residual or persistent $\mathrm{PH}$ after PEA, presumably due to components of persistent pulmonary microvascular arteriopathy and/or residual thrombotic material. These patients may experience progressive clinical symptoms of dyspnea, fatigue and edema, in additon to developing RV failure, similar to patients with other types of $\mathrm{PH}$. The degree of residual PH post-PEA significantly influences the risk of death following PEA. A large case series of 500 patients with a postoperative PVR of greater than 500 dyne.s $/ \mathrm{cm}^{5}$ undergoing PEA conducted between 1998 and 2002 (118), reported a mortality rate of 30.6\%, whereas a mortality rate of only $0.9 \%$ was found in patients with a postoperative PVR of less than 500 dyne.s $/ \mathrm{cm}^{5}$. In patients with residual PH following PEA surgery, $\mathrm{PH}$-specific medical therapy may be beneficial to improve clinical outcomes, similar to the benefits documented in patients with PAH.

Key evidence: No studies have specifically addressed this clinical question. Patients with residual PH post-PEA have been included in a few studies assessing the benefits of various PAH-therapies (PDE-5i, ERA and prostanoid) in CTEPH patients (Table 7). However, in most of these studies, the study population was heterogeneous and the specific number of patients with residual PH post-PEA was either not stated or limited to only a few subjects. Moreover, specific data regarding PAH therapies in these patients were not reported. A single placebo-controlled RCT of the ERA bosentan in 157 CTEPH patients (141) included patients with residual PH post-PEA. Bosentan therapy for 16 weeks in 22 post-PEA patients was associated with $34 \%$ reduction in PVR and a nonsignificant decline in 6MWD. There were no other data on secondary end points in patients with residual $\mathrm{PH}$ post-PEA.

Thus, the recommendation informing this question is based on weak evidence and the consensus of the expert panel.

Expert panel synthesis of clinical judgment: The low-grade evidence in support of the benefits of PH-specific medical therapy was recognized. Several panel members reported success with the use of oral medical therapies including the ERA bosentan and the PDE-5i sildenafil in CTEPH patients with residual $\mathrm{PH}$ post-PEA surgery; this clinical experience was also considered. However, the panel discussed a low likelihood of direct benefit to the patient, and only limited potential impact of all PAH therapies on morbidity and mortality given the low-grade evidence that only indirectly addresses the clinical question. The low burden of adherence and overall minimal adverse effects of oral $\mathrm{PH}$-specific therapy were recognized, as well as the lack of any costeffectiveness data. There was a lack of clinical experience with PAH therapy using prostanoids. Moreover, specifically for parenteral prostanoids (eg, intravenous epoprostenol and subcutaneous/intravenous treprostinil), a higher burden of adherence and serious adverse effects were considered, as well as a consensus that such therapies were not currently cost effective. As a result, there was consensus for weak recommendations.

\section{Clinical question}

Should patients with symptomatic residual PH post-PEA be treated with $\mathrm{PH}$-specific medications (ERAs, PDE-5is or prostanoids) to improve clinical outcomes?

Recommendations 18, 19 and 20

- We suggest ERA monotherapy in patients with symptomatic, residual PH post-PEA (grade of recommendation: 2C). This recommendation currently applies only to the ERA bosentan because there are no data available to assess the potential benefits of other ERAs (eg, sitaxsentan and ambrisentan) in CTEPH patients.

- We suggest PDE-5i monotherapy in patients with symptomatic, residual PH post-PEA (grade of recommendation: 2C). This recommendation currently applies only to the PDE-5i sildenafil because there are no data available to assess the potential benefits of other PDE-5is (eg, tadalafil and vardenafil) in CTEPH patients.

- We suggest that parenteral prostanoid monotherapy could be considered in specific patients with symptomatic, residual $\mathrm{PH}$ post-PEA in whom oral $\mathrm{PH}$-specific therapy has not been effective or was not tolerated (grade of recommendation: 2C). This recommendation currently applies only to the parenteral prostanoids (eg, intravenous epoprostenol and subcutaneous/intravenous treprostinil) because there are no data available to assess the potential benefits of oral (eg, beraprost) or inhaled prostanoids (eg, iloprost and treprostinil).

The panel did address the question of combination therapy (ie, combinations of ERA, PDE-5i and/or prostanoids) in residual $\mathrm{PH}$ post-PEA separately (see recommendation 24).

\section{Management of CTEPH patients not eligible for PEA 1. Introduction}

PEA surgery remains the approach of choice for patients with surgically accessible large vessel (main, lobar and segmental pulmonary artery) CTEPH; however, up to one-half of CTEPH patients are ineligible for PEA because of predominantly distal or surgically inaccessible disease, extremely elevated PVR, or underlying significant comorbid illnesses such as LV or pulmonary parenchymal disease. In addition, a small number of patients who are offered PEA surgery decline the procedure.

There is considerable rationale to suggest that $\mathrm{PH}$-specific medical therapies may have clinical benefits in CTEPH patients. Although the distinction between PAH and CTEPH is often emphasized, there are many similarities between the conditions including clinical presentation with progressive $\mathrm{PH}$ and RV failure, and pathophysiological overlap. PAH and CTEPH may represent extremes of a disease continuum based on several lines of evidence such as the observation that a microvascular arteriopathy with plexiform lesions can exist in the obstructed and unobstructed vascular bed of CTEPH patients (142).

The role of several $\mathrm{PH}$-specific medical therapies in these groups of CTEPH patients has been explored in many small, predominantly uncontrolled studies. Early indications are that medical therapies may have promise in all of these subgroups of CTEPH patients; however, the precise role of 


\section{TABLE 7}

Effects of pulmonary hypertension (PH)-specific monotherapy in chronic thromboembolic PH (CTEPH) patients experiencing symptomatic residual $\mathrm{PH}$ following pulmonary endarterectomy (PEA)

\begin{tabular}{|c|c|c|c|c|c|}
\hline $\begin{array}{l}\text { Author } \\
\text { (reference), year }\end{array}$ & Design & Patients & Intervention & Comparator & Significant outcomes \\
\hline $\begin{array}{l}\text { Machherndl et al } \\
(167), 2001\end{array}$ & Case series & $\begin{array}{l}n=2, \text { subgroup in } \\
\text { study of } P H(n=12)\end{array}$ & $\begin{array}{l}\text { inh iloprost } \\
100-150 \mu \mathrm{g} / \text { day } \\
\times 4-18 \text { months }\end{array}$ & None & $\begin{array}{l}\text { *Decreased 6MWD }(-189 \mathrm{~m}) \text {; increased PVR (+27\%), } \\
\text { decreased } \mathrm{Cl}(-10 \%) \text {; no change in WHO FC }\end{array}$ \\
\hline $\begin{array}{l}\text { Hoeper et al } \\
(150), 2005\end{array}$ & Case series & $\begin{array}{l}\mathrm{n}=4 \text {, subgroup in } \\
\text { study of CTEPH } \\
(\mathrm{n}=19)\end{array}$ & $\begin{array}{l}\text { Bosentan } 125 \mathrm{mg} \text { bid } \\
\times 3 \text { months }\end{array}$ & None & $\begin{array}{l}\text { *Entire group: improved 6MWD (+73 m), decreased PVR } \\
(-33 \%) \text {, increased } \mathrm{CO}(+18 \%) \text {, decreased NT-pro-BNP } \\
\text { level; no change in } \mathrm{VO}_{2} \mathrm{max}, \mathrm{WHO} F \mathrm{FC}\end{array}$ \\
\hline $\begin{array}{l}\text { Hughes et al } \\
(147), 2005\end{array}$ & Case series & $\begin{array}{l}\mathrm{n}=5 \text {, subgroup in } \\
\text { study of CTEPH } \\
(\mathrm{n}=20)\end{array}$ & $\begin{array}{l}\text { Bosentan } 125 \mathrm{mg} \text { bid } \\
\times 3 \text { months }\end{array}$ & None & $\begin{array}{l}\text { *Improved 6MWD (+45 m) } \\
\text { Decreased PVR (-28\%), increased CO (+21\%) }\end{array}$ \\
\hline $\begin{array}{l}\text { Lang et al (163), } \\
\qquad 2006\end{array}$ & Case series & $\begin{array}{l}n=5, \text { subgroup in } \\
\text { study of } C T E P H \\
(n=23) \text { among } P H \\
(n=122)\end{array}$ & $\begin{array}{l}\text { sc treprostinil } 16 \text { to } \\
84 \mathrm{ng} / \mathrm{kg} / \mathrm{min} \\
\times 3-57 \text { months }\end{array}$ & None & $\begin{array}{l}\text { *Entire group: improved } 6 \mathrm{MWD}(+65 \mathrm{~m}) \text { and WHO FC }(-0.7) \text {; } \\
\text { survival } 89 \%, 71 \%, 66 \% \text { at } 1,3 \text { and } 4 \text { years, respectively; } \\
10 \% \text { discontinued }\end{array}$ \\
\hline $\begin{array}{l}\text { Hughes et al } \\
(151), 2006\end{array}$ & Case series & $\begin{array}{l}n=8, \text { subgroup in } \\
\text { study of CTEPH } \\
(n=47)\end{array}$ & $\begin{array}{l}\text { Bosentan } 125 \mathrm{mg} \text { bid } \\
\times 12 \text { months }\end{array}$ & None & $\begin{array}{l}\text { Improved 6MWD (+52 m) and WHO FC (24\%); } \\
\text { decreased TPR }(-12 \%) \text {, increased } \mathrm{Cl}(+10 \%) \\
\text { survival } 96 \%, 86 \% \text { at } 1,2 \text { years, respectively }\end{array}$ \\
\hline $\begin{array}{l}\text { Seyfarth et al } \\
(152), 2007\end{array}$ & Case series & $\begin{array}{l}\mathrm{n}=2 \text {, subgroup in } \\
\text { study of CTEPH } \\
(\mathrm{n}=12)\end{array}$ & $\begin{array}{l}\text { Bosentan } 125 \mathrm{mg} \text { bid } \\
\times \leq 24 \text { months }\end{array}$ & None & $\begin{array}{l}\text { *Improved 6MWD and Tei index; improved WHO FC from III } \\
\text { to II }(n=6) ; \text { no deaths, no discontinuations at } 24 \text { months }\end{array}$ \\
\hline $\begin{array}{l}\text { Suntharalingam } \\
\text { et al (144), } \\
2008\end{array}$ & $\begin{array}{l}\text { PC RCT; } \\
\text { LT open-label, } \\
\text { cross-over }\end{array}$ & $\begin{array}{l}\mathrm{n}=9 \text {, subgroup in } \\
\text { study of CTEPH } \\
(\mathrm{n}=19)\end{array}$ & $\begin{array}{l}\text { Sildenafil 40mg tid } \\
\times 3-12 \text { months }\end{array}$ & $\begin{array}{l}\text { RCT: placebo } \\
\text { LT, open-label: } \\
\text { none }\end{array}$ & $\begin{array}{l}\text { *RCT: decreased PVR }(-24 \%) \text {, improved WHO FC; } \\
\text { no change in QOL, 6MWD, Cl or NT-pro-BNP level. } \\
\text { Open-label: improved 6MWD (+36 m), decreased PVR } \\
(-21 \%) \text { and CI (-9\%); decreased CAMPHOR symptom/ } \\
\text { activity and NT-pro-BNP }(-189)\end{array}$ \\
\hline $\begin{array}{l}\text { Jais et al (141), } \\
2008\end{array}$ & $\mathrm{DB}, \mathrm{PC}, \mathrm{RCT}$ & $\begin{array}{l}\mathrm{n}=19, \text { subgroup in } \\
\text { study of CTEPH } \\
(\mathrm{n}=77)\end{array}$ & $\begin{array}{l}\text { Bosentan } 125 \mathrm{mg} \text { bid } \\
\times 16 \text { weeks }\end{array}$ & $\mathrm{n}=22$, placebo & $\begin{array}{l}\text { *Decreased PVR (-24\%); decreased Borg dyspnea index } \\
\text { (-0.6 units); no change in } \mathrm{CI}, 6 \mathrm{MWD}, \text { WHO FC or TCW; } \\
\text { decreased NT-pro-BNP }(-622)\end{array}$ \\
\hline
\end{tabular}

medical therapy in each situation remains unclear. Moreover, studies to date have not demonstrated effectiveness in $\mathrm{CTEPH}$ as convincingly as for PAH patients in whom $\mathrm{PH}$-specific medications are associated with better HRQoL including less dyspnea, better exercise capacity and longer survival (143).

Other CTEPH patients that may be considered for treatment with $\mathrm{PH}$-specific medications include those ineligible for PEA but offered and awaiting lung transplantation. $\mathrm{PH}$-specific therapies have been used as a 'bridge' to transplantation. It must be emphasized that the currently available evidence does not justify the pursuit of medical therapy in these patients if it adversely delays timely access to lung transplantation.

\section{PH-specific medical therapy in patients with inoperable CTEPH}

Clinical question: Should patients with inoperable CTEPH be treated with PH-specific medications (ERAs, PDE-5is, prostanoids) to improve clinical outcomes?

Introduction: Many patients with CTEPH are not eligible for PEA surgery. This may be due to the absence of significant disease in the proximal (main, lobar or segmental) pulmonary arteries and/or the presence of underlying comorbid illnesses that preclude major surgery. These patients typically experience progressive clinical symptoms of $\mathrm{PH}$ and RV failure including dyspnea, edema, chest pain and syncope. In these CTEPH patients, $\mathrm{PH}$-specific medical therapy may be beneficial to improve clinical outcomes, similar to the benefits documented in patients with PAH. Moreover, PH-specific medical therapy could also stabilize a CTEPH patient, serving as a 'bridge' to transplantation.

Key evidence: Many studies have addressed this clinical question, although randomized, placebo-controlled designs were used in only four: an RCT of bosentan that included both inoperable CTEPH and post-PEA patients (141); two crossover studies of sildenafil in 11 patients $(144,145)$; and a subgroup of 57 patients in an RCT of inhaled iloprost study (146) (Table 8). The others were mostly small, uncontrolled case series consisting of two to 104 patients, for a total experience of approximately 385 patients with inoperable CTEPH who were exposed to prostanoids, ERAs and PDE-5is.

The ERA bosentan was associated with improvements in 6MWD and PVR in four case series of 15 to 19 patients each over three to six months (147-150). Moreover, the improvements appeared sustained at one year in a series of 39 patients (151) and 
at two years in a 10-patient series (152). An overall survival rate of $96 \%$ at one year was better than in historical studies of patients with similar hemodynamic severity of CTEPH (151). However, the subsequent multicentre, placebo-controlled RCT of bosentan (141) failed to demonstrate a significant improvement in 6MWD in a subgroup of 55 inoperable CTEPH patients despite a $19.5 \%$ reduction in PVR at four months. The Borg dyspnea index scores and NTpro-BNP levels did improve in this study; however, HRQoL scores, WHO functional class, and time to clinical worsening were not different from placebo-treated patients.

The PDE-5i sildenafil has also been associated with improved short- and long-term outcomes in uncontrolled studies $(145,153$ 156), the largest of which (157) included 104 inoperable patients. In this study, a $51 \mathrm{~m}$ improvement in 6MWD and a $21 \%$ reduction in PVR were observed at one year. A small crossover randomized study including 10 inoperable and nine post-PEA (65) patients showed a similar reduction in PVR at three months that appeared sustained in an openlabel extension after 12 months. This study failed to show improvements in exercise tolerance during the three-month placebo-controlled portion, but did show improvements in WHO functional class at three months, NT-proBNP levels and Cambridge PH Outcome Review (CAMPHOR) $\mathrm{PH}$-specific HRQoL scores at 12 months.

The effects of prostanoids including epoprostenol (158-161), treprostinil $(162,163)$ beraprost $(164-166)$ and iloprost $(146,161,167,168)$ have been assessed in inoperable CTEPH patients, but in an uncontrolled fashion in all except one study. A retrospective subgroup analysis of 57 inoperable CTEPH patients included in the inhaled iloprost RCT of $146 \mathrm{PH}$ patients (146) failed to demonstrate any benefits of this agent in inoperable CTEPH. However, the experience with epoprostenol and treprostinil has been more positive, with improvements of $46 \mathrm{~m}$ to $105 \mathrm{~m}$ in 6MWD noted at 19 to 20 months, and a suggestion of increased long-term survival relative to historical controls in small case series $(159,162)$.

The recommendation informing this question is based on the above evidence and the consensus of the expert panel.

Expert panel synthesis of clinical judgment: The panel graded the evidence supporting the benefits of $\mathrm{PH}$-specific medical therapy in CTEPH patients as moderate (ERAs, PDE-5i) or low (prostanoids). Several panel members reported success with the use of oral medical therapies including the ERA bosentan and the PDE-5i sildenafil in patients with inoperable CTEPH, or with residual $\mathrm{PH}$ post-PEA; this clinical experience was also considered. However, the panel discussed the low likelihood of direct benefit to the individual patient and only limited potential overall impact of $\mathrm{PAH}$ therapies on morbidity and mortality in CTEPH patients given the low-grade evidence that only indirectly addresses the clinical question. The low burden of adherence and overall minimal adverse effects of oral $\mathrm{PH}$-specific therapy were recognized in addtion to the lack of any cost-effectiveness data. There was a lack of clinical experience with prostanoid PAH therapy. Moreover, specifically for parenteral prostanoids (eg, intravenous epoprostenol and subcutaneous/intravenous treprostinil), a higher burden of adherence and serious adverse effects were considered, and a consensus that such therapies were currently not cost effective.
As a result, there was consensus for weak recommendations.

Clinical question

Should patients with inoperable CTEPH be treated with $\mathrm{PH}$-specific medications (ERAs, PDE-5is or prostanoids) to improve clinical outcomes?

Recommendations 21, 22 and 23

- We suggest ERA monotherapy in patients with symptomatic, inoperable CTEPH to improve symptoms and exercise capacity, short-term hemodynamics and, possibly, survival (grade of recommendation: 2C). This recommendation currently applies only to the ERA bosentan becauses there are no data available to assess the potential benefits of other ERAs (eg, sitaxsentan and ambrisentan).

- We suggest PDE-5i monotherapy for patients with symptomatic, inoperable CTEPH to improve short-term hemodynamics and WHO functional class and, possibly, long-term exercise capacity and HRQoL (grade of recommendation: $2 \mathrm{C}$ ). This recommendation currently applies only to the PDE-5i sildenafil becauses there are no data available to assess the potential benefits of other PDE-5is (eg, tadalafil and vardenafil).

- We suggest monotherapy with parenteral prostanoids (eg, intravenous epoprostenol and subcutaneous/ intravenous treprostinil) could be considered in patients with symptomatic, inoperable CTEPH (grade of recommendation: $2 \mathrm{C}$ ).

As a result, there was consensus for weak recommendations.

The panel noted that the benefits following sildenafil therapy were all achieved at doses greater than the currently approved PAH dose in Canada of $20 \mathrm{mg}$ three times daily, and that there were no data supporting efficacy of this dose in CTEPH. There is insufficient evidence to currently recommend other prostanoids (eg, inhaled iloprost or treprostinil, or oral beraprost), but they may be of benefit in individual patients. The panel notes that inhaled or oral prostanoids are presently not approved or available in Canada.

Although PH-specific medical therapy may not necessarily improve short- or long-term clinical outcomes in all CTEPH patients, this approach may be of benefit in stabilizing individual CTEPH patients over the short-term until definitive treatment such as lung transplantation.

\section{Combination PH-specific medical therapy in CTEPH patients}

Clinical question: Should symptomatic CTEPH patients who are inoperable or experience residual $\mathrm{PH}$ post-PEA surgery receive $\mathrm{PH}$-specific combination therapy to improve clinical outcomes?

Introduction: The clinical benefits of monotherapy with individual $\mathrm{PH}$-specific medications have been demonstrated in certain subgroups of PAH patients. However, none of these agents cure $\mathrm{PH}$, and many patients still have severe disease, remain very limited functionally, and have significant morbidity and high mortality despite monotherapy. Combinations of two or more disease-specific medications are increasingly being studied in additon to being used clinically in patients with PAH. Combination therapy is also potentially beneficial in CTEPH patients. 
TABLE 8

Effects of pulmonary hypertension (PH)-specific monotherapy in inoperable chronic thromboembolic $\mathrm{PH}(\mathrm{CTEPH})$ patients

\begin{tabular}{|c|c|c|c|c|c|}
\hline $\begin{array}{l}\text { Author } \\
\text { (reference), year }\end{array}$ & Design & Patients & Intervention & Comparator & Significant outcomes \\
\hline $\begin{array}{l}\text { McLaughlin et al } \\
(160), 1999\end{array}$ & Case series & $\begin{array}{l}n=3, \text { subgroup of CTEPH in } \\
\text { study of } \mathrm{PH}(\mathrm{n}=33)\end{array}$ & $\begin{array}{l}\text { iv epoprostenol } \\
\text { for } 12 \text { months }\end{array}$ & None & ${ }^{\star}$ Entire group: decreased PVR (-50\%) \\
\hline $\begin{array}{l}\text { Machherndl et al } \\
\text { (167), } 2001\end{array}$ & Case series & $\begin{array}{l}\mathrm{n}=2 \text {, subgroup in study of } \\
\mathrm{PH}(\mathrm{n}=12)\end{array}$ & $\begin{array}{l}\text { inh iloprost } \\
100-150 \mu \mathrm{g} / \mathrm{day} \\
\times 4-18 \text { months }\end{array}$ & None & $\begin{array}{l}\text { Decreased 6MWD (-189 m); increased PVR (+27\%), } \\
\text { decreased CI (-10\%); no change in WHO FC }\end{array}$ \\
\hline $\begin{array}{l}\text { Olschewski et al } \\
\text { (146), } 2002\end{array}$ & $\mathrm{DB}, \mathrm{PC}, \mathrm{RCT}$ & $\begin{array}{l}n=33, \text { subgroup of CTEPH } \\
\text { in study of non-IPAH } \\
(n=50) \text { and IPAH }(n=51)\end{array}$ & $\begin{array}{l}\text { inh iloprost } 30 \mu \mathrm{g} / \mathrm{day} \text {, } \\
\text { divided } 6-9 \text { doses } \\
\times 12 \text { weeks }\end{array}$ & $\mathrm{n}=24$, placebo & $\begin{array}{l}\text { *Entire group: OR } 3.97 \text { for improved 6MWD }>10 \% \text { and } \\
\text { improved WHO FC; "no heterogeneity" between types } \\
\text { of PH; non-IPAH group (including CTEPH): overall, no } \\
\text { change in 6MWD or WHO FC }\end{array}$ \\
\hline $\begin{array}{l}\text { Bharani et al } \\
(145), 2003\end{array}$ & $\begin{array}{l}\text { DB, PC, } \\
\text { crossover } \\
\text { RCT }\end{array}$ & $\begin{array}{l}n=1 \text {, subgroup in study of } \\
\text { CTEPH }(n=10)\end{array}$ & $\begin{array}{l}\text { Sildenafil } 25 \mathrm{mg} \text { tid } \\
\times 2 \text { weeks }\end{array}$ & Placebo & Decreased echo-RVSP; improved 6MWD, BDI score \\
\hline $\begin{array}{l}\text { Ghofrani et al } \\
\text { (156), } 2003\end{array}$ & Case series & $\mathrm{n}=12$ & $\begin{array}{l}\text { Sildenafil } 50 \mathrm{mg} \text { tid } \\
\times 6.5 \text { months }\end{array}$ & None & $\begin{array}{l}\text { Improved 6MWD (+54 m); decreased PVRI (-30\%), } \\
\text { increased } \mathrm{Cl}(+20 \%)\end{array}$ \\
\hline $\begin{array}{l}\text { Ono et al (164), } \\
2003\end{array}$ & $\begin{array}{l}\text { Retrospective } \\
\text { cohort }\end{array}$ & $n=20$ & $\begin{array}{l}\text { Beraprost } 132 \mu \mathrm{g} / \text { day, } \\
\text { divided tid-qid } \\
\times 44-58 \text { months }\end{array}$ & $\begin{array}{l}\mathrm{n}=23 \\
\text { conventional } \\
\text { therapy }\end{array}$ & $\begin{array}{l}\text { Improved WHO FC in } 50 \% \text {; decreased TPR }(-16 \%) \\
\text { Survival } 100 \%, 85 \%, 76 \% \text { versus } 87 \%, 60 \%, 46 \% \text { at } \\
\text { 1,3,5 years in beraprost versus comparator }\end{array}$ \\
\hline $\begin{array}{l}\text { Ono et al (165), } \\
2003\end{array}$ & Case series & $\begin{array}{l}n=8 \text {, subgroup in study of } \\
n=18\end{array}$ & $\begin{array}{l}\text { Beraprost } 143 \mu \mathrm{g} / \mathrm{day} \\
\times 2.3 \text { months }\end{array}$ & None & $\begin{array}{l}\text { *Entire group: Improved WHO FC in } 56 \% \text {, decreased } \\
\text { PVR }(-17 \%) \text {, decreased BNP levels }\end{array}$ \\
\hline $\begin{array}{l}\text { Scelsi et al (158), } \\
2004\end{array}$ & Case series & $\begin{array}{l}n=11, \text { subgroup in study of } \\
\mathrm{PH}(\mathrm{n}=27)\end{array}$ & $\begin{array}{l}\text { iv epoprostenol } \\
\quad \times 12 \text { months }\end{array}$ & None & Improved 6MWD; improved LVED on echo \\
\hline $\begin{array}{l}\text { Hoeper et al } \\
\text { (150), } 2005\end{array}$ & Case series & $\begin{array}{l}n=15 \text {, subgroup in study of } \\
\text { CTEPH }(n=19)\end{array}$ & $\begin{array}{l}\text { Bosentan } 125 \mathrm{mg} \text { bid } \\
\times 3 \text { months }\end{array}$ & None & $\begin{array}{l}\text { Entire group: Improved 6MWD (+73 m), decreased PVR } \\
(-33 \%) \text {, increased } \mathrm{CO}(+18 \%) \text {, decreased NT-pro-BNP } \\
\text { levels; no change in } \mathrm{VO}_{2 \mathrm{max}}, \mathrm{WHO} \mathrm{FC}\end{array}$ \\
\hline Bonderman et al & Case series & $\mathrm{n}=14$; inoperable, severe & Bosentan $125 \mathrm{mg}$ bid & None & Improved 6MWD (+92 m); decreased NT-BNP levels \\
\hline
\end{tabular}

(148), 2005

comorbidity, or refused PEA

Sharma et al

(178), 2005

Sheth et al (155), Case-series $n=6$ 2005

Hughes et al

(147), 2005

Hughes et al

(151), 2006

Andreassen et a

(179), 2006

Kourouklis et al

(180), 2006

Lang et al (163), Case series 2006

Case series

$\mathrm{n}=15$, subgroup in study of CTEPH $(n=20)$

Case series

$\mathrm{n}=39$, subgroup in study of CTEPH $(n=47)$

$\times 6$ months

Bosentan $125 \mathrm{mg}$ bid None

Sildenafil $50 \mathrm{mg}$ tid None

$\times 6$ weeks

Bosentan $125 \mathrm{mg}$ bid None $\times 3$ months

Bosentan $125 \mathrm{mg}$ bid None $\times 12$ months

Case-series

$n=19^{\dagger}$, subgroup of CTEPH in study of $\mathrm{PH}(\mathrm{n}=61)$

Various: inhaled or iv prostanoids, oral ERAs or sildenafil

$n=10$, age/sex-

Bosentan $125 \mathrm{mg}$ bid None

$\times 9$ months

$\mathrm{n}=18$, subgroup in study of sc treprostinil None

CTEPH $(n=23)$ among $\mathrm{PH} \quad 16-84 \mathrm{ng} / \mathrm{kg} / \mathrm{min}$ $(n=122)$

Vizza et al (166), Case control $n=8$

2006

Cabrol et al (159), Case series $n=27$ 2007

Madden et al

Case series

(153), 2007

Reichenberger et al (157), 2007

Case series $n=104$

n=6; "unsuitable for PEA", subgroup of CTEPH in larger study of $\mathrm{PH}(\mathrm{n}=16)$

Seyfarth et al (152), 2007
Case series $n=10$, subgroup in study of CTEPH $(n=12)$ $\times$ 3-57 months

Beraprost $275 \mu \mathrm{g} /$ day $\mathrm{n}=8$, IPAH

$\times 6$ months

iv epoprostenol

$\times$ 3-20 months

Sildenafil $50 \mathrm{mg}$ tid None

$\times 2-22$ months

Sildenafil $50 \mathrm{mg}$ tid None × 3-12 months

Bosentan $125 \mathrm{mg}$ bid None

$x \leq 24$ months 6MWD matched for WHO FC in both groups

Improved 6MWD (+66 m) and WHO FC (48\%); decreased TPR (-22\%), increased $\mathrm{Cl}(+21 \%)$; survival $73 \%, 59 \%, 41 \%$ at 1,2 and 3 years, respectively

*Entire group: improved 6MWD, Cl, PVR at 2 months and LT

Improved 6MWD $(+51,+56 \mathrm{~m})$ at 3,12 months; reduced PVR (-12\%) and Cl (-14\%); no change in WHO FC

*Improved 6MWD and Tei index; improved WHO FC from III to II $(n=6)$; no deaths, no discontinuations at 24 months 
TABLE 8 - CONTINUED

Effects of pulmonary hypertension (PH)-specific monotherapy in inoperable chronic thromboembolic PH (CTEPH) patients

\begin{tabular}{|c|c|c|c|c|c|}
\hline $\begin{array}{l}\text { Author } \\
\text { (reference), year }\end{array}$ & Design & Patients & Intervention & Comparator & Significant outcomes \\
\hline $\begin{array}{l}\text { Ulrich et al (149), } \\
2007\end{array}$ & Case series & $\begin{array}{l}\mathrm{n}=15 \text {; inoperable or refused } \\
\text { PEA }\end{array}$ & $\begin{array}{l}\text { Bosentan } 125 \mathrm{mg} \text { bid } \\
\times 6 \text { months }\end{array}$ & None & $\begin{array}{l}\text { Improved 6MWD and QOL; improved WHO FC }(n=4) ; \\
\text { decreased mPAP and PVR, increased } \mathrm{Cl}\end{array}$ \\
\hline $\begin{array}{l}\text { Skoro-Sajer et al } \\
\text { (162), } 2007\end{array}$ & Case control & $\begin{array}{l}\mathrm{n}=17 \text {, subgroup in study of } \\
\text { CTEPH }(\mathrm{n}=25)\end{array}$ & $\begin{array}{l}\text { sc treprostinil } \\
21 \mathrm{ng} / \mathrm{kg} / \mathrm{min} \\
\times 19 \text { months }\end{array}$ & $\begin{array}{l}\mathrm{n}=31 \text { matched, } \\
\text { historical } \\
\text { cohort }\end{array}$ & $\begin{array}{l}\text { Improved 6MWD (+59 m, }+105 \mathrm{~m}) \text { at } 6,12 \text { months; } \\
\text { decreased PVR (-13\%) and } \mathrm{Cl}(-14 \%) \text {; survival } 80 \% \text {, } \\
80 \%, 53 \% \text { versus } 67 \%, 37 \%, 16 \% \text { at } 1,3 \text { and } 5 \text { years, } \\
\text { repectively, in treprostinil versus comparator }\end{array}$ \\
\hline $\begin{array}{l}\text { Rossi et al (154), } \\
2008\end{array}$ & Case series & $n=9$ & $\begin{array}{l}\text { Sildenafil } 25-100 \mathrm{mg} \\
\text { tid } \times 6 \text { months }\end{array}$ & None & $\begin{array}{l}\text { Improved 6MWD, mPAP, PVR, Cl and RAP; improved } \\
\text { WHO FC }\end{array}$ \\
\hline $\begin{array}{l}\text { Suntharalingam et } \\
\text { al (144), } 2008\end{array}$ & $\begin{array}{l}\text { PC RCT; } \\
\text { LT open } \\
\text { label, } \\
\text { crossover }\end{array}$ & $\begin{array}{l}n=10, \text { subgroup in study of } \\
\text { CTEPH }(n=19)\end{array}$ & $\begin{array}{l}\text { Sildenafil } 40 \mathrm{mg} \text { tid } \\
\times 3-12 \text { months }\end{array}$ & $\begin{array}{l}\text { RCT: placebo } \\
\text { LT open } \\
\text { label: none }\end{array}$ & $\begin{array}{l}\text { RCT: decreased PVR (-24\%), Improved WHO FC; } \\
\text { no change in QOL, 6MWD, CI or NT-pro-BNP levels } \\
\text { Open label: improved 6MWD (+36 m), decreased PVR } \\
(-21 \%) \text { and CI (-9\%); decreased CAMPHOR symptom/ } \\
\text { activity and NT-pro-BNP levels (-189) }\end{array}$ \\
\hline $\begin{array}{l}\text { Jaïs et al (141), } \\
2008\end{array}$ & $\mathrm{DB}, \mathrm{PC}, \mathrm{RCT}$ & $\begin{array}{l}\mathrm{n}=47 \text {, subgroup in study of } \\
\text { CTEPH }(\mathrm{n}=77)\end{array}$ & $\begin{array}{l}\text { Bosentan } 125 \mathrm{mg} \text { bid } \\
\times 16 \text { weeks }\end{array}$ & $\mathrm{n}=49$, placebo & $\begin{array}{l}\text { Decreased PVR (-24\%); decreased BDI (-0.6 units); } \\
\text { no change in CI, 6MWD, WHO FC, TCW; decreased } \\
\text { NT-pro-BNP levels (-622) }\end{array}$ \\
\hline
\end{tabular}

Unless otherwise indicated, the number of patients refers specifically to inoperable CTEPH patients. ${ }^{*}$ No specific data on treatments or outcomes in CTEPH patients; ${ }^{\dagger}$ CTEPH patients not characterized as inoperable versus residual PH postpulmonary endarterectomy (PEA). 6MWD 6 min walk test distance; BDI Borg dyspnea index; bid Twice daily; CAMPHOR Cambridge PH Outcome Review; Cl Cardiac index (L/min); CO Cardiac output; DB Double blinded; echo Echocardiography; ERA Endothelinreceptor antagonist; FC Functional class; inh Inhaled; IPAH Idiopathic pulmonary arterial hypertension; iv Intravenous; LT Long term; LVED Left ventricular end diastolic; mPAP Mean pulmonary arterial pressure; MRC Medical Research Council; NT-pro-BNP N-Terminal probrain natriuretic peptide (pg/mL); PC Placebo controlled; PVR Pulmonary vascular resistance; PVRI PVR index; qid Four times daily; QOL Quality of life; RAP Right atrial pressure; RCT Randomized controlled trial; RVSP Right ventricular systolic pressure; sc Subcutaneous; TCW Time to clinical worsening; tid Three times daily; TPR Total peripheral resistance; VO 2 max Maximal oxygen uptake

Key evidence: No studies that rigorously addressed the clinical benefit of combination medical therapy in CTEPH patients were identified, although various combinations of $\mathrm{PH}$-specific therapy have been reported in a small number of CTEPH patients. In one study (169), the effects of combination $\mathrm{PH}$-specific therapy were assessed in patients with different types of $\mathrm{PH}$ including CTEPH, but specific data in the CTEPH patients were not reported; therefore, no conclusions regarding efficacy in these subjects can be drawn. The combination of oral beraprost and vardenafil specifically improved WHO functional class in two CTEPH patients, while pulmonary hemodynamics and BNP levels were also improved in the group of five patients with $\mathrm{PH}$ as a whole (170). In another case series of 15 bosentan-treated CTEPH patients who were either inoperable or refused PEA (149), six of the subjects continued previous therapy with inhaled iloprost. However, no specific data on the benefits of bosentan monotherapy versus combination therapy were provided. A small case series (171) reported improved pulmonary hemodynamics over one year following addition of oral dipyridamole or sildenafil in three patients with severe inoperable CTEPH (WHO class III or IV) who were clinically deteriorating despite therapy with inhaled nitric oxide for one year (171).

Presently, these combinations of medical therapies are not often clinically used or available, and the specific benefits of combination versus monotherapy have not been rigorously assessed.

The recommendation informing this question is based on this low-grade evidence and the consensus of the expert panel.

Expert panel synthesis of clinical judgment: The panel recognized that the low-grade evidence only indirectly assesses the benefits of combination $\mathrm{PH}$-specific medical therapy in inoperable CTEPH patients. In addition, panel members reported limited clinical experience with this approach in CTEPH patients. The panel discussed the potential likelihood for greater adverse effects, a higher burden of adherence, and the greater cost with combination $\mathrm{PH}$-specific therapy, especially for treatment regimens that include parenteral prostanoids. Although there is the likelihood for some direct health benefit to the patient, the current evidence is insufficient to delineate the impact of combination therapy on morbidity and mortality in CTEPH patients.

As a result, there was consensus for a strong negative recommendation.

\section{Clinical question}

Should symptomatic CTEPH patients who are inoperable or experience residual $\mathrm{PH}$ post-PEA receive $\mathrm{PH}$-specific combination therapy to improve clinical outcomes?

Recommendation 24

- We do not currently recommend the routine clinical use of combination $\mathrm{PH}$-specific therapy in patients with inoperable CTEPH or residual PH post-PEA (grade of recommendation: $1 \mathrm{C}$ ).

The panel emphasized that combination $\mathrm{PH}$-specific therapy may be effective in specific individuals or in specific circumstances, such as in supporting a patient as a bridge to lung transplantation. In these individual circumstances, combination PH-specific therapy may be considered.

Areas for future research: $\mathrm{PH}$-specific medical therapy has been of significant clinical benefit in many patients with PAH. There is the potential for similar clinical benefit in CTEPH patients with residual $\mathrm{PH}$ post-PEA surgery or inoperable CTEPH patients. Indeed, many CTEPH patients have benefited since the institution of $\mathrm{PH}$-specific medical therapy.

Presently, the evidence supporting medical therapy for patients with CTEPH remains limited. Therefore, the panel supports further clinical research into the benefits and risks of $\mathrm{PH}$-specific medical therapy in CTEPH patients, especially 
longer term studies of clinically significant outcomes. The panel also recommends that such patients be considered for clinical research trials of current and future $\mathrm{PH}$-specific medications both as monotherapy and in combination therapy. The design of future trials should permit analysis separately for patients with residual $\mathrm{PH}$ post-PEA versus those with inoperable CTEPH, given that these are distinct subpopulations of CTEPH.

\section{Balloon angioplasty in patients with CTEPH}

Clinical question: Should patients with surgically accessible CTEPH who are not eligible for PEA undergo balloon angioplasty of the pulmonary arteries to improve clinical outcomes? Introduction: Some patients with CTEPH, despite proximal large pulmonary artery (main, lobar or segmental) occlusions, are not candidates for PEA surgery or refuse to undergo PEA. In these patients, catheter-directed balloon angioplasty may be a therapeutic option to relieve pulmonary arterial obstruction and improve the degree of $\mathrm{PH}$.

Key evidence: One uncontrolled case series of 18 patients (172) and a single case report (173) both demonstrated shortterm improvements in pulmonary hemodynamics, WHO functional class and exercise capacity. An average of 2.6 procedures (range one to five) and six dilations (range one to 12) were performed. Eleven of the 18 patients in the case series and the single patient in the case report developed reperfusion pulmonary edema, and one patient died from RV failure. There was no information on medical treatment before or following angioplasty.

Thus, the recommendation informing this question is based on weak evidence and the consensus of the expert panel.

Expert panel synthesis of clinical judgment: The low grade of evidence was emphasized. Possible direct health benefit in the individual patient was recognized, but limited long-term overall impact on morbidity and mortality in a CTEPH population was anticipated. Moreover, the indirect nature of the evidence supporting angioplasty, and the moderate to serious adverse effects including mortality, unclear burden of adherence and inconclusive economic effects were also discussed.

As a result, there was consensus for a weak recommendation.

\section{Clinical question}

Should patients with surgically accessible CTEPH who are not eligible for PEA undergo balloon angioplasty of the pulmonary arteries to improve clinical outcomes?

\section{Recommendation 25}

- We suggest that balloon pulmonary angioplasty be considered in patients with surgically accessible CTEPH who are ineligible for PEA to improve pulmonary hemodynamics, WHO functional class and exercise capacity (grade of recommendation: 2C).

The panel strongly emphasized that eligibility for PEA and for angioplasty be determined in a centre experienced with $\mathrm{CTEPH}$, and in consultation with a PEA surgeon. Balloon angioplasty is currently not available in a Canadian centre.

\section{E. Consideration of transplantation in CTEPH patients 1. Referral of CTEPH patients for lung transplantation Clinical question: Should WHO functional class III/IV CTEPH patients who are inoperable or have residual $\mathrm{PH}$}

post-PEA be referred for lung transplantation to improve clinical outcomes?

Introduction: In many patients with end-stage lung disease including $\mathrm{PH}$, lung transplantation is an important treatment modality that improves both HRQoL and survival. Lung transplantation may also be of clinical benefit in CTEPH patients.

Key evidence: Although no studies that specifically addressed this clinical question were identified, patients with CTEPH have been included in studies of lung transplantation for $\mathrm{PH}$, and in reports of international transplantation societies (174). Median survival for idiopathic PAH patients undergoing lung transplantation is 5.6 years.

Thus, the recommendation informing this question is based on the consensus of the expert panel.

Expert panel synthesis of clinical judgment: The lack of any direct evidence in favour of lung transplantation over medical therapy, specifically in CTEPH patients, was appreciated. However, the potentially significant health benefits of lung transplantation, and a high impact on morbidity and mortality in selected CTEPH patients was emphasized. Many panel members had personal experiences with very successful lung transplantation in CTEPH patients. The panel also recognized the potential for serious adverse effects and a high burden of adherence for patients undergoing lung transplantation, in addition to inconclusive cost effectiveness. The consensus of the panel was that the clinical outcomes and risks of lung transplantation are in CTEPH patients and patients with other types of $\mathrm{PH}$ are similar. As a result, there was consensus for a strong recommendation.

\section{Clinical question}

Should WHO functional class III/IV CTEPH patients who are inoperable or have residual $\mathrm{PH}$ post-PEA be referred for lung transplantation to improve clinical outcomes?

\section{Recommendation 26}

- We recommend that CTEPH patients who are inoperable or experience residual PH post-PEA and who remain in WHO functional class III or IV, despite optimal medical therapy, be referred for evaluation for lung transplantation (grade of recommendation: 1C). Because there can be significant delays until transplantation, early referral is important.

Areas for future research: The panel supports the collection and reporting of data specifically in CTEPH patients undergoing lung transplantation to confirm long-term benefit with regard to clinically significant outcomes. Further information on comparative outcomes between medical management and transplantation for CTEPH patients will be helpful in future clinical decision making. Future study to identify specific predictors of survival in CTEPH patients post-transplantation would also be clinically helpful.

\section{SECTION V: DIAGNOSIS AND MANAGEMENT OF CTEPH: SUMMARY OF RECOMMENDATIONS (TABLE 9)}


TABLE 9

Diagnosis and management of CTEPH: Summary of recommendations

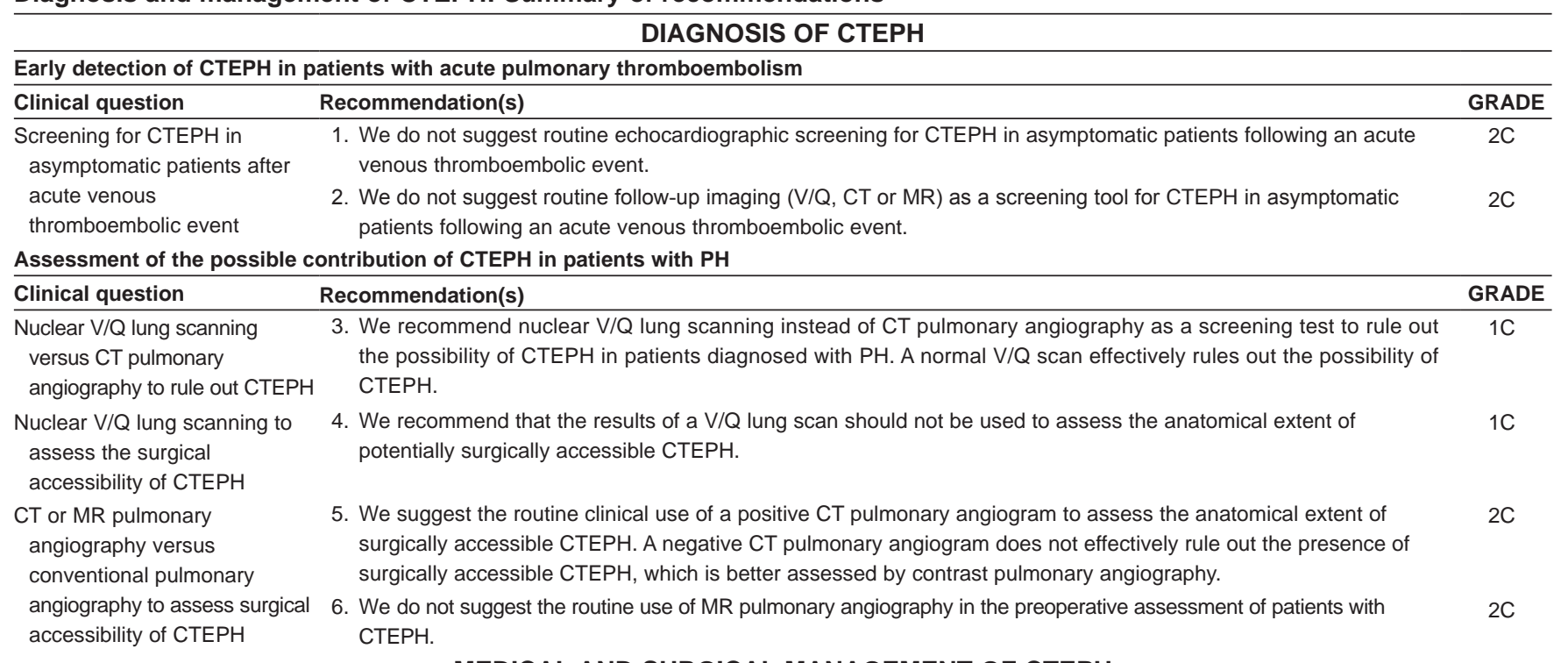

MEDICAL AND SURGICAL MANAGEMENT OF CTEPH

General medical management of CTEPH patients

\begin{tabular}{lll}
\hline Clinical question & Recommendation(s) & GRADE \\
\hline Chronic anticoagulation & $\begin{array}{l}\text { 7. We suggest that all CTEPH patients, including patients who do not undergo PEA and patients post-PEA surgery, be } \\
\text { chronically anticoagulated. }\end{array}$
\end{tabular}

Calcium-channel blocker

8. We strongly recommend against the use of high-dose calcium channel blockers in patients with CTEPH.

therapy

Digoxin therapy

9. We do not suggest routine digoxin therapy in patients with CTEPH. The expert panel recognized that in selected CTEPH patients with RV failure or atrial arrhythmias, digoxin may be of some limited benefit.

Supplemental nocturnal/ exertional oxygen therapy

10. In patients with CTEPH who manifest isolated nocturnal and/or exertional oxygen desaturation, there was no expert consensus on a recommendation for or against the use of supplemental oxygen. Treatment with supplemental oxygen is clearly indicated for CTEPH patients who manifest hypoxaemia at rest.

Cardiopulmonary exercise

11. We suggest cardiopulmonary exercise rehabilitation in CTEPH patients.

rehabilitation

12. There was no expert consensus on a recommendation for or against the routine use of IVC filters in patients with CTEPH. _

Use of IVC filters

Management of CTEPH patients before PEA surgery

\begin{tabular}{l} 
Clinical question \\
\hline Parenteral prostanoid therapy \\
in CTEPH patients pre-PEA \\
surgery \\
Oral PH-specific medical \\
therapy in CTEPH patients \\
pre-PEA surgery
\end{tabular}

Recommendation(s)

13. We suggest pre-PEA treatment with intravenous epoprostenol in selected patients with severe surgically accessible $2 \mathrm{C}$ CTEPH (WHO class III or IV, with PVR $>1200 \mathrm{dyne} \cdot \mathrm{s} / \mathrm{cm}^{5}$, and/or RV failure) because this may improve hemodynamics and operability. The decision to institute pre-PEA parenteral epoprostenol therapy should be at the discretion of a centre with experience treating CTEPH patients, in consultation with a PEA surgeon.

14. We do not currently recommend for or against the use of oral PH-specific medical therapy in CTEPH patients who are being considered for PEA. The panel emphasized that a decision to treat CTEPH patients with oral PH medications should not delay referral to an expert centre for consideration of PEA in patients with surgically accessible CTEPH because such a delay may adversely impact the clinical outcome.

PEA in CTEPH patients

Clinical question

Recommendation(s)

PEA in patients with surgically

15. We recommend PEA as the treatment of choice in patients with surgically accessible CTEPH.

PEA in patients with distal CTEPH

16. We suggest that patients with distal CTEPH be considered for PEA on an individual basis at a center experienced with PEA.

Post-PEA long-term follow-up 17. We suggest that post-PEA CTEPH patients may benefit from long-term follow-up in a PH expert centre.

in a $\mathrm{PH}$ centre

$\mathrm{PH}$-specific medical therapy in CTEPH patients with residual $\mathrm{PH}$ post-PEA surgery

18. We suggest ERA monotherapy in patients with symptomatic, residual PH post-PEA. This recommendation currently applies only to the ERA bosentan because there are no data available to assess the potential benefits of other ERAs (eg, sitaxsentan and ambrisentan) in CTEPH patients.

19. We suggest PDE-5i monotherapy in patients with symptomatic, residual $\mathrm{PH}$ post-PEA. This recommendation currently applies only to the PDE-5i sildenafil because there are no data available to assess the potential benefits of other PDE-5i's (eg, tadalafil and vardenafil) in CTEPH patients.

20. We suggest that parenteral prostanoid monotherapy could be considered in specific patients with symptomatic, residual $\mathrm{PH}$ post-PEA in whom oral $\mathrm{PH}$-specific therapy has not been effective or was not tolerated. This recommendation currently applies only to the parenteral prostanoids (eg, intravenous epoprostenol and subcutaneous/intravenous treprostinil) because there are no data available to assess the potential benefits of oral (eg, beraprost) or inhaled (eg, iloprost, treprostinil) prostanoids. 
TABLE 9 - CONTINUED

Diagnosis and management of CTEPH: Summary of recommendations

\begin{tabular}{|c|c|c|}
\hline \multicolumn{3}{|c|}{ Management of patients not eligible for PEA } \\
\hline Clinical question & Recommendation(s) & GRADE \\
\hline \multirow[t]{3}{*}{$\begin{array}{l}\text { PH-specific medical therapy in } \\
\text { patients with inoperable } \\
\text { CTEPH }\end{array}$} & $\begin{array}{l}\text { 21. We suggest ERA monotherapy in patients with symptomatic, inoperable CTEPH to improve symptoms and exercise } \\
\text { capacity, short-term hemodynamics and, possibly, survival. This recommendation currently applies only to the ERA } \\
\text { bosentan because there are no data available to assess the potential benefits of other ERAs (eg, sitaxsentan and } \\
\text { ambrisentan). }\end{array}$ & $2 \mathrm{C}$ \\
\hline & $\begin{array}{l}\text { 22. We suggest PDE-5i monotherapy in patients with symptomatic, inoperable CTEPH to improve short-term } \\
\text { hemodynamics and WHO functional class, and possibly long-term exercise capacity and HRQL. This } \\
\text { recommendation currently applies only to the PDE-5i sildenafil because there are no data available to assess the } \\
\text { potential benefits of other PDE-5is (eg, tadalafil and vardenafil). }\end{array}$ & $2 \mathrm{C}$ \\
\hline & $\begin{array}{l}\text { 23. We suggest monotherapy with parenteral prostanoids (eg, intravenous epoprostenol, subcutaneous/intravenous } \\
\text { treprostinil) could be considered in patients with symptomatic, inoperable CTEPH. }\end{array}$ & $2 \mathrm{C}$ \\
\hline $\begin{array}{l}\text { Combination } \mathrm{PH} \text {-specific medical } \\
\text { therapy in } \mathrm{CTEPH} \text { patients }\end{array}$ & $\begin{array}{l}\text { 24. We do not currently recommend routine clinical use of combination } \mathrm{PH} \text {-specific therapy in patients with inoperable } \\
\text { CTEPH or residual } \mathrm{PH} \text { post-PEA. }\end{array}$ & $1 \mathrm{C}$ \\
\hline $\begin{array}{l}\text { Balloon angioplasty in patients } \\
\text { with CTEPH }\end{array}$ & $\begin{array}{l}\text { 25. We suggest that balloon pulmonary angioplasty be considered in patients with surgically accessible CTEPH who } \\
\text { are ineligible for PEA to improve pulmonary hemodynamics, WHO functional class and exercise capacity. }\end{array}$ & $2 \mathrm{C}$ \\
\hline \multicolumn{3}{|c|}{ Consideration of transplantation in CTEPH patients } \\
\hline Clinical question & Recommendation(s) & GRADE \\
\hline $\begin{array}{l}\text { Referral of CTEPH patients for } \\
\text { lung transplantation }\end{array}$ & $\begin{array}{l}\text { 26. We recommend that CTEPH patients who are inoperable or have residual PH post-PEA and who remain in WHO } \\
\text { functional class III or IV, despite optimal medical therapy, be referred for evaluation for lung transplantation. } \\
\text { Because there can be significant delays until transplantation, early referral is important. }\end{array}$ & $1 \mathrm{C}$ \\
\hline
\end{tabular}

CONTRIBUTORS: All authors contributed substantially to the literature review, data abstraction, draft recommendations, writing and revision of the article. All authors approved the final version for publication.

DISCLOSURE OF COMPETING INTERESTS: Members of the CTS Pulmonary Vascular Diseases Expert Committee declared potential conflicts of interest at the time of appointment, and these were updated throughout the development process in accordance with the CTS Conflict of Interest Disclosure Policy. Collectively, physicians on the CTS Pulmonary Vascular Diseases Expert Committee have on at least one occasion acted as consultants for, received research funds from, or received speaker's fees from pharmaceutical companies. Committee members did not receive any direct or indirect funding from external sources in the development of this document.

FUNDING: The CTS receives unrestricted grants which are combined into a central operating account to facilitate the production, dissemination and implementation activities of CTS Guideline Committees from the Canadian Institutes of Health Research, AstraZeneca Canada, GlaxoSmithKline Inc, Pfizer Canada and Boehringer Ingelheim Canada.

\section{APPENDIX 1: LITERATURE SEARCH STRATEGY}

The following literature databases were searched:

- MEDLINE (OVID: 1960 through October 2008),

- EMBASE OVID: (1960 through October 2008),

- the Cochrane Library (OVID; Issue 3, 2008),

- the Canadian Medical Association InfoBase, and

- the National Guideline Clearinghouse.

- Reference lists of identified papers and recent review articles were also reviewed for additional citations.
No sponsors played a role in the collection, review, analysis or interpretation of the scientific literature or in any decisions regarding the key messages presented in this document. As such, the CTS Pulmonary Vascular Diseases Expert Committee is functionally and editorially independent from any funding sources of the CTS, and is accountable to the CTS Respiratory Guidelines Committee and the CTS Board of Directors.

ACKNOWLEDGEMENTS: The authors thank the Canadian Thoracic Society for their invaluable administrative support, including specifically Director Janet Sutherland, and Guidelines Coordinators Elena Goubanova, Stella Muthuri and Candice Brown. This guideline was developed under the aegis of the CTS Canadian Respiratory Guidelines Committee, and we specifically thank the Chair, Dr LouisPhilippe Boulet and Dr Samir Gupta for their expertise and guidance throughout the guidelines process. Kelly Lang-Robertson, MLIS provided advice and literature search expertise. Tom Oliver was instrumental with advice on guideline and consensus methodological issues. The authors also thank our Canadian and International PH Expert Peer Reviewers: Dr Zoheir Bshouty (Winnipeg), Dr Pungi Dorasamy (Hamilton), Dr Kristina Kemp (Moncton), Dr Donna Maziak (Ottawa, for the Canadian Association of Thoracic Surgeons), Dr William Geerts (Hamilton, for the Thrombosis Interest Group of Canada), Dr Irene Lang (Vienna, Austria) and Dr Peter Fedullo (San Diego, USA).

The literature search of the electronic databases combined the following $\mathrm{MeSH}$ heading terms and text search terms to identify the body of published evidence on chronic thromboembolic PH related to the following:

1. pulmonary hypertension,

2. thromboemboli* or thrombo-emboli* or CTEPH or CTPH or VTE or pulmonary embolism or deep vein thrombosis or DVT

3. 1 AND 2 


\section{Epidemiology}

4. 2 AND ([time course or resolution] or [dyspnea or exercise limitation] or [V/Q or ventilation-perfusion or ventilation:perfusion] ADJ [scan or lung scan]) or (CT scan or CAT scan or computed tomogram*) or (MRA or MR angiogram or magnetic resonance scan or MR scan or MRI or magnetic resonance angiogram or angiogra* or pulmonary angiogra*) or (echo or echocardiogra*) or catheterization or hemodynamics or RVSP or right ventricular systolic pressure or PAP or pulmonary artery pressure or PVR or pulmonary vascular resistance or cardiac output or $\mathrm{CO}$ or cardiac index or $\mathrm{CI}$ or RAP or right atrial pressure or central venous pressure or CVP or $\mathrm{SVO}_{2}$ or mixed-venous or mixed venous) ]

5. 3 AND ([incidence or prevalence or frequency or diagnosis] or [massive or sub-massive or acute or sub-acute or gender or age or race or ethnic])

6. 3 AND ([thrombophilia or hypercoagulability or coagulopathy or predisposing factor or risk factor or associated factor or idiopathic] or [splenectomy or lupus inhibitor or lupus anticoagulant or antiphospholipid or anti-phospholipid or anti-thrombin or protein $\mathrm{C}$ or protein S or Factor V Leiden or prothrombin 20210A or prothrombin variant or Factor VIII or homocysteine or fibrinogen or lipoprotein] or [splenectomy or ventriculoatrial shunt or inflammatory disease or inflammatory disorder or osteomyelitis or inflammatory bowel disease or myeloproliferative disease or blood group or HLA or hypothyroidism or thyroid disease or malignancy or cancer])

\section{Diagnosis}

7. 3 AND ([diagnosis or screening] or ([V/Q or ventilationperfusion or ventilation:perfusion]) ADJ ([scan or lung scan]) or (CT scan or CAT scan or computed tomogra*) or (magnetic resonance scan or MR scan or MRI or magnetic resonance angiogram or MR angiogram or MRA or angiogra* or pulmonary angiogra*])

8. 3 AND ([echo or echocardiogra*] or catheterization or hemodynamics or right ventricular systolic pressure or RVSP or pulmonary artery pressure or PAP or pulmonary vascular resistance or PVR or cardiac output or $\mathrm{CO}$ or cardiac index or $\mathrm{CI}$ or right atrial pressure or RAP or central venous pressure or CVP or SVO2 or mixed-venous or mixed venous])

\section{Therapy}

9. 3 AND ([severity or outcomes or survival or mortality or clinical worsening or deterioration] or [dyspnea or edema or hypotension or blood pressure or shock or exercise capacity or functional capacity or quality of life or qualityof-life or QOL or HRQoL or SF-36 or CRQ or CAMPHOR] or [WHO or NYHA or functional class or return to work])

10. 3 AND ([eligibility or operability or postoperative or postoperative or perioperative or peri-operative])
11. 3 AND ([surgery or PEA or PTE or endarterectomy or end-arterectomy or thromboendarterectomy or thromboendarterectomy or Jamieson or surgically accessible or proximal or distal])

12. 3 AND ([therapy or monotherapy or treatment or medication or antagonist or inhibitor or blocker or analogue] or [CCB or calcium channel or calciumchannel or nifedipine or diltiazem or amlodipine] or [ERA or endothelin-receptor or endothelin receptor or bosentan or sitaxsentan or sitaxentan or ambrisentan] or [PDE or phosphodiesterase or sildenafil or tadalafil or vardenafil] or [prostaglandin or prostacyclin or epoprostenol or treprostinil or iloprost or beraprost])

13. 3 AND ([combination or goal oriented or goal-oriented or goal directed or goal-directed] adj [therapy or treatment])

14. 3 AND ([(lung or pulmonary or heart-lung or heart lung) and [transplant*] or international society or ISHLT or United network for organ sharing or UNOS)

15. 3 AND ([idiopathic or primary] adj [pulmonary hypertension or pulmonary arterial hypertension or PAH] or PAH or IPAH or PPH])

16. 3 AND ([(Inferior vena cava or IVC or superior vena cava or SVC or Greenfield or Nitinol) and (filter)]) or (Retroperitoneal hemorrhage or retroperitoneal bleed* or filter migration or filter embolization or post-phlebitic or postphlebitic)

17. 3 AND ([anticoagula*] or [international normalized ratio or INR or coumadin or warfarin or dicoumarol or dicumarol] or [heparin or low molecular weight or LMW or tinzaparin or enoxaparin or dalteparin or fragiparin] or [bleed* or hemorrhag* or haemorrhag*])

18. 3 AND ([Pulmonary artery thrombosis or pulmonary thrombosis or recurrent or recurrence])

19. 3 AND ([digoxin or lanoxin or digitalis]) or [arrhythmia or dysrhythmia or fibrillation or flutter or tachycardia or atrial or ventricular])

20. 3 AND ([balloon or pulmonary artery] and [angioplasty or dilatation])

21. 3 AND ([desaturation or hypox* or oxygen])

22. 3 AND ([medical or pulmonary hypertension or PH] adj [centre or clinic or expert or physician])

23. 3 AND ([exercise or training or aerobic or rehabilitation or fitness]) AND Limits: Humans, English/ or French/, All Adult: $16+$ years

AND inclusion/exclusion criteria (["systematic review*” OR "systematic literature review*" OR meta-analysis [pt] OR meta-analysis [ti] OR metaanalysis [ti] OR meta-analyses [ti] OR evidence-based medicine OR (evidence-based AND (guideline* [tw] OR recommendation*)) OR (evidenced-based AND [guideline* (tw) OR recommendation*]) OR consensus development conference [pt] OR guideline [pt] OR cochrane database syst rev OR acp journal 
club OR ((systematic [tw] OR systematically OR critical [tw] OR (study [tiab] AND selection [tiab]) OR (predetermined OR inclusion AND criteri* [tw]) OR exclusion criteri* OR "main outcome measures" OR "standard of care") AND (survey [tw] OR surveys [tw] OR overview* OR review [tw] OR reviews [tw] OR search* OR handsearch OR analysis [tw] OR critique [tw] OR appraisal OR (reduction AND risk AND (death OR recurrence))) AND (literature [tw] OR articles OR publication* [tw] OR bibliography* [tw] OR published OR unpublished OR citation* OR database OR internet [tw] OR trials OR meta-analysis [mh] OR (clinical [tw] AND stud*))) NOT (editorial [ti] OR editorial [pt] OR letter [pt] OR newspaper article $[\mathrm{pt}]))$

\section{REFERENCES}

1. Riedel M, Stanek V, Widimsky J, Prerovsky I. Longterm follow-up of patients with pulmonary thromboembolism. Late prognosis and evolution of hemodynamic and respiratory data. Chest 1982;81:151-8.

2. Lewczuk J, Piszko P, Jagas J, et al. Prognostic factors in medically treated patients with chronic pulmonary embolism. Chest 2001;119:818-23.

3. Badesch DB, Abman SH, Ahearn GS, et al. Medical therapy for pulmonary arterial hypertension: ACCP evidence-based clinical practice guidelines. Chest 2004;126:35S-62S.

4. McLaughlin VV, Presberg KW, Doyle RL, et al. Prognosis of pulmonary arterial hypertension: ACCP evidence-based clinical practice guidelines. Chest 2004;126:78S-92S.

5. Langleben D, Archer S, Granton J, et al. Canadian Cardiovascular Society and Canadian Thoracic Society position statement on pulmonary arterial hypertension. Can Respir J 2005;12:303-15

6. Badesch DB, Abman SH, Simonneau G, Rubin LJ, McLaughlin VV. Medical therapy for pulmonary arterial hypertension: Updated ACCP evidence-based clinical practice guidelines. Chest 2007;131:1917-28.

7. Barst RJ, Gibbs JS, Ghofrani HA, et al. Updated evidence-based treatment algorithm in pulmonary arterial hypertension. J Am Coll Cardiol 2009;54:S78-S84.

8. Galie N, Hoeper MM, Humbert M, et al. Guidelines for the diagnosis and treatment of pulmonary hypertension. Eur Respir J 2009;34:1219-63.

9. Guyatt G, Gutterman D, Baumann MH, et al. Grading strength of recommendations and quality of evidence in clinical guidelines: Report from an American College of Chest Physicians Task Force. Chest 2006;129:174-81.

10. Anderson FA Jr, Wheeler HB, Goldberg RJ, et al. A populationbased perspective of the hospital incidence and case-fatality rates of deep vein thrombosis and pulmonary embolism. The Worcester DVT Study. Arch Intern Med 1991;151:933-8.

11. Silverstein MD, Heit JA, Mohr DN, Petterson TM, O'Fallon WM, Melton LJ III. Trends in the incidence of deep vein thrombosis and pulmonary embolism: A 25-year population-based study. Arch Intern Med 1998;158:585-93.

12. Nordstrom M, Lindblad B. Autopsy-verified venous thromboembolism within a defined urban population - the city of Malmo, Sweden. APMIS 1998;106:378-84.

13. Nijkeuter M, Hovens MM, Davidson BL, Huisman MV. Resolution of thromboemboli in patients with acute pulmonary embolism: A systematic review. Chest 2006;129:192-7.

14. Stevinson BG, Hernandez-Nino J, Rose G, Kline JA. Echocardiographic and functional cardiopulmonary problems 6 months after first-time pulmonary embolism in previously healthy patients. Eur Heart J 2007;28:2517-24.

15. Ribeiro A, Lindmarker P, Johnsson H, Juhlin-Dannfelt A, Jorfeldt L. Pulmonary embolism: One-year follow-up with echocardiography doppler and five-year survival analysis. Circulation 1999;99:1325-30.
16. Ciurzynski M, Kurzyna M, Bochowicz A, et al. Long-term effects of acute pulmonary embolism on echocardiographic Doppler indices and functional capacity. Clin Cardiol 2004;27:693-7.

17. Lund O, Nielsen TT, Schifter S, Roenne K. Treatment of pulmonary embolism with full-dose heparin, streptokinase or embolectomy - results and indications. Thorac Cardiovasc Surg 1986;34:240-6.

18. Remy-Jardin M, Louvegny S, Remy J, et al. Acute central thromboembolic disease: Posttherapeutic follow-up with spiral CT angiography. Radiology 1997;203:173-80.

19. Mastora I, Remy-Jardin M, Masson P, et al. Severity of acute pulmonary embolism: Evaluation of a new spiral CT angiographic score in correlation with echocardiographic data. Eur Radiol 2003;13:29-35.

20. Dalen JE, Alpert JS. Natural history of pulmonary embolism. Prog Cardiovasc Dis 1975;17:259-70.

21. Fedullo PF, Auger WR, Kerr KM, Rubin LJ. Chronic thromboembolic pulmonary hypertension. N Engl J Med 2001;345:1465-72.

22. Pengo V, Lensing AW, Prins $M H$, et al. Incidence of chronic thromboembolic pulmonary hypertension after pulmonary embolism. N Engl J Med 2004;350:2257-64.

23. Miniati M, Monti S, Bottai M, et al. Survival and restoration of pulmonary perfusion in a long-term follow-up of patients after acute pulmonary embolism. Medicine (Baltimore) 2006;85:253-62.

24. Becattini C, Agnelli G, Pesavento R, et al. Incidence of chronic thromboembolic pulmonary hypertension after a first episode of pulmonary embolism. Chest 2006;130:172-5.

25. Surie S, Gibson NS, Gerdes VE, et al. Active search for chronic thromboembolic pulmonary hypertension does not appear indicated after acute pulmonary embolism. Thromb Res 2010;125:e202-e205.

26. Klok FA, Zondag W, van Kralingen KW, et al. Patient outcomes after acute pulmonary embolism. A pooled survival analysis of different adverse events. Am J Respir Crit Care Med 2010;181:501-6.

27. Klok FA, van Kralingen KW, van Dijk AP, Heyning FH, Vliegen HW, Huisman MV. Prospective cardiopulmonary screening program to detect chronic thromboembolic pulmonary hypertension in patients after acute pulmonary embolism. Haematologica 2010;95:970-5.

28. Condliffe R, Kiely DG, Gibbs JS, et al. Improved outcomes in medically and surgically treated chronic thromboembolic pulmonary hypertension. Am J Respir Crit Care Med 2008; 177:1122-7.

29. Tueller C, Stricker H, Soccal P, et al. Epidemiology of pulmonary hypertension: New data from the Swiss registry. Swiss Med Wkly 2008;138:379-84.

30. Lang IM. Chronic thromboembolic pulmonary hypertension not so rare after all. N Engl J Med 2004;350:2236-8.

31. Condliffe R, Kiely DG, Gibbs JS, et al. Prognostic and aetiological factors in chronic thromboembolic pulmonary hypertension. Eur Respir J 2009;33:332-8.

32. Bonderman D, Wilkens $\mathrm{H}$, Wakounig $\mathrm{S}$, et al. Risk factors for chronic thromboembolic pulmonary hypertension. Eur Respir J 2009;33:325-31.

33. Moser KM, Auger WR, Fedullo PF. Chronic major-vessel thromboembolic pulmonary hypertension. Circulation 1990;81:1735-43.

34. Moser KM, Auger WR, Fedullo PF, Jamieson SW. Chronic thromboembolic pulmonary hypertension: Clinical picture and surgical treatment. Eur Respir J 1992;5:334-42.

35. Moser KM, Daily PO, Peterson K, et al. Thromboendarterectomy for chronic, major-vessel thromboembolic pulmonary hypertension. Immediate and long-term results in 42 patients. Ann Intern Med 1987;107:560-5.

36. Ribeiro A, Lindmarker P, Johnsson H, Juhlin-Dannfelt A, Jorfeldt L. Pulmonary embolism: A follow-up study of the relation between the degree of right ventricle overload and the extent of perfusion defects. J Intern Med 1999;245:601-10.

37. Azarian R, Wartski M, Collignon MA, et al. Lung perfusion scans and hemodynamics in acute and chronic pulmonary embolism. J Nucl Med 1997;38:980-3.

38. Torbicki A, Perrier A, Konstantinides S, et al. Guidelines on the diagnosis and management of acute pulmonary embolism: The Task Force for the Diagnosis and Management of Acute 
Pulmonary Embolism of the European Society of Cardiology (ESC). Eur Heart J 2008;29:2276-315.

39. Lund O, Nielsen TT, Ronne K, Schifter S. Pulmonary embolism: Long-term follow-up after treatment with full-dose heparin, streptokinase or embolectomy. Acta Med Scand 1987;221:61-71.

40. Sharma GV, Folland ED, McIntyre KM, Sasahara AA. Long-term benefit of thrombolytic therapy in patients with pulmonary embolism. Vasc Med 2000;5:91-5.

41. The urokinase pulmonary embolism trial. A national cooperative study. Circulation 1973;47:II1-108.

42. Urokinase-streptokinase embolism trial. Phase 2 results. A cooperative study. JAMA 1974;229:1606-13.

43. McQuillan BM, Picard MH, Leavitt M, Weyman AE. Clinical correlates and reference intervals for pulmonary artery systolic pressure among echocardiographically normal subjects. Circulation 2001;104:2797-2802.

44. Tumminello G, Lancellotti P, Lempereur M, D’Orio V, Pierard LA. Determinants of pulmonary artery hypertension at rest and during exercise in patients with heart failure. Eur Heart J 2007;28:569-74.

45. Suntharalingam J, Machado RD, Sharples LD, et al. Demographic features, BMPR2 status and outcomes in distal chronic thromboembolic pulmonary hypertension. Thorax 2007;62:617-22.

46. Wolf M, Boyer-Neumann C, Parent F, et al. Thrombotic risk factors in pulmonary hypertension. Eur Respir J 2000;15:395-9.

47. Nakamura M, Okada O, Sakuma M, et al. Incidence and clinical characteristics of chronic pulmonary thromboembolism in Japan compared with acute pulmonary thromboembolism: Results of a multicenter registry of the Japanese Society of Pulmonary Embolism Research. Circ J 2002;66:257-60.

48. Tanabe N, Kimura A, Amano S, et al. Association of clinical features with HLA in chronic pulmonary thromboembolism. Eur Respir J 2005;25:131-8.

49. Rees DC, Cox M, Clegg JB. World distribution of factor V Leiden. Lancet 1995;346:1133-4.

50. Lang IM, Klepetko W, Pabinger I. No increased prevalence of the factor $V$ Leiden mutation in chronic major vessel thromboembolic pulmonary hypertension (CTEPH). Thromb Haemost 1996;76:476-7.

51. Wong CL, Szydlo R, Gibbs S, Laffan M. Hereditary and acquired thrombotic risk factors for chronic thromboembolic pulmonary hypertension. Blood Coagul Fibrinolysis 2010;21:201-6.

52. Colorio CC, Martinuzzo ME, Forastiero RR, Pombo G, Adamczuk Y, Carreras LO. Thrombophilic factors in chronic thromboembolic pulmonary hypertension. Blood Coagul Fibrinolysis 2001;12:427-32.

53. Auger WR, Permpikul P, Moser KM. Lupus anticoagulant, heparin use, and thrombocytopenia in patients with chronic thromboembolic pulmonary hypertension: A preliminary report. Am J Med 1995;99:392-6.

54. Bonderman D, Turecek PL, Jakowitsch J, et al. High prevalence of elevated clotting factor VIII in chronic thromboembolic pulmonary hypertension. Thromb Haemost 2003;90:372-6.

55. Jais X, Ioos V, Jardim C, et al. Splenectomy and chronic thromboembolic pulmonary hypertension. Thorax 2005;60:1031-4.

56. Martinuzzo ME, Pombo G, Forastiero RR, Cerrato GS, Colorio CC, Carreras LO. Lupus anticoagulant, high levels of anticardiolipin, and anti-beta2-glycoprotein I antibodies are associated with chronic thromboembolic pulmonary hypertension. J Rheumatol 1998;25:1313-9.

57. Jeremic M, Weisert O, Gedde-Dahl TW. Factor VIII (AHG) levels in 1016 regular blood donors. The effects of age, sex, and ABO blood groups. Scand J Clin Lab Invest 1976;36:461-6.

58. Orstavik KH, Magnus P, Reisner H, Berg K, Graham JB, Nance W. Factor VIII and factor IX in a twin population. Evidence for a major effect of ABO locus on factor VIII level. Am J Hum Genet 1985;37:89-101.

59. Ignatescu M, Kostner K, Zorn G, et al. Plasma Lp(a) levels are increased in patients with chronic thromboembolic pulmonary hypertension. Thromb Haemost 1998;80:231-2.

60. Rosenhek R, Korschineck I, Gharehbaghi-Schnell E, et al. Fibrinolytic balance of the arterial wall: Pulmonary artery displays increased fibrinolytic potential compared with aorta. Lab Invest 2003;83:871-6.
61. Lang IM, Marsh JJ, Olman MA, Moser KM, Schleef RR. Parallel analysis of tissue-type plasminogen activator and type 1 plasminogen activator inhibitor in plasma and endothelial cells derived from patients with chronic pulmonary thromboemboli. Circulation 1994;90:706-12.

62. Olman MA, Marsh JJ, Lang IM, Moser KM, Binder BR, Schleef RR. Endogenous fibrinolytic system in chronic large-vessel thromboembolic pulmonary hypertension. Circulation 1992;86:1241-8.

63. Lang IM, Marsh JJ, Olman MA, Moser KM, Loskutoff DJ, Schleef RR. Expression of type 1 plasminogen activator inhibitor in chronic pulmonary thromboemboli. Circulation 1994;89:2715-21.

64. Morris TA, Marsh JJ, Chiles PG, Auger WR, Fedullo PF, Woods VL Jr. Fibrin derived from patients with chronic thromboembolic pulmonary hypertension is resistant to lysis. Am J Respir Crit Care Med 2006;173:1270-5.

65. Suntharalingam J, Goldsmith K, van Marion V, et al. Fibrinogen A alpha Thr312Ala polymorphism is associated with chronic thromboembolic pulmonary hypertension. Eur Respir J 2008;31:736-41.

66. Morris TA, Marsh JJ, Chiles PG, et al. High prevalence of dysfibrinogenemia among patients with chronic thromboembolic pulmonary hypertension. Blood 2009;114:1929-36.

67. Bonderman D, Skoro-Sajer N, Jakowitsch J, et al. Predictors of outcome in chronic thromboembolic pulmonary hypertension. Circulation 2007;115:2153-8.

68. Jais X, Till SJ, Cynober T, et al. An extreme consequence of splenectomy in dehydrated hereditary stomatocytosis: Gradual thrombo-embolic pulmonary hypertension and lung-heart transplantation. Hemoglobin 2003;27:139-47.

69. Chou R, DeLoughery TG. Recurrent thromboembolic disease following splenectomy for pyruvate kinase deficiency. Am J Hematol 2001;67:197-9.

70. Cappellini MD, Robbiolo L, Bottasso BM, Coppola R, Fiorelli G, Mannucci AP. Venous thromboembolism and hypercoagulability in splenectomized patients with thalassaemia intermedia. Br J Haematol 2000;111:467-73.

71. Stewart GW, Amess JA, Eber SW, et al. Thrombo-embolic disease after splenectomy for hereditary stomatocytosis. Br J Haematol 1996;93:303-10.

72. Bonderman D, Jakowitsch J, Adlbrecht C, et al. Medical conditions increasing the risk of chronic thromboembolic pulmonary hypertension. Thromb Haemost 2005;93:512-6.

73. Kominami S, Tanabe N, Ota M, et al. HLA-DPB1 and NFKBIL1 may confer the susceptibility to chronic thromboembolic pulmonary hypertension in the absence of deep vein thrombosis. J Hum Genet 2009;54:108-14.

74. Sanchez O, Helley D, Couchon S, et al. Perfusion defects after pulmonary embolism: Risk factors and clinical significance. J Thromb Haemost 2010;8:1248-55.

75. Dartevelle P, Fadel E, Mussot S, et al. Chronic thromboembolic pulmonary hypertension. Eur Respir J 2004;23:637-48.

76. Tardivon AA, Musset D, Maitre S, et al. Role of CT in chronic pulmonary embolism: Comparison with pulmonary angiography. J Comput Assist Tomogr 1993;17:345-51.

77. Reichelt A, Hoeper MM, Galanski M, Keberle M. Chronic thromboembolic pulmonary hypertension: Evaluation with 64-detector row CT versus digital substraction angiography. Eur J Radiol 2009;71:49-54.

78. Garg K, Welsh CH, Feyerabend AJ, et al. Pulmonary embolism: Diagnosis with spiral CT and ventilation-perfusion scanning correlation with pulmonary angiographic results or clinical outcome. Radiology 1998;208:201-8.

79. Falaschi F, Palla A, Formichi B, et al. CT evaluation of chronic thromboembolic pulmonary hypertension. J Comput Assist Tomogr 1992;16:897-903.

80. Heinrich M, Uder M, Tscholl D, Grgic A, Kramann B, Schafers HJ. CT scan findings in chronic thromboembolic pulmonary hypertension: Predictors of hemodynamic improvement after pulmonary thromboendarterectomy. Chest 2005;127:1606-13.

81. King MA, Ysrael M, Bergin CJ. Chronic thromboembolic pulmonary hypertension: CT findings. AJR Am J Roentgenol 1998;170:955-60.

82. Kauczor HU, Schwickert HC, Mayer E, Schweden F, Schild HH, Thelen M. Spiral CT of bronchial arteries in chronic thromboembolism. J Comput Assist Tomogr 1994;18:855-61. 
83. Coulden R. State-of-the-art imaging techniques in chronic thromboembolic pulmonary hypertension. Proc Am Thorac Soc 2006;3:577-83.

84. Kaplinsky EJ, Favaloro RR, Pombo G, et al. Primary pulmonary artery sarcoma resembling chronic thromboembolic pulmonary disease. Eur Respir J 2000;16:1202-4.

85. Kreitner KF, Ley S, Kauczor HU, et al. Chronic thromboembolic pulmonary hypertension: Pre- and postoperative assessment with breath-hold MR imaging techniques. Radiology 2004;232:535-43.

86. Kruger S, Haage P, Hoffmann R, et al. Diagnosis of pulmonary arterial hypertension and pulmonary embolism with magnetic resonance angiography. Chest 2001;120:1556-61.

87. Ley S, Kauczor HU, Heussel CP, et al. Value of contrast-enhanced MR angiography and helical CT angiography in chronic thromboembolic pulmonary hypertension. Eur Radiol 2003; $13: 2365-71$

88. Tunariu N, Gibbs SJ, Win Z, et al. Ventilation-perfusion scintigraphy is more sensitive than multidetector CTPA in detecting chronic thromboembolic pulmonary disease as a treatable cause of pulmonary hypertension. J Nucl Med 2007;48:680-4.

89. Worsley DF, Palevsky HI, Alavi A. Ventilation-perfusion lung scanning in the evaluation of pulmonary hypertension. J Nucl Med 1994;35:793-6.

90. Bergin CJ, Sirlin CB, Hauschildt JP, et al. Chronic thromboembolism: Diagnosis with helical CT and MR imaging with angiographic and surgical correlation. Radiology 1997;204:695-702.

91. Moller HE, Chen XJ, Saam B, et al. MRI of the lungs using hyperpolarized noble gases. Magn Reson Med 2002;47:1029-51.

92. Moser KM, Rhodes PG, Ufnagel CC. Chronic unilateral pulmonary-artery thrombosis: Successfull thromendarectomy with thirty-month follow-up observation. N Engl J Med 1965;272:1195-9.

93. Houk VN, Hfnagel CA, McClenathan JE, Moser KM. Chronic thrombotic obstruction of major pulmonary arteries. Report of a case successfully treated by thromboendartectomy, and a review of the literature. Am J Med 1963;35:269-82.

94. Moser KM, Bloor CM. Pulmonary vascular lesions occurring in patients with chronic major vessel thromboembolic pulmonary hypertension. Chest 1993;103:685-92.

95. Skoro-Sajer N, Hack N, Sadushi-Kolici R, et al. Pulmonary vascular reactivity and prognosis in patients with chronic thromboembolic pulmonary hypertension: A pilot study. Circulation 2009; 119:298-305.

96. Mereles D, Ehlken N, Kreuscher S, et al. Exercise and respiratory training improve exercise capacity and quality of life in patients with severe chronic pulmonary hypertension. Circulation 2006;114:1482-9.

97. Nagaya N, Sasaki N, Ando M, et al. Prostacyclin therapy before pulmonary thromboendarterectomy in patients with chronic thromboembolic pulmonary hypertension. Chest 2003;123:338-43.

98. Bresser P, Fedullo PF, Auger WR, et al. Continuous intravenous epoprostenol for chronic thromboembolic pulmonary hypertension. Eur Respir J 2004;23:595-600.

99. Jamieson SW. Historical perspective: Surgery for chronic thromboembolic disease. Semin Thorac Cardiovasc Surg 2006;18:218-22.

100. Rubens FD, Bourke M, Hynes M, et al. Surgery for chronic thromboembolic pulmonary hypertension - inclusive experience from a national referral center. Ann Thorac Surg 2007;83:1075-81.

101. Madani MM, Jamieson SW. Technical advances of pulmonary endarterectomy for chronic thromboembolic pulmonary hypertension. Semin Thorac Cardiovasc Surg 2006;18:243-9.

102. Kunieda T, Nakanishi N, Satoh T, Kyotani S, Okano Y, Nagaya N. Prognoses of primary pulmonary hypertension and chronic major vessel thromboembolic pulmonary hypertension determined from cumulative survival curves. Intern Med 1999;38:543-6.

103. Archibald CJ, Auger WR, Fedullo PF, et al. Long-term outcome after pulmonary thromboendarterectomy. Am J Respir Crit Care Med 1999;160:523-8.

104. Thistlethwaite PA, Mo M, Madani M, Deutsch R, Blanchard D, Kapelanski DP. Operative classification of thromboembolic disease determines outcome after pulmonary endarterectomy. J Thorac Cardiovasc Surg 2002;124:1203-11.
105. Tscholl D, Langer F, Wendler O, Wilkens H, Georg T, Schafers HJ. Pulmonary thromboendarterectomy - risk factors for early survival and hemodynamic improvement. Eur J Cardiothorac Surg 2001;19:771-6.

106. Mayer E, Dahm M, Hake U, et al. Mid-term results of pulmonary thromboendarterectomy for chronic thromboembolic pulmonary hypertension. Ann Thorac Surg 1996;61:1788-92.

107. Hartz RS, Byrne JG, Levitsky S, Park J, Rich S. Predictors of mortality in pulmonary thromboendarterectomy. Ann Thorac Surg 1996;62:1255-9.

108. Dartevelle P, Fadel E, Chapelier A, et al. Angioscopic videoassisted pulmonary endarterectomy for post-embolic pulmonary hypertension. Eur J Cardiothorac Surg 1999;16:38-43.

109. Zoia M, D’Armini AM, Beccaria M, et al. Mid term effects of pulmonary thromboendarterectomy on clinical and cardiopulmonary function status. Thorax 2002;57:608-12.

110. Oikonomou A, Dennie CJ, Muller NL, Seely J, Matzinger FR, Rubens FD. Chronic thromboembolic pulmonary arterial hypertension: Correlation of postoperative results of thromboendarterectomy with preoperative helical contrastenhanced computed tomography. J Thorac Imag 2004;19:67-73.

111. Casaclang-Verdoza G, McCully RB, Oh JK, Miller FA Jr, McGregor CG. Effects of pulmonary thromboendarterectomy on right-sided echocardiographic parameters in patients with chronic thromboembolic pulmonary hypertension. Mayo Clinic Proceed 2006;81:777-82.

112. Mellemkjaer S, Ilkjaer LB, Klaaborg KE, et al. Pulmonary endarterectomy for chronic thromboembolic pulmonary hypertension. Ten years experience in Denmark. Scand Card J 2006;40:49-53

113. D’Armini AM, Cattadori B, Monterroso C, et al. Pulmonary thromboendarterectomy in patients with chronic thromboembolic pulmonary hypertension: Hemodynamic characteristics and changes. Eur J Cardiothorac Surg 2000;18:696-702.

114. Reesink HJ, Tulevski II, Marcus JT, et al. Brain natriuretic peptide as noninvasive marker of the severity of right ventricular dysfunction in chronic thromboembolic pulmonary hypertension. Ann Thorac Surg 2007;84:537-43.

115. Mikus PM, Mikus E, Martin-Suarez S, et al. Pulmonary endarterectomy: An alternative to circulatory arrest and deep hypothermia: Mid-term results. Eur J CardioThorac Surg 2008;34:159-63.

116. Petrucci L, Carlisi E, Ricotti S, et al. Pulmonary endarterectomy in chronic thromboembolic pulmonary hypertension: Short-term functional assessment in a longitudinal study. Europa Medicophysica 2007;43:147-53.

117. Tanabe N, Okada O, Nakagawa Y, et al. The efficacy of pulmonary thromboendarterectomy on long-term gas exchange. Eur Respir J 1997;10:2066-72.

118. Jamieson SW, Kapelanski DP, Sakakibara N, et al. Pulmonary endarterectomy: Experience and lessons learned in 1,500 cases. Ann Thorac Surg 2003;76:1457-62.

119. Puis L, Vandezande E, Vercaemst L, et al. Pulmonary thromboendarterectomy for chronic thromboembolic pulmonary hypertension. Perfusion 2005;20:101-8.

120. Matsuda H, Ogino H, Minatoya K, et al. Long-term recovery of exercise ability after pulmonary endarterectomy for chronic thromboembolic pulmonary hypertension. Ann Thorac Surg 2006;82:1338-43.

121. Ogino H, Ando M, Matsuda H, et al. Japanese single-center experience of surgery for chronic thromboembolic pulmonary hypertension. Ann Thorac Surg 2006;82:630-6.

122. Hardziyenka M, Reesink HJ, Bouma BJ, et al. A novel echocardiographic predictor of in-hospital mortality and mid-term haemodynamic improvement after pulmonary endarterectomy for chronic thrombo-embolic pulmonary hypertension. Eur Heart J 2007;28:842-9.

123. Corsico AG, D’Armini AM, Cerveri I, et al. Long-term outcome after pulmonary endarterectomy. Am J Respir Crit Care Med 2008; 178:419-24.

124. Yoshimi S, Tanabe N, Masuda M, et al. Survival and quality of life for patients with peripheral type chronic thromboembolic pulmonary hypertension. Circ J 2008;72:958-65.

125. Iino M, Dymarkowski S, Chaothawee L, Delcroix M, Bogaert J. Time course of reversed cardiac remodeling after pulmonary 
endarterectomy in patients with chronic pulmonary thromboembolism. Eur Radiol 2008;18:792-9.

126. Ishida K, Masuda M. Thromboendarterectomy for severe chronic thromboembolic pulmonary hypertension. Ann Asian Cardiovasc Thorac 2007;15:229-33.

127. Iwase T, Nagaya N, Ando M, et al. Acute and chronic effects of surgical thromboendarterectomy on exercise capacity and ventilatory efficiency in patients with chronic thromboembolic pulmonary hypertension. Heart 2001;86:188-92.

128. Linder J, Jansa P, Kunstyr J, et al. Implementation of a new programme for the surgical treatment of CTEPH in the Czech republic - pulmonary endarterectomy. Thorac Cardiovasc Surg 2006;54:528-31.

129. Menzel T, Kramm T, Mohr-Kahaly S, Mayer E, Oelert H, Meyer J. Assessment of cardiac performance using ten indices in patients undergoing pulmonary thromboendarterectomy. Ann Thorac Surg 2002;73:762-6.

130. Thistlethwaite PA, Madani M, Jamieson SW. Outcomes of pulmonary endarterectomy surgery. Semin Thorac Cardiovasc Surg 2006; 18:257-64.

131. Dittrich HC, Nicod PH, Chow LC, Chappuis FP, Moser KM, Peterson KL. Early changes of right heart geometry after pulmonary thromboendarterectomy. J Am Coll Cardiol 1988;11:937-43.

132. Menzel T, Kramm T, Wagner S, Mohr-Kahaly S, Mayer E, Meyer J. Improvement of tricuspid regurgitation after pulmonary thromboendarterectomy. Ann Thorac Surg 2002;73:756-61.

133. Archibald CJ, Auger WR, Fedullo PF. Outcome after pulmonary thromboendarterectomy. Semin Thorac Cardiovasc Surg 1999;11:164-71.

134. Moser KM, Metersky ML, Auger WR, Fedullo PF. Resolution of vascular steal after pulmonary thromboendarterectomy. Chest 1993;104:1441-4.

135. Olman MA, Auger WR, Fedullo PF, Moser KM. Pulmonary vascular steal in chronic thromboembolic pulmonary hypertension. Chest 1990;98:1430-4.

136. D'Armini AM, Cattadori B, Monterroso C, et al. Pulmonary thromboendarterectomy in patients with chronic thromboembolic pulmonary hypertension: Hemodynamic characteristics and changes. Eur J Cardiothoracic Surg 2000;18:696-702.

137. Matsuda H, Ogino H, Minatoya K, et al. Long-term recovery of exercise ability after pulmonary endarterectomy for chronic thromboembolic pulmonary hypertension. Ann Thorac Surg 2006;82:1338-43.

138. Ogino H, Ando M, Matsuda H, et al. Japanese single-center experience of surgery for chronic thromboembolic pulmonary hypertension. Ann Thorac Surg 2006;82:630-6.

139. Archibald CJ, Auger WR, Fedullo PF, et al. Long-term outcome after pulmonary thromboendarterectomy. Am J Respir Crit Care Med 1999;160:523-8.

140. Bergin CJ, Sirlin C, Deutsch R, et al. Predictors of patient response to pulmonary thromboendarterectomy. AJR Am J Roentgenol 2000;174:509-15.

141. Jais X, D'Armini AM, Jansa P, et al. Bosentan for treatment of inoperable chronic thromboembolic pulmonary hypertension: BENEFiT (Bosentan Effects in iNopErable Forms of chronIc Thromboembolic pulmonary hypertension), a randomized, placebo-controlled trial. J Am Coll Cardiol 2008;52:2127-34.

142. Peacock A, Simonneau G, Rubin L. Controversies, uncertainties and future research on the treatment of chronic thromboembolic pulmonary hypertension. Proc Am Thorac Soc 2006;3:608-14.

143. Galie N, Manes A, Negro L, Palazzini M, Bacchi-Reggiani ML, Branzi A. A meta-analysis of randomized controlled trials in pulmonary arterial hypertension. Eur Heart J 2009;30:394-403.

144. Suntharalingam J, Treacy CM, Doughty NJ, et al. Long-term use of sildenafil in inoperable chronic thromboembolic pulmonary hypertension. Chest 2008;134:229-36.

145. Bharani A, Mathew V, Sahu A, Lunia B. The efficacy and tolerability of sildenafil in patients with moderate-to-severe pulmonary hypertension. Indian Heart J 2003;55:55-9.

146. Olschewski H, Simonneau G, Galie N, et al. Inhaled iloprost for severe pulmonary hypertension. N Engl J Med 2002;347:322-9.

147. Hughes R, George P, Parameshwar J, et al. Bosentan in inoperable chronic thromboembolic pulmonary hypertension. Thorax 2005;60:707.
148. Bonderman D, Nowotny R, Skoro-Sajer N, et al. Bosentan therapy for inoperable chronic thromboembolic pulmonary hypertension. Chest 2005;128:2599-603.

149. Ulrich S, Speich R, Domenighetti G, et al. Bosentan therapy for chronic thromboembolic pulmonary hypertension. A national open label study assessing the effect of Bosentan on haemodynamics, exercise capacity, quality of life, safety and tolerability in patients with chronic thromboembolic pulmonary hypertension (BOCTEPH-Study). Swiss Med Wkly 2007;137:573-80.

150. Hoeper MM, Kramm T, Wilkens H, et al. Bosentan therapy for inoperable chronic thromboembolic pulmonary hypertension. Chest 2005;128:2363-7.

151. Hughes RJ, Jais X, Bonderman D, et al. The efficacy of bosentan in inoperable chronic thromboembolic pulmonary hypertension: A 1-year follow-up study. Eur Respir J 2006;28:138-43.

152. Seyfarth HJ, Hammerschmidt S, Pankau H, Winkler J, Wirtz H. Long-term bosentan in chronic thromboembolic pulmonary hypertension. Respiration 2007;74:287-92.

153. Madden BP, Sheth A, Wilde M, Ong YE. Does Sildenafil produce a sustained benefit in patients with pulmonary hypertension associated with parenchymal lung and cardiac disease? Vascul Pharmacol 2007;47:184-8.

154. Rossi R, Nuzzo A, Lattanzi A, Coppi F, Modena MG. Sildenafil improves endothelial function in patients with pulmonary hypertension. Pulm Pharmacol Ther 2008;21:172-7.

155. Sheth A, Park JE, Ong YE, Ho TB, Madden BP. Early haemodynamic benefit of sildenafil in patients with coexisting chronic thromboembolic pulmonary hypertension and left ventricular dysfunction. Vascul Pharmacol 2005;42:41-5.

156. Ghofrani HA, Schermuly RT, Rose F, et al. Sildenafil for long-term treatment of nonoperable chronic thromboembolic pulmonary hypertension. Am J Respir Crit Care Med 2003;167:1139-41.

157. Reichenberger F, Voswinckel R, Enke B, et al. Long-term treatment with sildenafil in chronic thromboembolic pulmonary hypertension. Eur Respir J 2007;30:922-7.

158. Scelsi L, Ghio S, Campana C, et al. Epoprostenol in chronic thromboembolic pulmonary hypertension with distal lesions. Ital Heart J 2004;5:618-23.

159. Cabrol S, Souza R, Jais X, et al. Intravenous epoprostenol in inoperable chronic thromboembolic pulmonary hypertension. J Heart Lung Transplant 2007;26:357-62.

160. McLaughlin VV, Genthner DE, Panella MM, Hess DM, Rich S. Compassionate use of continuous prostacyclin in the management of secondary pulmonary hypertension: A case series. Ann Intern Med 1999;130:740-3.

161. Higenbottam TW, Butt AY, Dinh-Xaun AT, Takao M, Cremona G, Akamine S. Treatment of pulmonary hypertension with the continuous infusion of a prostacyclin analogue, iloprost. Heart 1998;79:175-9.

162. Skoro-Sajer N, Bonderman D, Wiesbauer F, et al. Treprostinil for severe inoperable chronic thromboembolic pulmonary hypertension. J Thromb Haemost 2007;5:483-9.

163. Lang I, Gomez-Sanchez M, Kneussl M, et al. Efficacy of long-term subcutaneous treprostinil sodium therapy in pulmonary hypertension. Chest 2006;129:1636-43.

164. Ono F, Nagaya N, Okumura H, et al. Effect of orally active prostacyclin analogue on survival in patients with chronic thromboembolic pulmonary hypertension without major vessel obstruction. Chest 2003;123:1583-8.

165. Ono F, Nagaya N, Kyotani S, Oya H, Nakanishi N, Miyatake K. Hemodynamic and hormonal effects of beraprost sodium, an orally active prostacyclin analogue, in patients with secondary precapillary pulmonary hypertension. Circ J 2003;67:375-8.

166. Vizza CD, Badagliacca R, Sciomer S, et al. Mid-term efficacy of beraprost, an oral prostacyclin analog, in the treatment of distal CTEPH: A case control study. Cardiology 2006;106:168-73.

167. Machherndl S, Kneussl M, Baumgartner H, et al. Long-term treatment of pulmonary hypertension with aerosolized iloprost. Eur Respir J 2001;17:8-13.

168. Reichenberger F, Mainwood A, Doughty N, Fineberg A, Morrell NW, Pepke-Zaba J. Effects of nebulised iloprost on pulmonary function and gas exchange in severe pulmonary hypertension. Respir Med 2007;101:217-22. 
169. Beyer S, Speich R, Fischler M, Maggiorini M, Ulrich S. Long-term experience with oral or inhaled vasodilator combination therapy in patients with pulmonary hypertension. Swiss Medical Weekly 2006;136:114-8.

170. Aizawa K, Hanaoka T, Kasai H, et al. Long-term vardenafil therapy improves hemodynamics in patients with pulmonary hypertension. Hypertens Res 2006;29:123-8.

171. Perez-Penate GM, Julia-Serda G, Ojeda-Betancort N, et al. Long-term inhaled nitric oxide plus phosphodiesterase 5 inhibitors for severe pulmonary hypertension. J Heart Lung Transplant 2008;27:1326-32.

172. Feinstein JA, Goldhaber SZ, Lock JE, Ferndandes SM, Landzberg MJ. Balloon pulmonary angioplasty for treatment of chronic thromboembolic pulmonary hypertension. Circulation 2001;103:10-13.

173. Voorburg JA, Cats VM, Buis B, Bruschke AV. Balloon angioplasty in the treatment of pulmonary hypertension caused by pulmonary embolism. Chest 1988;94:1249-53.

174. Christie JD, Edwards LB, Aurora P, et al. The Registry of the International Society for Heart and Lung Transplantation: Twenty-sixth Official Adult Lung and Heart-Lung Transplantation Report - 2009. J Heart Lung Transplant 2009;28:1031-49.
175. Simonneau G, Robbins IM, Beghetti M, et al. Updated clinical classification of pulmonary hypertension. J Am Coll Cardiol 2009;54:S43-S54.

176. Hall RJ, Sutton GC, Kerr IH. Long-term prognosis of treated acute massive pulmonary embolism. Br Heart J 1977;39:1128-34.

177. Jerjes-Sanchez C, Ramirez-Rivera A, Arriaga-Nava R, et al. High dose and short-term streptokinase infusion in patients with pulmonary embolism: Prospective with seven-year follow-up trial. J Thromb Thrombolysis 2001;12:237-47.

178. Sharma S, Kashour T, Philipp R. Secondary pulmonary arterial hypertension: Treated with endothelin receptor blockade. Tex Heart Inst J 2005;32:405-10.

179. Andreassen AK, Wergeland R, Simonsen S, Geiran O, Guevara C, Ueland T. N-terminal pro-B-type natriuretic peptide as an indicator of disease severity in a heterogeneous group of patients with chronic precapillary pulmonary hypertension. Am J Cardiol 2006;98:525-9.

180. Kourouklis S, Christopoulos A, Liagkas K, Paradellis G, Kyriakides ZS. Bosentan in Eisenmenger syndrome and chronic thromboembolic pulmonary hypertension. Eur J Clin Invest 2006;36(Suppl 3):39-43. 


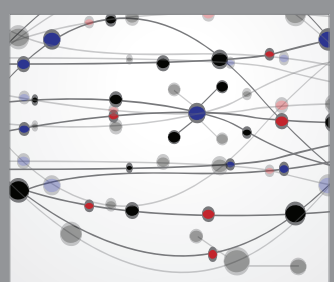

The Scientific World Journal
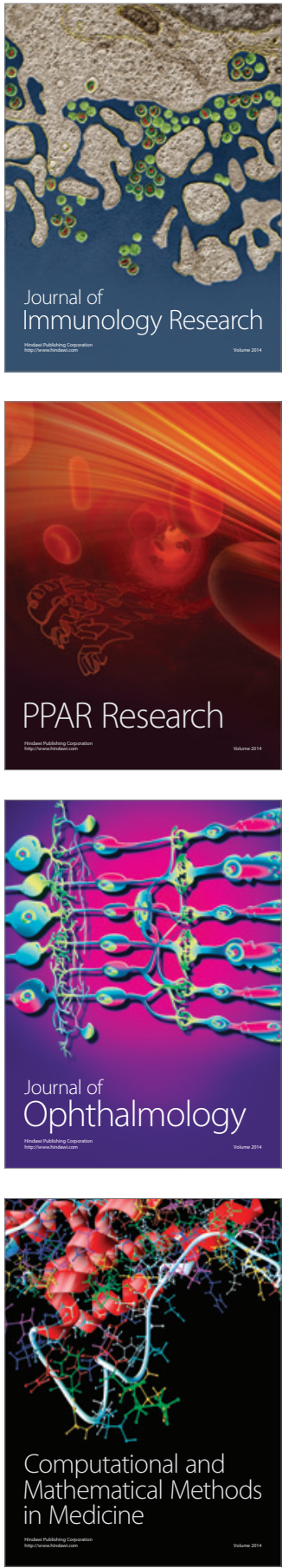

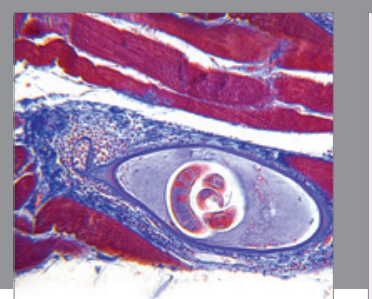

Gastroenterology Research and Practice

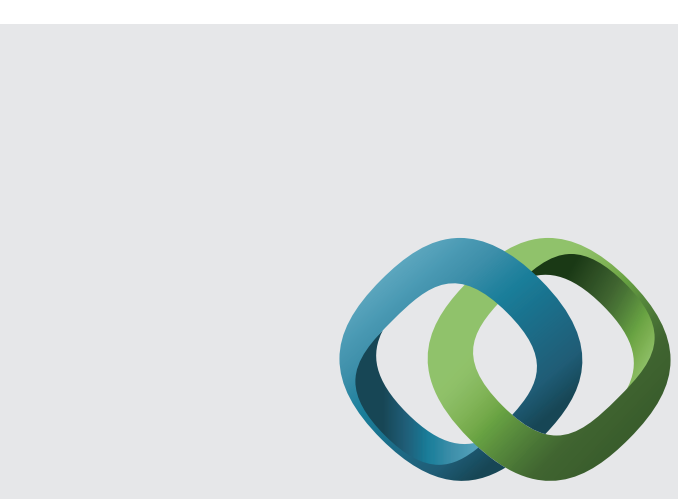

\section{Hindawi}

Submit your manuscripts at

http://www.hindawi.com
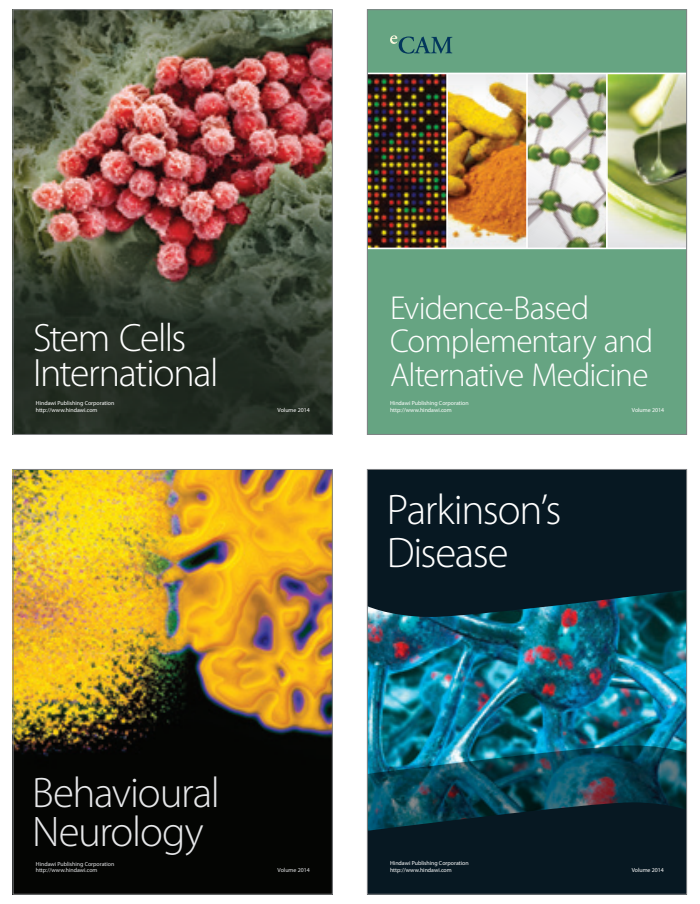
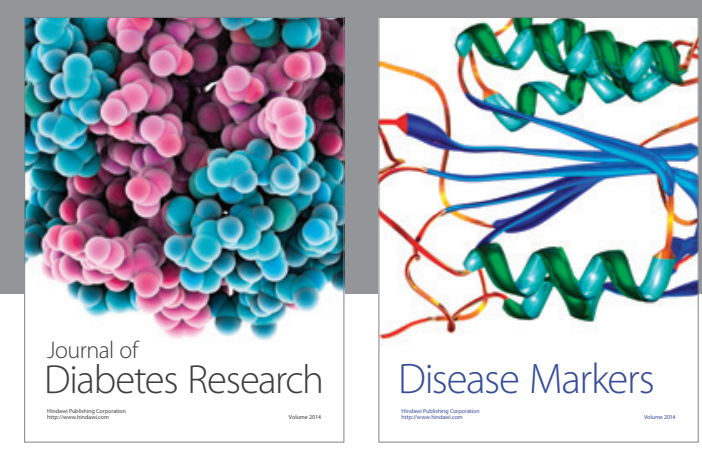

Disease Markers
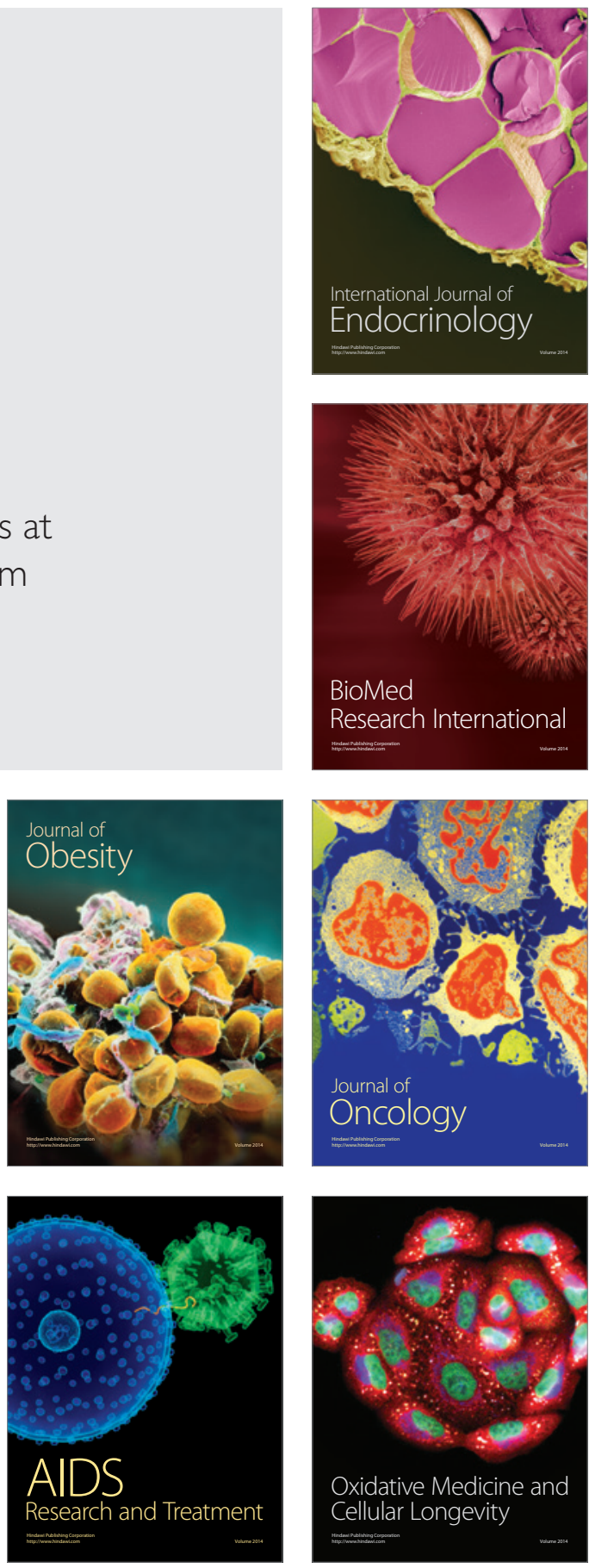